\title{
WestVirginiaUniversity
}

THE RESEARCH REPOSITORY @ WVU

Graduate Theses, Dissertations, and Problem Reports

2021

\section{Calibration of IRI-based PSI Equation using Updated Quarter-Car Parameters}

Shirin Bahaaeldin Hassan

sh0006@mix.wvu.edu

Follow this and additional works at: https://researchrepository.wvu.edu/etd

Part of the Civil Engineering Commons, Construction Engineering and Management Commons, and the Transportation Engineering Commons

\section{Recommended Citation}

Hassan, Shirin Bahaaeldin, "Calibration of IRI-based PSI Equation using Updated Quarter-Car Parameters" (2021). Graduate Theses, Dissertations, and Problem Reports. 8258.

https://researchrepository.wvu.edu/etd/8258

This Thesis is protected by copyright and/or related rights. It has been brought to you by the The Research Repository @ WVU with permission from the rights-holder(s). You are free to use this Thesis in any way that is permitted by the copyright and related rights legislation that applies to your use. For other uses you must obtain permission from the rights-holder(s) directly, unless additional rights are indicated by a Creative Commons license in the record and/ or on the work itself. This Thesis has been accepted for inclusion in WVU Graduate Theses, Dissertations, and Problem Reports collection by an authorized administrator of The Research Repository @ WVU. For more information, please contact researchrepository@mail.wvu.edu. 
Calibration of IRI-based PSI Equation using Updated Quarter-Car Parameters

Shirin Hassan

Thesis submitted

To the Benjamin M. Statler College of Engineering and Mineral Resources at West Virginia University

in partial fulfillment of the requirements for the degree of

Master of Science in

Civil Engineering

Yoojung Yoon, Ph.D., Chair

Dimitra Pyrialakou, Ph.D.

Fei Dai, Ph.D.

Department of Civil and Environmental Engineering

Morgantown, West Virginia

2021

Keywords: Pavement Quality, Present Serviceability Index, International Roughness Index, Quarter-Car Parameters

Copyright 2021 Shirin Hassan 


\title{
ABSTRACT \\ Calibration of IRI-based PSI Equation using Updated Quarter-Car Parameters
}

\author{
Shirin Hassan
}

The international roughness index (IRI) was established in the 1980s and later used in generating the present serviceability index (PSI), which was developed to predict present serviceability rating (PSR). PSR is a measure of ride quality ratings made by a panel of highway users. The ratings range from 0 to 5 , where " 0 " for very poor and " 5 " for very good. Various studies had formulated the relationship between IRI and PSI for different types of pavements, such as flexible, rigid, and composite pavements. The current IRIbased PSI equation being used among many state Departments of Transportation (DOTs) was proposed by Al-Omari and Darter in 1994. They analyzed the data collected from six different states: Louisiana, Michigan, New Jersey, New Mexico, Ohio, and Indiana. The use of the equation has been helpful for many state DOTs for general design decisions and pavement management practices, along with other physical conditions and smoothness measures. However, there have been increasing demands in adjusting the PSI equation with disparities between IRI-based design requirements for new pavements and PSI values estimated from IRI. For example, according to the PSR descriptions approved by Federal Highway Administration (FHWA), pavement surfaces below 4.0 begin to show visible signs of surface deterioration. Meanwhile, the acceptable IRI values for new asphalt and concrete pavements range from 52 to 66 inches/mile and from 57 to 72 inches/mile, respectively. The IRI values for asphalts and concretes are equivalent to 4.04 to $3.81 \mathrm{PSI}$ and 3.96 to $3.75 \mathrm{PSI}$, indicating that most of the new pavements have preservation needs for the year when constructed according to the equation. Therefore, the objective of this study was to calibrate the current IRI-based PSI equation for reliable use in pavement design and management. The primary approach used to calibrate the current PSI equation was comparing the IRI values calculated from the quarter car parameters of the golden car used to develop the current PSI equation and modern passenger cars found from an extensive discovery search. The approach was driven by the hypothesis that there has been improvement in the suspension systems of modern passenger cars that significantly impact the comfort levels of users driving on pavements. The data analysis results presented a newly adjusted PSI equation in the format of the current equation. The calibrated PSI equation was evaluated in terms of three aspects, such as the similarity between the current and calibrated PSI equations, the consistency between IRI requirements for new pavements and PSR definitions, and acceptable ride quality based on IRI. The evaluation found that the calibrated PSI equation is not very distinctive for the first and section evaluation aspects. However, the calibrated PSI equation could be considered to revise the national IRI criterion for acceptable ride quality on national highway systems. Finally, the contributions of this thesis are as follow: 1. It makes clear that the calibrated PSI equation can potentially replace the current PSI equations so that state DOTs can determine acceptable ride quality for national highway systems; 2 . It solidifies the research approach as the most cost-effective to determine the current PSI equations; 3. It reinforces the value of the primary research approach for state DOTs looking to adjust quarter-parameters in IRI measurement equipment; and, 4. Provides evaluative criteria that future researchers can utilize to update the current PSI equation. 


\section{Dedication}

My beloved dad, mom, siblings, family and friends.

Those who supported me to this point.

My best friend, my partner, and my person, Assem Almadani. 


\section{Acknowledgments}

Alhamdulillah.

First and foremost, I would like to thank my advisor and my mentor Dr. Yoojung Yoon for his help, encouragement, motivation, and advice. If it were not for him, I would not have expanded my knowledge or completed my master's degree. Thank you.

Secondly, I would love to thank Dr. Dimitra Pyrialakou for always helping me through my bachelor's and master's degrees. I have learned so much from you, and I will forever appreciate you giving me the opportunity.

I would also love to thank Dr. Fei Dai for making me pursue a construction management degree in Civil Engineering by showing his passion for the subject when teaching and driving the students and me to challenge ourselves.

My best friend and partner, I am not sure how to thank you enough for the support you have given me through all my college years. I consider myself the luckiest for having this much support and learning from you daily, Assem Almadani. Thank you for everything you have done for me.

My parents, Mr. Bahaaeldin and Ms. Madiha thank you for supporting me since day one, believing in me, and trusting me. I wish to make you proud now and forever. 


\section{Table of Contents}

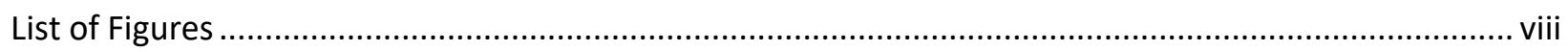

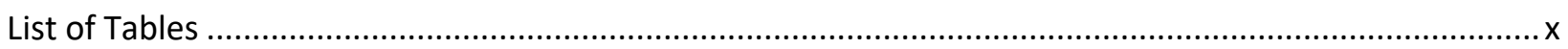

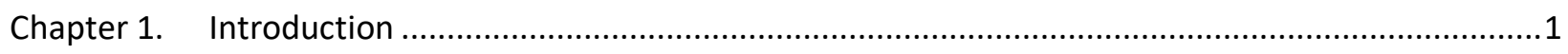

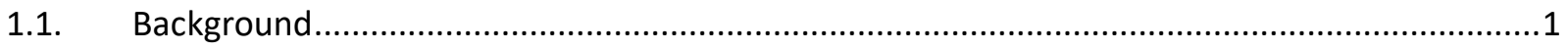

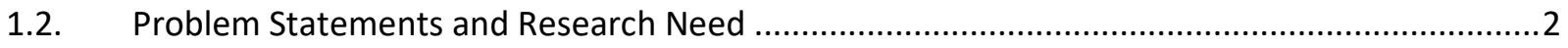

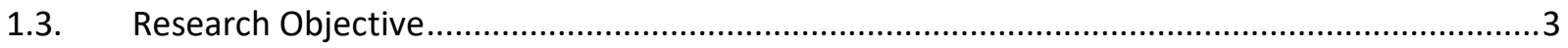

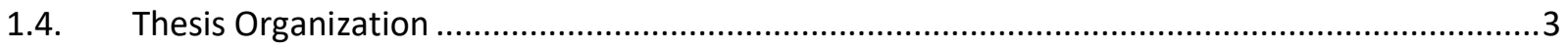

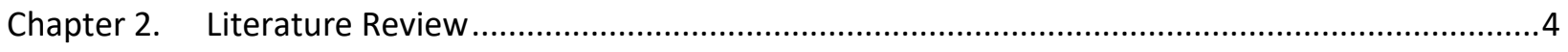

2.1. Pavement Performance Indicators …........................................................................

2.1.1. Pavement Performance Indicators with Common Purposes .......................................... 6

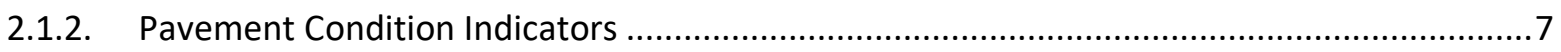

2.1.3. Pavement Functional Indicators .............................................................................

2.1.4. Pavement Surface Evaluation Indicators ................................................................

2.1.5. Pavement Performance According to Surface Type ....................................................20

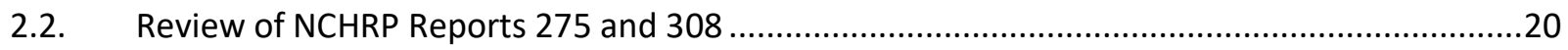

2.2.1. NCHRP Report 275: Pavement Roughness and Rideability (Janoff et al., 1985) ..................21

2.2.2. NCHRP Report 308: Pavement Roughness and Rideability - Field Evaluation (Janoff, 1988) 23

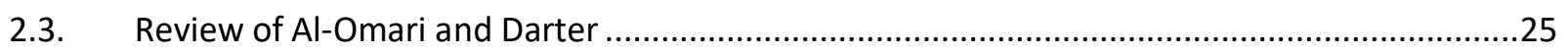




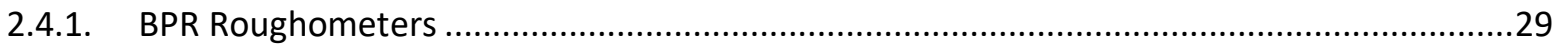

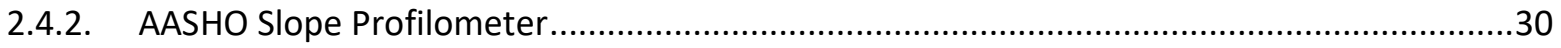

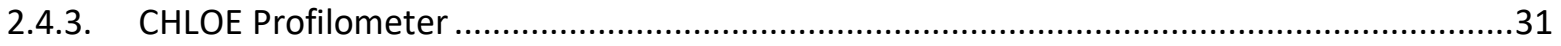

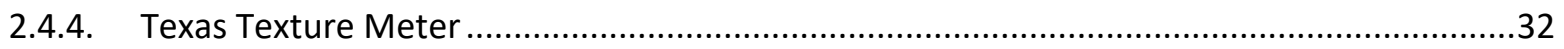

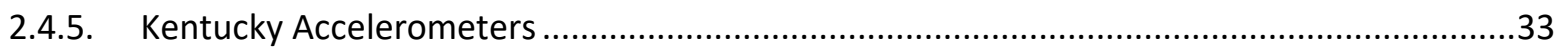

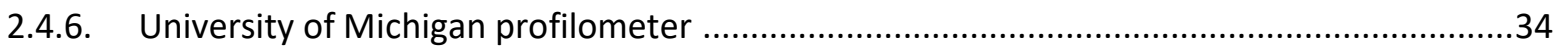

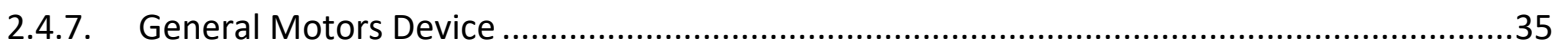

2.4.8. Multiple Roles of Pavement Performance Indicators.....................................................39

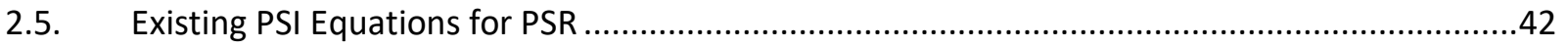

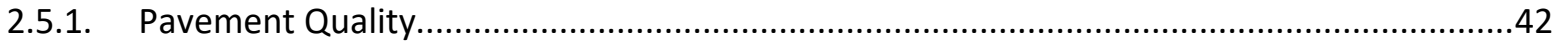

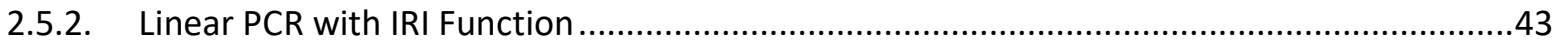

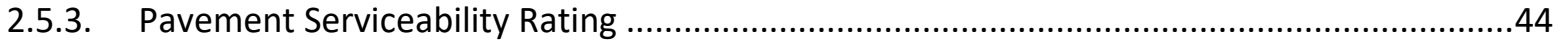

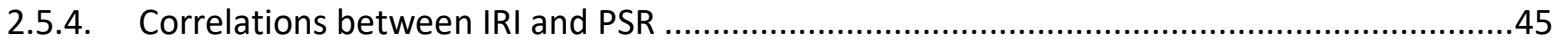

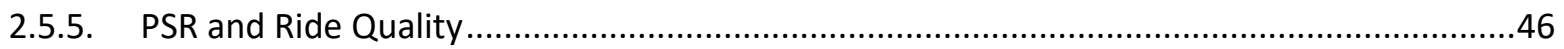

2.5.6. Selecting Appropriate Correlation Functions ...............................................................48

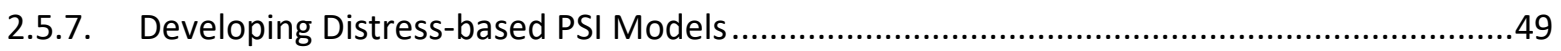

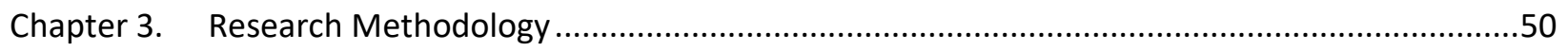

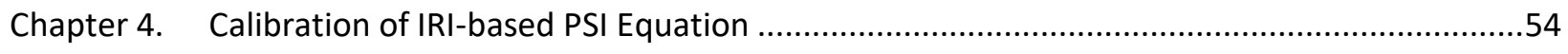

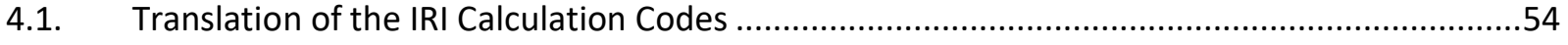


4.2. Data Collection for the Calibration of PSI Equation

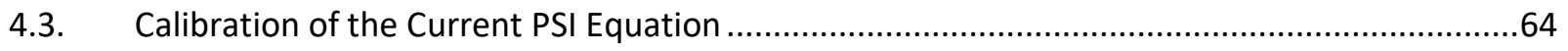

4.4. Evaluation of the Calibrated PSI Equation ..............................................................69

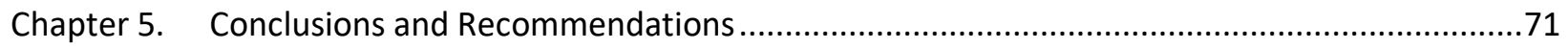

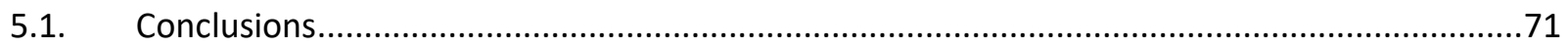

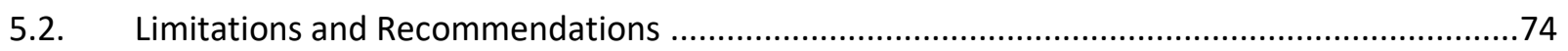

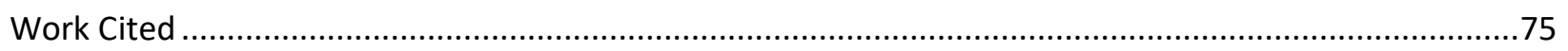

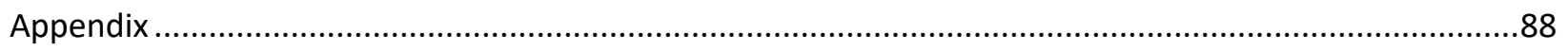

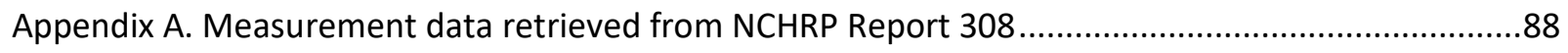

Appendix B. IRI results generated from the golden-car and test parameters ................................93 


\section{List of Figures}

Figure 2-1. Mays ride meter mounted on a vehicle (Sayers and Karamihas, 1998) .22

Figure 2-2: BPR Roughometer (Yoder and Milhous, 1965) .30

Figure 2-3: AASHO Road Test Profilometer (Carey et al., 1962) .31

Figure 2-4: CHLOE Profilometer (Potter et al., 1987) .32

Figure 2-5: Texas Rough Texture instrument (Yoder and Milhous, 1965) ...... .33

Figure 2-6: Michigan Profilometer (Yoder and Milhous, 1965) .34

Figure 2-7: General Motors Pavement measurement device (Yoder and Milhous, 1965) .35

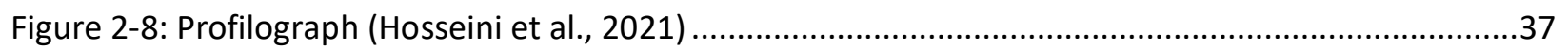

Figure 2-9: Perspectives (Karlaftis et al., 2012) .............................................................................41

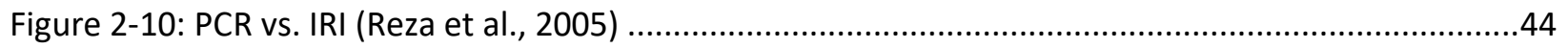

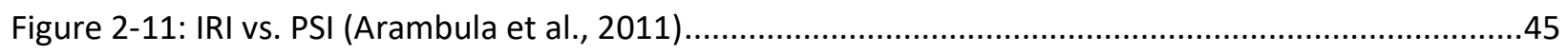

Figure 2-12: Ride quality based on common pavement rating (Al-Khateeb et al., 2020) .......................46

Figure 2-13: PSR by Road User vs. PSR by Panel of Engineers (Al-Khateeb et al., 2020) ........................47

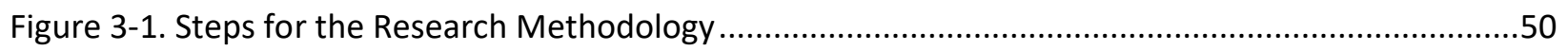

Figure 3-2. Quarter-Car Model (Sayers and Karamihas, 1996) .........................................................52

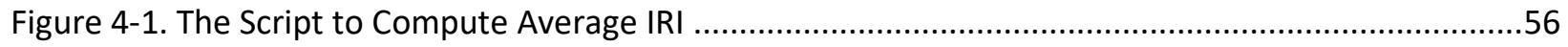

Figure 4-2. Function to Set the Model Matrices..............................................................................5

Figure 4-3. Function to Set the State Transition Matrices .............................................................5

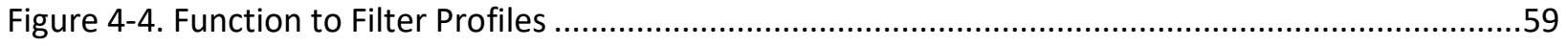

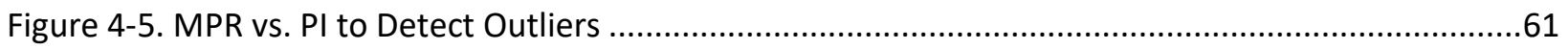

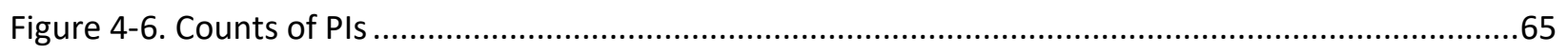

Figure 4-7. IRI Values estimated from MPR using the PSI Equation...................................................66

Figure 4-8. Comparison of Average IRI Values at each PI Group .....................................................68 
Figure 4-9. Calibration of the Current PSI Equation ...

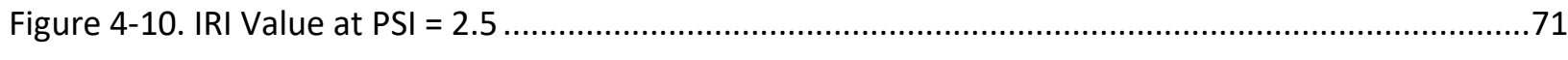




\section{List of Tables}

Table 2-1: The pavement performance indicators with their purpose and surface type (Ningyuan et al.,

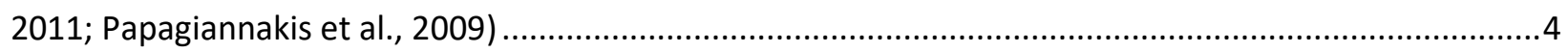

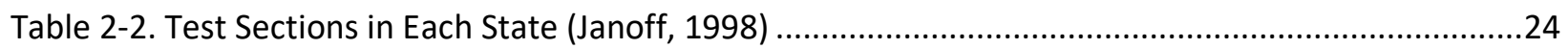

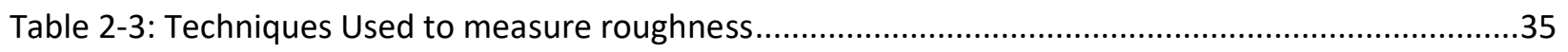

Table 2-4: Summary of measurement devices used. (Khattak et al., 2009) ...........................................39

Table 4-1. Data Points retrieved from NCHRP Report 308 ..............................................................60

Table 4-2. Mechanical Properties of the Representative Vehicle Classes...........................................63

Table 4-3. Quarter-Car Parameters derived from Table 4-2 ...........................................................64

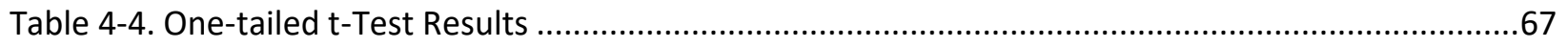

Table 4-5. Rehabilitation Cost Saving due to the Increased IRI ..........................................................71 


\section{Chapter 1. Introduction}

\subsection{Background}

Performance indices are helpful in the assessment of pavement distresses, which leads to facilitating pavement management strategies and consequently providing user convenience driving on highways. These performance indices include, for example, the Internal Roughness Index, Urban Distress Index, and Present Serviceability Index. Particularly, according to Mubaraki and Sallam (2021), the Present Serviceability Index (PSI) makes it appropriate in the assessment of road users' perception of pavement performance. Road users have varying perceptions of pavement ride quality. According to Arellana et al. (2021), most road users are sensitive when driving on pavements in poor surface quality. As such, the various perceptions given by the road users are essential in the formulation of PSI, which in turn facilitates the improvement of the pavement condition.

The concept of the present serviceability index was adopted during the American Association of State Highway Officials (AASHO) road test from 1950 to 1959. It was deemed the most effective approach in the assessment of road performance. Pavement sections are vulnerable to deterioration due to climatic conditions and traffic loading. As such, PSI has been used to estimate users' subjective ratings (i.e., Present Serviceability Rating) on pavement quality along with other physical pavement performance data (Sharma et al., 2019). All types of pavements, such as rigid, flexible, and composite pavements, can be assessed by PSI. The reliability of PSI is important to road agencies, especially in developing the right direction to enhance pavement performance from the user's perspective. Thus, applying PSI as a good and reliable measure is useful both for the government and the individual road users. 


\subsection{Problem Statements and Research Need}

PSI was developed to predict present serviceability rating (PSR), which is a mean of individual ratings (i.e., from 0 to 5 , where " 0 " for very poor and " 5 " for very good) made by a panel of highway users on the ride quality of a given pavement section (Carey and Irick 1960, Janoff et al. 1985, Karaşahin and Terzi 2014). Various PSI equations had been developed since the AASHO Road Test in 1958. These equations were formulated considering different factors such as slope variance over the section from the CHLOE profilometer, mean rut depth, cracking, patching, and the number of sections (Al-Omari and Darter, 1994). The slope of variance determined from the longitudinal pavement profiles was indicated as the most considerable factor in these PSI equations (AI-Omari and Darter, 1994). The PSI equation that many state Department of Transportation (DOTs) are using was developed by Al-Omari and Darter (1994). They presented the current PSI equation by analyzing the relationship between the pavement profile data and panel ratings. The pavement profiles are represented as the International Roughness Index (IRI) in their equation. The data were obtained from the two National Cooperative Highway Research Program (NCHRP) reports published by Janoff et al. (1985) and Janoff (1988). Currently, many state DOTs have been employing the equation in general pavement designs and management for asphalt, concrete, and composite pavements. However, there has been an inconsistency between the IRI-based acceptance limits for new pavements and the PSIs translated for the IRI limits using the equation. For example, the West Virginia Department of Highways (WVDOH) recommends the PSI of 4.2 for new pavement design (WVDOH, 2014). On the other hand, the study of Merritt et al. (2015) found that the acceptable IRI values for new asphalt pavement ranged from 52 to 66 inches/mi. The IRI range is calculated from 4.04 to 3.81 PSI by the equation. According to the Federal Highway Administration (FHWA) PSI definitions, pavement surfaces below 4.0 PSI show defects, such as rutting and fine cracks. It indicates that some new pavements have a preventive maintenance action need when they are newly constructed. 


\subsection{Research Objective}

The objective of this thesis is to calibrate the current IRI-based PSI equation for its reliable and consistent use in pavement design and management. The primary approach to the research objective is based on the hypothesis: there has been improvement in the suspension systems of modern passenger cars. The specific objectives of this study include:

1. Review the existing studies in the development of the current PSI equation, NCHRP reports used as the data sources for the current PSI equation, and other supplemental documents needed to understand the development of existing PSI equations

2. Determine the data types required and retrieve/collect data for data analysis

3. Conduct data analysis that compares the IRI values calculated from the quarter car parameters of the golden car and the IRI values of modern passenger cars.

4. Calibrate the current IRI-based PSI equation based on the comparison results

5. Evaluate the calibrated PSI equation, focusing on the consistency between IRI requirements and PSIbased design recommendations

\subsection{Thesis Organization}

This thesis is structured as follows: Chapter 2 covers the literature reviews for the themes, such as pavement performance and conditions, previous work done by the NCHRP, various roughness measurement methods, and existing PSI equations for PSR. Chapter 3 shows the research methodology for the objective in this thesis. Chapter 4 presents the procedures conducted to calibrate the PSI equation, following the steps discussed in Chapter 3. Finally, Chapter 5 concludes the thesis by answering the research objective and recommending future work. 


\section{Chapter 2. Literature Review}

\subsection{Pavement Performance Indicators}

Pavement performance presupposes the serviceability trend of pavements over a given period, along with the capacity of the pavement to serve the traffic demands in the existing condition (Ahmed et al., 2016). Pavement performance indicators are used to understand the current performance status of pavements so that pavement improvement priorities can be determined for pavement management practices (Marcelino et al., 2018). There are various pavement performance indicators in the United States. Table 2-1 below provides a summary of the pavement performance indicators with their purposes and target surface types.

Table 2-1: The pavement performance indicators with their purpose and surface type (Ningyuan et al., 2011; Papagiannakis et al., 2009)

\begin{tabular}{|c|c|c|c|}
\hline $\begin{array}{l}\text { Pavement } \\
\text { performance } \\
\text { indicators }\end{array}$ & States & Purpose & Pavement surface type \\
\hline $\begin{array}{l}\text { Present } \\
\text { Serviceability } \\
\text { Index - PSI }\end{array}$ & $\begin{array}{l}\text { Alaska } \\
\text { Arizona Missouri } \\
\text { South Dakota } \\
\text { Wyoming } \\
\text { Vermont }\end{array}$ & $\begin{array}{l}\text { Provides a serviceability } \\
\text { measure of a a } \\
\text { pavement/quality rating } \\
\text { of a ride }\end{array}$ & $\begin{array}{l}\text { Asphalt concrete (AC), Portland } \\
\text { cement concrete (PCC) pavement, } \\
\text { Composite (concrete + asphalt), } \\
\text { Surface Treated (ST) pavements }\end{array}$ \\
\hline $\begin{array}{l}\text { International } \\
\text { Roughness Index- } \\
\text { IRI }\end{array}$ & $\begin{array}{l}\text { Arkansas } \\
\text { Colorado } \\
\text { Louisiana } \\
\text { Nevada } \\
\text { New Hampshire } \\
\text { New Jersey } \\
\text { New Mexico } \\
\text { New York } \\
\text { North Dakota } \\
\text { Oklahoma } \\
\text { Illinois } \\
\text { Indiana } \\
\text { Kentucky } \\
\text { Nebraska } \\
\text { Maryland }\end{array}$ & $\begin{array}{l}\text { Measuring pavement } \\
\text { roughness or riding } \\
\text { quality }\end{array}$ & AC, PCC, Composite, ST pavements \\
\hline
\end{tabular}




\begin{tabular}{|c|c|c|c|}
\hline $\begin{array}{l}\text { Pavement } \\
\text { Condition Index - } \\
\mathrm{PCl}\end{array}$ & $\begin{array}{l}\text { Hawaii } \\
\text { lowa } \\
\text { Kentucky } \\
\text { New York } \\
\text { Vermont } \\
\text { Washington }\end{array}$ & $\begin{array}{l}\text { Measures the overall } \\
\text { condition and pavement } \\
\text { serviceability }\end{array}$ & AC, PCC, Composite, ST pavements \\
\hline $\begin{array}{l}\text { Mean Riding Index } \\
-M R I\end{array}$ & $\begin{array}{l}\text { New Hampshire } \\
\text { Connecticut } \\
\text { Florida } \\
\text { Massachusetts } \\
\text { Montana } \\
\text { Pennsylvania } \\
\text { Vermont } \\
\text { Utah }\end{array}$ & $\begin{array}{l}\text { Measures pavement } \\
\text { smoothness/roughness }\end{array}$ & AC, PCC, Composite, ST pavements \\
\hline $\begin{array}{ll}\text { Half-Car } & \text { Ride } \\
\text { Index-HRI } & \end{array}$ & $\begin{array}{l}\text { New Hampshire } \\
\text { Connecticut } \\
\text { Florida } \\
\text { Massachusetts } \\
\text { Montana } \\
\text { Pennsylvania } \\
\text { Vermont } \\
\text { Utah }\end{array}$ & $\begin{array}{l}\text { Measures pavement } \\
\text { smoothness/roughness }\end{array}$ & AC, PCC, Composite \\
\hline Cracking Index $-\mathrm{Cl}$ & $\begin{array}{l}\text { Florida } \\
\text { Mississippi } \\
\text { Montana } \\
\text { Idaho } \\
\end{array}$ & $\begin{array}{l}\text { Measures safety and } \\
\text { comfort of a pavement }\end{array}$ & AC, PCC, Composite \\
\hline $\begin{array}{l}\text { Riding Comfort } \\
\text { Index }-\mathrm{RCl}\end{array}$ & New Hampshire & $\begin{array}{l}\text { Measures riding } \\
\text { condition/comfort }\end{array}$ & AC, PCC, Composite, ST pavements \\
\hline $\begin{array}{l}\text { Distress } \\
\text { Manifestation } \\
\text { Index - DMI }\end{array}$ & $\begin{array}{l}\text { Alaska } \\
\text { Alabama } \\
\text { California } \\
\text { Colorado } \\
\text { Georgia } \\
\text { Illinois } \\
\text { Michigan } \\
\text { New Hampshire } \\
\text { Vermont } \\
\text { Maryland } \\
\text { Mississippi } \\
\text { Ohio } \\
\text { Oregon } \\
\text { Rhode Island } \\
\text { Texas } \\
\text { Virginia } \\
\text { West Virginia } \\
\text { Canada }\end{array}$ & $\begin{array}{l}\text { Measures pavement } \\
\text { surface distresses } \\
\text { (cracks, defects, and } \\
\text { distortion) }\end{array}$ & AC, PCC, Composite \\
\hline
\end{tabular}




\begin{tabular}{|c|c|c|c|}
\hline $\begin{array}{l}\text { Surface/Pavement } \\
\text { Distress Index - } \\
\text { S/PDI }\end{array}$ & $\begin{array}{l}\text { Wisconsin } \\
\text { Pennsylvania } \\
\text { South Carolina } \\
\text { Tennessee } \\
\text { Canada }\end{array}$ & 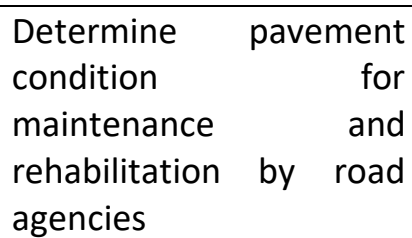 & AC, PCC, Composite \\
\hline $\begin{array}{l}\text { Pavement Quality } \\
\text { Index-PQI }\end{array}$ & $\begin{array}{l}\text { Minnesota } \\
\text { South Carolina } \\
\text { Tennessee } \\
\text { Indiana } \\
\text { Canada }\end{array}$ & $\begin{array}{l}\text { Quantify the overall } \\
\text { condition of the } \\
\text { pavement (factors in } \\
\text { pavement roughness and } \\
\text { distress data) }\end{array}$ & AC, PCC, Composite, ST pavements \\
\hline $\begin{array}{l}\text { Structural } \\
\text { Adequacy Index - } \\
\text { SAI }\end{array}$ & Canada & $\begin{array}{l}\text { Evaluate the structural } \\
\text { capacity of a pavement }\end{array}$ & AC, PCC, Composite, ST pavements \\
\hline $\begin{array}{l}\text { Structural } \\
\text { Strength Index - } \\
\text { SSI }\end{array}$ & Canada & $\begin{array}{l}\text { Structural evaluation of } \\
\text { pavement for } \\
\text { management and } \\
\text { rehabilitation purposes }\end{array}$ & AC, PCC, Composite, ST pavements \\
\hline $\begin{array}{l}\text { International } \\
\text { Friction Index - IFI }\end{array}$ & Canada & $\begin{array}{l}\text { Standardized friction } \\
\text { measurements obtained } \\
\text { from different friction } \\
\text { measuring tools } \\
\text { IFI uses the speed } \\
\text { constant parameter } \\
\text { measurement technique } \\
\text { to determine how } \\
\text { pavement friction varies } \\
\text { with slip speed }\end{array}$ & AC, PCC, Composite, ST pavements \\
\hline $\begin{array}{l}\text { Friction Number - } \\
\text { FN }\end{array}$ & $\begin{array}{l}\text { Nevada } \\
\text { Canada }\end{array}$ & $\begin{array}{l}\text { Measures skid resistance } \\
\text { performance of a } \\
\text { pavement }\end{array}$ & AC, PCC, Composite, ST pavements \\
\hline $\begin{array}{l}\text { Road Safety Index } \\
- \text { RSI }\end{array}$ & $\begin{array}{l}\text { Pennsylvania } \\
\text { Delaware } \\
\text { Maine } \\
\text { Canada }\end{array}$ & $\begin{array}{l}\text { Evaluate pavement } \\
\text { safety based on the road } \\
\text { safety elements and } \\
\text { safety engineering during } \\
\text { road management }\end{array}$ & AC, PCC, Composite, ST pavements \\
\hline
\end{tabular}

\subsubsection{Pavement Performance Indicators with Common Purposes}

Pavement performance indicators provide crucial information to road agencies about the structural condition of pavement and functionality in terms of serviceability level and road safety. Performance indicators are important in road management, where they are used to establish trigger levels in relation to pavement service standards for technical and economic purposes (Ningyuan et al., 2011). Condition, 
functional, and structural pavement indicators are important to evaluate pavement conditions and make better decisions regarding maintenance and rehabilitation interventions to ensure better performance (Marcelino et al., 2018). Pavement performance reports are used to evaluate how federal-aid funds impact infrastructure conditions based on national development goals. They also provide information to the government and the general public about the condition of the state and federal pavement network, including the target performance achievement for each state. State Departments of Transportation have adopted different performance indicators to describe pavement design, construction, condition, and maintenance requirements.

Generally, performance indicators are grouped according to purpose (See Table 2-1), which includes condition evaluation, functional evaluation, and structural evaluation. All pavement performance indicators reflect the pavement's relative ability to provide safe traffic conditions over its service life. The State Department of Transportation across various states use a system of objective measurements to quantify the condition and performance of pavement, which is useful to make decisions relating to maintenance priorities and rehabilitation strategies and to predict overall pavement performance.

\subsubsection{Pavement Condition Indicators}

The Pavement Condition Index (PCI), Distress Manifestation Index (DMI), Surface/Pavement Distress Index (S/PDI), and Pavement Quality Index (PQI) are pavement condition indicators since they are used to measure the overall condition of pavement. 


\section{a) Pavement Condition Index (PCI)}

The purpose of $\mathrm{PCl}$ is to evaluate the alterations that occur in the pavement network system to determine Long-Term Pavement Performance (LTPP). Karim et al. (2016) indicate that the $\mathrm{PCl}$ assesses the maintenance and rehabilitation requirements of the pavement section in the whole pavement section. The PCl anchors on the road distress conditions captured in LTPP, including pavement surface defects, pavement surface deformations, and cracking (Llopis-Castello et al., 2020; Arhin et al., 2015). Thus, $\mathrm{PCl}$ is concerned with measuring the levels of pavement deterioration over time.

The $\mathrm{PCl}$ utilizes the value range numerical measurement method. The numerical rating ranges from 0 to designate the possible worst condition of the pavement to 100 to signify the best/perfect possible condition (Ahmed et al., 2016; Marcelino et al., 2018; Bryce et al., 2019; Arhin et al., 2015; Wang et al., 2017). The measurement method enables the pavement maintenance team to establish the type of maintenance strategy the pavement might need at any given time.

The $\mathrm{PCl}$ has advantages and disadvantages. Advantages include identifying the requirement for immediate maintenance and rehabilitation, determining preventive maintenance strategies, and assessing pavement materials and architectural design (Karim et al., 2016). However, the $\mathrm{PCl}$ does not measure structural capacity, roughness, and skid resistance (Karim et al., 2016; Marcelino et al., 2018). Therefore, the observed pavement surface cannot be used to extrapolate the structural capacity of the pavement. 


\section{b) Distress Manifestation Index (DMI)}

DMI has a high correlation with the Pavement Condition Index. Hence, the purpose of DMI is similar to the purpose of $\mathrm{PCl}$ since they both measure the type and severity of the distress on the pavement surface such as cracks and rutting (Wang et al., 2017). Additionally, DMI measures pavement smoothness and ride comfort. The measurement methods that DMI uses to determine pavement performance are statistical analyses to measure the type, frequency, and severity of the manifested pavement distress. Similarly, DMI uses visual inspections and observation to evaluate the severity and frequency of the manifested distress. New York has developed guidelines to assess the dominant distress features such as pavement cracks, surface deformation, and surface defects (Llopis-Castello et al., 2020; Wang et al., 2017). The New York Department of Transportation rates the distress conditions of the pavement surface in by assigning ratings based on what is present on the ground compared with the pre-defined rating scale (Wang et al., 2017). However, MDI is subjective because it is challenging to determine which pavement is excellent or poor by only looking at the surface conditions.

\section{c) Surface/Pavement Distress Index (S/PDI)}

The purpose of the pavement distress index performance indicator is to determine the pavement condition in order to allocate resources for maintenance and rehabilitation. Rahman et al. (2017) indicates that the PDI assesses the surface of the old and newly constructed pavements to determine if they are distress-free. The pavement performance indicator evaluates distress factors such as spalling, traverse cracking, surface deterioration, number of potholes over a pavement section, rutting depth, and faulting. For asphalt concrete pavements, PDI observes distress elements such as raveling, fatigue cracking, and longitudinal cracking (Rahman et al., 2017). The measurement method for PDI is the adjustment distress value (ADV), ranging from 0 to 5 . The newly developed pavements are considered distress-free when the ADV is 5 (perfect condition) and not distress-free when the ADV value is 0 (failed condition) (Rahman et 
al., 2017). The South Carolina Department of Transportation uses PDI to evaluate the future performance of asphalt concrete roads and initiate pavement deterioration prevention measures.

d) Pavement Quality Index (PQI)

The purpose of the PQI pavement performance indicator is to quantify the overall condition of the pavement. The performance indicator factors pavement roughness and distress data (Marcelino et al., 2018). The PQI uses the rating panel and regression analysis as the measurement methods to correlate panel assessment with International Roughness Index values (Marcelino et al., 2018). The PQI has an advantage since it measures pavement distress elements such as ruts, cracks, and patches (Marcelino et al., 2018). The Minnesota Department of Transportation formulated the PQI to determine pavement performance. However, the drawback of $P Q I$ is that it depends on pavement quality index and surface roughness only.

Pavement condition indicators form an integral part of road management. The $\mathrm{PCl}$ is a statistical measure that evaluates the general condition of pavement using IRI and IDM. According to Nguyen (2017), PSI and IRI in asphalt concrete road pavements are closely correlated and can be used to establish the quality of such pavements. The DMI indicates the overall condition of a pavement surface and its performance over time. Distresses in pavements are caused by traffic loads, aging, and environmental factors (Chamorro et al., 2009). SDI requires visual evaluation to determine the SDI value for pavement maintenance purposes (Arianto et al., 2017). The PQI is a metric function of RCI, SDI, and SAI (in Canada) or the Pavement Condition Rating (PCR) and the International Roughness Index (IRI) (in the USA), which gives the overall score of the pavement condition (Reza et al., 2006). The PCI, DMI, SDI, and PQI all provide information about the measure of the performance and level of service of a pavement. The data obtained from these 
measurements facilitate the evaluation of the degradation status of pavement in order to make sound decisions regarding road operation, repair, improvement, and maintenance.

\subsubsection{Pavement Functional Indicators}

The Present Serviceability Index (PSI), International Roughness Index (IRI), Mean Riding Index (MRI), HalfCar Ride Index (HRI), Cracking Index (Cl), Riding Comfort Index (RCI), International Friction Index (IFI), Friction Number (FN), and Road Safety Index (RSI) are as pavement functional indicators.

\section{a) Present Serviceability Index (PSI)}

The purpose of the PSI pavement performance indicator is to estimate the serviceability of the pavement. Aleadelat and Ksaibati (2017) state that pavement serviceability entails the interactions of elements such as road profile, the attributes of a vehicle, and the perceptions of pavement users. The road profile, in this regard, covers macro-texture, surface defects, cracking, friction, and bearing capacity (Llopis-Castello et al., 2020). Aleadelat and Ksaibati (2017) note that PSI primarily factors pavement users needing services (Aleadelat \& Ksaibati, 2017). In essence, the actual judgment of pavement users while using the pavement is regarded as the major method of measuring how the pavement serves its intended purpose (Aleadelat \& Ksaibati, 2017). Therefore, Bryce et al. (2019) indicate that the PSI is a pavement performance measure that demonstrates the cumulative quality of the ride on the pavement based on user perspective. The use of the PSI is to determine how pavements cumulatively serve their objectives concerning functional behavior (serviceability). 
The value range is the measurement method employed to measure PSI. The value ranges from $0-1$, implying very poor, 1-2 indicating poor, 2-3 suggesting fair, 3-4 predicating good, and 4-5 showing excellent pavement serviceability (Terzi, 2006). Marcelino et al. (2018) add that the 0.0 value intimates the worst condition, and 5.0 expresses the best condition of the pavement. Thus, the measurement method of PSI is determined by using correlations between the users' opinions and pavement's functional behavior.

PSI has advantages and disadvantages. One of the advantages is to show the momentary (present) capacity of the pavement to serve the public. Additionally, PSI exhibits the serviceability history and load application history to determine how the condition of the pavement changes over time (Terzi, 2006). However, PSI is subjective since the pavement performance is based on the opinion of pavement users (Terzi, 2006). Besides, the judgment of the users of the pavement is impractical to rate pavement performance because the human mind is flexible, which exposes the ratings to diverse personal interpretations (Aleadelat \& Ksaibati, 2017). Hence, the subjectivity of PSI is the primary disadvantage.

\section{b) International Roughness Index (IRI)}

The purpose of IRI is to calibrate pavement roughness measurement. Park et al. (2007) indicate that in 1982, the World Bank proposed the IRI as a standard statistic to compare, correlate, and calibrate roughness measurements. Abulizi et al. (2016) opine that IRI was developed based on the outcomes of International Road Roughness tests undertaken in Brazil. Abulizi et al. (2016) add that Since pavement roughness is categorized as the primary indicator of the costs linked to pavement conditions, IRI is used internationally to measure pavement roughness. 
The cumulative suspension motion in moving cars over the traveled distance is the measurement method deployed in the IRI pavement performance indicator. Ahmed et al. (2016) opine that the IRI utilizes longitudinal profile measurement to establish deformities that impact pavement users' comfort and safety. Llopis-Castello et al. (2020) add that the IRI is calculated by factoring in a simulated user vehicle traveling at $80 \mathrm{~km} / \mathrm{h}$ to assess pavement performance. The $\mathrm{Km} / \mathrm{h}$ measurement is utilized as scale rating measurement where the IRI of lower rating value, for example, IRI of $0.0 \mathrm{~km} / \mathrm{h}$, designates pavement with a perfectly flat profile, and the IRI rating beyond $8 \mathrm{~km} / \mathrm{h}$ signifies impassible pavements (Park et al., 2007; Ahmed et al., 2016). However, the IRI has no upper rating value. Hence, the IRI measurement method captures pavement roughness based on longitudinal profiles.

The IRI has advantages and disadvantages. Abulizi et al. (2016) state that the IRI is stable over time and is transferable globally. Llopis-Castello et al. (2020) mention that the IRI has an impressive correlation with pavement distress in the interurban environment. Nevertheless, the IRI pavement performance indicator cannot adequately represent pavement characteristics in the urban environment since it faces challenges collecting low-speed data in urban pavements (Llopis-Castello et al., 2020; Wang et al., 2017). Similarly, it only uses a single tire system (quarter-car model) to determine how the pavement profile affects the car (Múčka, 2019; Zang et al., 2018). The disadvantages make the IRI only suitable for measuring pavement performance in high-speed environments. 
c) Mean Riding Index (MRI)

MRI has no significant dissimilarities to IRI. Since IRI is a quarter-car model for measuring the performance of a pavement profile (pavement surface roughness), MRI computes the average of the left and right profiles of cars. Thus, the purpose of the MRI, which is the mean IRI value collected from two-wheel paths, is to assess the roughness of the pavement network and determines if the smoothness of the pavement meets the outlined smoothness level (Múčka, 2019). The measurement method used in MRI is the mean value from the two wheels of a car (Zang et al., 2018). The advantage of MRI is that it can be deployed to acquire rough estimates of the association between pavement types (Múčka, 2019). However, even though many states in the United States use MRI specifications, it cannot be utilized to generate specifications for formal reporting objectives.

d) Half-Car Ride Index (HRI)

Similarly, HRI has no essential differences from IRI. Therefore, the purpose of HRI is to calculate the average of two parallel pavement profiles (Zang et al., 2018). Múčka (2019) argues that HRI, compared to $I R I$, is a pavement performance indicator that computes the average of two pavement profiles based on the left and right wheel paths of a car. The HRI utilizes equations deployed in the IRI (quarter-car model) to compute the HRI (Múčka, 2019). States such as Colorado, Tennessee, and Georgia use the HRI because it determines the performance of asphalt pavements and concrete pavements regarding smoothness (Múčka, 2019). One of the major disadvantages of the HRI is that the left and the right wheels must be well aligned and synchronized to acquire accurate results. 

e) Cracking Index (CI)

The purpose of $\mathrm{Cl}$ is to determine the safety and comfort of the pavement. The $\mathrm{Cl}$ measures several types of distresses on pavements, including fatigue cracking, edge cracking, reflection cracking, longitudinal cracking, traverse cracking and block cracking (Ragnoli et al., 2018; Shah et al., 2013). The measurement methods used to determine the severity of different types of pavement cracking may include pavement penetrating radar and infrared imaging (Coenen et al., 2017). The $\mathrm{Cl}$ benefits pavement performance since it determines how potholes, cracks, and rutting impact pavement users' comfort. Moreover, Cl establishes pavement maintenance and rehabilitation requirements.

f) Riding Comfort Index (RCI)/Rider Quality Index

The pavement performance indicator is based on the road users' comfort when they are riding on the road. Therefore, the purpose of the $\mathrm{RCl} /$ Rider Quality Index (RQI) is to collect views of the public concerning how they rate the quality of roads and pavements ("Pavement Condition Index 101"). The measurement method the Rider Quality Index uses is the scale rating of comfort levels from 0 to 10 . The rating level of 0-2 implies a very poor riding comfort level associated with bumps and depression. The rating level of 8-10 predicates excellent riding comfort associated with the smooth ride ("Pavement Condition Index 101"). In the State of New York, a rider quality pavement condition index has been developed (Wang et al., 2017). Additionally, the state of Michigan has the Michigan Rider Quality Index, and the state of Minnesota has a Minnesota Ride Quality Index for assessing rider comfort (Loprencipe and Zoccali, 2017). Be that as it may, the RQI pavement performance indicator is a subjective measure of determining the quality of the pavement 

g) International Friction Index (IFI)

The purpose of IFI is to standardize friction measurements acquired from various friction measuring tools on a similar sample of the pavement surface. Fuentes et al. (2012) indicates that the sample pavement surfaces must have a common calibration index to generate the required performance measurement. IFI uses the speed constant parameter (SP) measurement method to dictate the level of variation of pavement friction with slip speed (Fuentes et al., 2012). IFI has numerous advantages. For instance, it is the standard pavement performance indicator for evaluating pavement surface friction attributes. Additionally, it harmonizes measurements acquired from diverse friction measurement tools to a unifying calibrated friction index (Fuentes et al., 2012). The Virginia Smart Road has adapted IFI to measure the performance of pavements in some sections of the state roads (Fuentes et al., 2012). Nevertheless, since IFI is based on the empirical observations of the interplay between slip speed and friction, it limits the applicability of the pavement performance indicator.

\section{h) Friction Number (FN)}

The purpose of the FN pavement performance indicator is to measure skid resistance performance. Yu et al. (2017) argue that pavement friction is affected by water (hydroplaning speed of the tire), fictional attributes of the tire (the adhesive and hysteretic friction due to the contact between the pavement and the tire), and the anti-skid features of the pavement. The locked-wheel testing is the common measurement method used in FN. For example, the state of Florida uses a locked-wheel testing measurement method on the Belcher Road in Largo to determine pavement friction numbers (Smith \& Uddin, 2016). The FN pavement performance indicator has advantages since the numbers are used to improve brake efficiency for better safe driving (Yu et al., 2017). However, the disadvantage of FN is that it must include pavement aggregate hardness, pavement surface texture, and tire-pavement contact to achieve desirable numbers. 


\section{i) Road Safety Index (RSI)}

The purpose of the RSI pavement performance indicator is to assess pavement safety criteria by factoring in road safety elements and safety engineering during road management. Tighe et al. (2000) opine that the concern of RSI is to reduce road accidents based on all sectors of pavement engineering such as road roughness, road skid resistance, surface features, visibility, surface color, and other environmental conditions. RSI is beneficial to pavement performance because it classifies elements associated with pavement safety, determines causes of road accidents, and improves the standard of pavements (Tighe et al., 2000). For example, in the United States, the skid resistance measurement method is used to evaluate road safety. Road Safety Index data are used to inform drivers regarding the accident risks associated with the segment of the pavement they are traveling to avoid future pavement accidents.

Although pavement functional indicators also show the overall condition of the pavement, the emphasis is on the riding quality, comfort, and safety of the user rather than for maintenance purposes by road agencies. Pavement functional indicators focus on meeting user expectations and demands. The PSI is a performance indicator used to assess the functional condition of pavement with respect to serviceability and ride quality (Terzi, 2006). Ride quality and comfort are directly related to pavement smoothness/roughness. The IRI value has units of the slope, which reflect pavement roughness or riding quality. An IRI value of zero indicates an absolute perfect pavement. Some road agencies use the right and left IRI data to calculate the average, which represents the MRI value. On the other hand, the HRI uses a model to determine the average of the right and left wheel paths (US Department of Transportation, 56). The MRI and HRI are similar to IRI, and both are used to measure the smoothness/roughness of a pavement. 
The IFI and FN also function as pavement roughness indicators. The IFI is based on the speed constant and the harmonized friction at $60 \mathrm{~km} /$ hour (F60) (Flintsch et al., 2009). Adequate pavement friction is crucial for drivers to keep their lane and have the ability to manoeuver in lateral and longitudinal directions safely (Hall et al., 2009). The $\mathrm{Cl}$ is an indicator of the severity of distresses caused by transverse and longitudinal cracking of a pavement (Shaha et al., 2013). The RCI is based on the IRI value. Some road agencies use the IRI value directly as RCI. The RSI reflects the overall safety status of a pavement (Botha, 2005). The PSI, $\mathrm{IRI}, \mathrm{MRI}, \mathrm{HRI}, \mathrm{Cl}$, and $\mathrm{RCl}$ all factor in pavement roughness/smoothness, which is important pavement performance indicators since they affect ride quality, fuel consumption, vehicle delay costs, as well as maintenance costs.

\subsubsection{Pavement Surface Evaluation Indicators}

The Structural Adequacy Index (SAI) and Structural Strength Index (SSI) are grouped as pavement structural evaluation indicators.

\section{a) Structural Adequacy Index (SAI)}

The purpose of the SAI pavement performance indicator is to evaluate the structural capacity of flexible pavements and rigid pavements. Rada et al. (2012) argues that the SAI is a fundamental pavement performance indicator for making rational pavement investment decisions. Thus, many states in the United States use SAl as a critical segment in the pavement management system. The measurement methods utilized in SAl are effective pavement structural number and the structural adequacy index for flexible pavements. For rigid pavements, the measurement method is the effective concrete slab thickness (Rada et al., 2012). SAl is beneficial to the pavement management system since it enables highway agencies to determine the structural capacity of the road to sustain the anticipated traffic and 
load (Rada et al., 2012). Highway agencies in states such as Virginia, Arkansas, Arizona, and lowa use SAI as part of the international friction index pavement performance management system.

\section{b) Structural Strength Index (SSI)}

The purpose of the SSI is to incorporate the structural data of the pavement in the pavement management information system for efficient pavement management and rehabilitation. Bryce (2012) argues that SSI works on the principle of surface curvature index and deflection. The pavement performance indicator is calculated using the thin asphalt section and thicker asphalt pavements, and the ultimate structural strength is correlated using traffic and rainfall (Bryce, 2012). The indexing is based on a scale of 0 to 100 , where 0 connotes poor SSI and 100 connotes perfect SSI. (Bryce, 2012). SSI produces superior results because it is a statistically-based model. The Department of Transportation in Texas and Indiana created SSI as part of the pavement management system in the state.

The SAI reflects the structural capability of a pavement to carry loads. Generally, structural adequacy of $>50$ is acceptable (Newstead et al., 2018). The SSI is an assessment indicator for pavement structural conditions. It is useful to road agencies for prioritizing rehabilitation needs and routine preventive maintenance (Chang et al., 2002). Hence, the SSI is developed alongside thresholds for maintenance, reconstruction, and rehabilitation (Flora et al., 2010). Both SAI and SSI values can be determined using the Falling weight deflectometer (FWD) technique. 


\subsubsection{Pavement Performance According to Surface Type}

The pavement performance indicators also vary with the type of pavement surface material, as shown in table 1 . The pavement surface type is one of the key factors affecting pavement condition over time. In general, PCC pavements tend to be more durable under warmer climatic conditions than other types of pavement surface materials. On the other hand, asphalt pavements tend to be more resilient under cold weather conditions than other types of pavement surface materials. Another issue of concern in PCC pavements is the concrete joints. In asphalt and concrete pavements, the type of base material, sub-base material, pavement surface layer, and layer thickness greatly impact pavement performance and condition over time. Pavement surface types with better functional performance evaluation results provide safe driving conditions as they contribute to improved anti-stripping performance and anti-sliding performance, as well as reducing tire-pavement noise (Cai, 2020). The conditional, functional, and structural performance of pavement directly impacts the pavement maintenance actions and the economic benefit of the asset.

\subsection{Review of NCHRP Reports 275 and 308}

The NCHRP conducted Project 1-23 that published two reports, NCHRP Reports 275 and 308. The main purpose of these studies was to develop a new pavement roughness assessing method that correlates subjective panel ratings (rideability) with physical pavement profile measurements. Thus, the field testing on the pavement sections at the selected states was performed, and the data of panel ratings and profiles were produced and listed in the reports. The data is the only resource publicly available and accessible in an open source such as the Internet. The correct use of the data presented in the NCHRP Reports 275 and 308 needs to understand the full depth of the finding in these reports. 
2.2.1. NCHRP Report 275: Pavement Roughness and Rideability (Janoff et al., 1985)

The objectives of this study performed under NCHRP Project 1-23 included the development of a new pavement rating scale for ride quality from the public's perception, the formulation of panel rating scales in relation to pavement profiles, and the investigation of roughness statistics from RTRRMS to the panel ratings. The subjective measures of the public perception were statistically related to objective pavement roughness measures. The tasks necessary to achieve the study objective included a literature review to aid the proposed research, a guideline development for an experimental design that was divided into the pilot and main experiments, actual performance of the experiments, and data analysis. The data analysis was conducted to investigate the effects of various variables, such as vehicle size, vehicle speed, and the regionality and training of rating panel, on subjective ratings. Also, the analysis examined the transforms between the panel ratings and pavement roughness measures for all three surface types of bituminous concrete (BC), Portland cement concrete (PCC), and composite (COMP).

The pilot study collected the data of panel ratings and road profiles from the $34 \mathrm{BC}$ test sections in Pennsylvania and $31 \mathrm{BC}$ test sections in Florida. The panels involved in the pilot study consisted of 84 licensed drivers from both states (i.e., 63 from Pennsylvania and 21 from Florida) and 21 trained professionals from Pennsylvania. The length of each test section was equalized to $2,025 \mathrm{ft}$ to measure the roughness of the test sections. K-Cars were the main test vehicle selected for the study, and a subcompact car was also used to investigate the effect of vehicle size on panel ratings. Physical measurements of the pavement roughness were conducted with the Pennsylvania State University (PSU) profilometer and Mays ride meter (MRM) for the PA sections and the MRM for the FL sections. MRM is a vehicle vertical excursion measuring device at the rear axle and consists of the electrical and mechanical parts, as shown in Figure 2-1. The pilot study found that the panel regionality only could affect the appraisal of ride quality, and the amplitude of the longitudinal roughness was highly correlated with panel ratings. The pilot study also 
conducted graphical and comparative analyses to suggest the analysis methods to correlate subjective ratings with ride quality and physical profiles. The major conclusions from this analysis were: 1) the correlations between Pls with the frequency bands of above $0.09 \mathrm{c} / \mathrm{ft}$ (cycles per foot), $0.09-1.5 \mathrm{c} / \mathrm{ft}$, or $0.2-0.4 \mathrm{c} / \mathrm{ft}$ and mean panel ratings (MPRs) were excellent and 2) $\mathrm{PI}$ as a sole predictor could account for most of the MPR variances across various individual frequency bands. In particular, the first conclusion indicated that the use of pavement roughness data all across frequency bands was not relevant to account for ride quality from the public's perception.

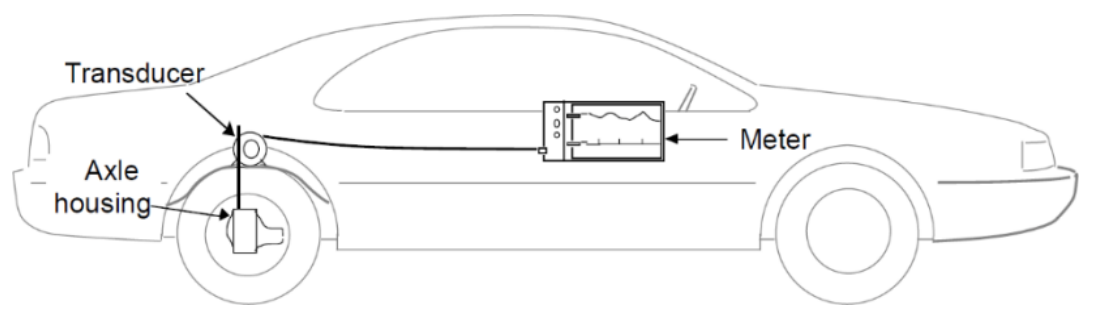

Figure 2-1. Mays ride meter mounted on a vehicle (Sayers and Karamihas, 1998)

The main experiment tested 81 sections of all three surface types (i.e., $25 \mathrm{BC}, 22 \mathrm{PCC}$, and 34 COMP) in Ohio with 36 drivers. Four K-cars of similar ages and mileages were used for the ratings on all test sections. The measuring instruments included the K. J. Law noncontact profilometer and MRM of the Ohio DOT (ODOT). The PSU profilometer was also used for some test sections to compare its measuring performance (e.g., $1 / 4$ car, profile index (PI), and graphical outputs, and others) with PSU. The main experiment found that the correlations, as around 0.9 , between MPR and $1 / 4$ car or MRM was generally good for the BC test sections. The one-third octave analysis revealed that the profiles in the frequency band of 0.125 to 0.630 c/ft (i.e., $10-50 \mathrm{~Hz}$ at $55 \mathrm{mph}$ ) were highly correlated with MPRs for all three surface types. The log transform of the PI values increased the correlation with the MPRs in general. The comparison between the Ohio and PSU profilometers by analyzing the profile data from 10 test sections verified almost identical PI values at the frequency band of $0.125-0.630 \mathrm{c} / \mathrm{ft}$, yielding the regression equation as follows:

$$
O D O T=-0.0006+0.84 P S U, r=0.99
$$


Based on the results from the pilot and main experiments, the report made the panel ratings-related discussions as follows:

- Estimation of rideability numbers (RNs) that are the expression of subjective ratings of the public's perception of rideability, through Equation 2.2:

$$
R N=-1.74-3.03 \log (P I)
$$

Equation 2.2 was valid for the pavement profiles measured in the frequency band of $0.125-0.630$ $\mathrm{c} / \mathrm{ft}$ and applicable for all pavement surface types.

- Transforms between subjective ratings and response-type roughness measures (e.g., MRM or $1 / 4$ index) for BC, PCC, COMP, and all surfaces combined, considering correlation coefficients $(=r)$ or regression coefficients $\left(=r^{2}\right)$. The log transform of MRM indices to MPRs for BC surfaces was relatively good for agencies to use, while others were not recommended due to the $r^{2}$ values less than the $r^{2}$ of the transform between PI and MPR.

\subsubsection{NCHRP Report 308: Pavement Roughness and Rideability - Field Evaluation (Janoff, 1988)}

This study aimed to verify the results from the previous NCHRP Project 1-23 (i.e., the NCHRP Report 275) using additional data collected from four more states such as New Jersey, Michigan, New Mexico, and Louisiana. The tasks for the verification included the accuracy of the transforms between the objective pavement roughness measures and the subjective panel ratings; the effects of surface type, road class, panel regionality, and vehicle size on panel ratings; and the evaluation of using one wheelpath-based pavement roughness. Also, the study conducted a review of a frequency band of profiles highly correlated with MPR. The data analysis for the verification tasks considered a total of 282 pavement sections of all three surface types (e.g., BC, PCC, and COMP) in the five states (see ), and the range of rideability on these sections was from 0.4 to 4.5 . The collection of panel ratings engaged 36 drivers in addition to 12 drivers to test the effect of the vehicle size. The main vehicles used were K-cars, but a small-size vehicle (Chevrolet 
Cavaliers) in Michigan and a full-size vehicle (Ford LTD) in New Jersey were also used for the vehicle size experiment. The instruments used to measure profiles were the Minnesota profilometer for Michigan and the PSU profilometer for all other three states. The Minnesota profilometer is exactly the same as the Ohio profilometer. In addition, Michigan computed $1 \frac{1}{4}$ indexes (simulated MRM), and MRM measurements were added to New Jersey and Louisiana.

Table 2-2. Test Sections in Each State (Janoff, 1998)

\begin{tabular}{|c|c|c|c|c|}
\hline \multirow{2}{*}{ State } & \multicolumn{4}{|c|}{ Test Sections } \\
\cline { 2 - 5 } & BC & PCC & COMP & Total \\
\hline New Jersey & 18 & 18 & 10 & 46 \\
\hline Michigan & 21 & 27 & 20 & 68 \\
\hline New Mexico & 41 & 10 & 13 & 64 \\
\hline Louisiana & 14 & 24 & 14 & 52 \\
\hline Ohio & 17 & 18 & 17 & 52 \\
\hline
\end{tabular}

The findings discussed in the NCHRP report, but limited to the ones related to this thesis, are summarized as follows:

- A linear regression equation to relate the PSU profilometer to the $\mathrm{OHIO}$ was derived through the data analysis of 12 test sections in Ohio:

$$
O H I O=0.817 P S U, r=0.94
$$

Equation 2.3 was used to adjust the profile data measured using the PSU profilometer in the states of New Jersey, New Mexico, and Louisiana.

- The profiles measured in the frequency band between $0.125-0.630 \mathrm{c} / \mathrm{ft}$ for all three surface types showed the best correlation with MPR. Thus, the profile data in this band were used to develop the regression equations relating PI to MPR.

- The linear and non-linear regression equations in the forms of

$$
M P R=a+b \log (P I) \text { and } M P R=5 e^{c P I^{d}}
$$


where the regression analyses determined $a, b, c$, and $d$ were developed for each state and all five states combined. The purpose of the non-linear regression equations was to represent the MPRs in very rough correctly (MPR $<0.5)$ or very smooth $(M P R>4.5)$. The correlation coefficients of the regression equations for all surfaced combined were above -0.90 . The preferred linear and non-linear equations to estimate subjective panel ratings are:

$$
\begin{gathered}
R N=-1.47-2.85 \log (P I) \\
R N=5 e^{-11.72 P I^{0.89}}
\end{gathered}
$$

The correlation coefficient of Equation 2.5 is -0.93 .

- The MPR data were also correlated with the $1 / 4$ indexes and MRM values. In general, the correlation coefficients for BC surfaces were the highest, followed by COMP and PCC surfaces at all states tested. However, the use of MRM for estimating panel ratings on BC surfaces only was preferred as the accuracy of the transforms for other surface types was very low.

- $\quad$ There were no effects of the variables such as surface type, road class, or vehicle size on panel ratings, while the effect of regionality was very marginal, which was the same as the findings in the NCHRP Report 275. Also, profiles measured from one wheelpath generated PI as accurately as PI from two wheelpaths.

\subsection{Review of Al-Omari and Darter}

A pavement is any hard surface covered by concrete or asphalt. The serviceability of pavements consists of the most critical signs that signal the secure and fluid movement of different means of transportation. When putting into consideration the Pavement Management System, pavement serviceability is expressed by the direct values of the changeable factors. These factors keep changing in a continuous way depending on the prevailing traffic load and the climatic conditions of the road. Variations in coarseness and roughness can be obtained in various forms. This literature review seeks to explore the various effects 
of pavement deterioration types on international roughness index and rehabilitation and further explore the relationships that exist between international roughness index and present serviceability rating. It establishes the related pavement indicators and the equations used in measuring them.

Multiple relationships between the present serviceability rating and the international roughness index exist when considering composite, rigid, and flexible pavement types. According to Al-Omari and Darter (1994), present serviceability rating is generally used to refer to the mean user panel rideability rating and is conventionally put on a scale that ranges from 0 to 5 , where zero is rated as very poor while five is put on a scale of very good. Al-Omari and Darter (1994) further agree that the international roughness index is the most widely accepted measuring index for the roughness of all paved rural major roads and freeways in urban settings, including arterial highways and interstates, and have been used since the year 1989. Present serviceability rating is determined by various methods, which include correlating the type of measurement for roughness achieved by using equipment made available by the state, which has to mean user readability. Al-Omari and Darter (1994) provide that this correlation is then used to get an estimation of the present serviceability rating as shown by the measurement of the roughness index on sections that contain pavements. According to Al-Omari and Darter (1994), another alternative to measuring the present serviceability rating is by using the state's visual rating scheme, which can be between 0 and 100, and then the ratings are divided by 20 to get an estimated value that will be in a range of zero to five. In addition, there has been a correlation that has been found to be to exist between the longitudinal profiles lope variance and the present serviceability rating. For asphalt concrete pavements,

$$
\begin{gathered}
P S R=5.03-1.91 \log (1+S V)-1.38 R D^{2}-0.01 \sqrt{C+P} \\
R 2=0.84, S E E=0.38, n=74
\end{gathered}
$$


In Equation 2.7, the slope variance was considered to be the most important factor in the equations. Although the equation has been used for a long, recent research suggests that a non-linear relationship between PSR and IRI that can fit in various situations and different sets of data is

$$
P S R=5 * e^{-0.18 * I R I}
$$

where IRI is in meters per kilometer.

In their study, Al-Omari and Darter (1994) noted that other studies showed that the total profile index that was found to be in band frequencies that ranged from 0.125 up to 0.630 cycles per feet was found to correlate with MPR, where the profile index was referred to the root mean square for the elevation. AlOmari and Darter (1994) further observed that when data from different states were put into a statistical analysis, results showed that the statistics could be compared favorably with prior statistics that were recorded from other studies, which can conclude that mean panel rating of rideability can reasonably be predicted from IRI in a wide range of conditions in the United States.

Earlier studies have sought to evaluate the relationship between the present serviceability rating and the international roughness index together with some selected types of pavement distress. For instance, AlOmari and Darter (1995) developed different predictive models that made it possible for them to assert that there are distress levels that have a much stronger effect on the international roughness index than others. In addition, Al-Omari and Darter (1995) observed that the severity of the different distress levels exhibited is of great importance because, with an increase in the distress levels, the IRI equally increases. When developing the relationship between the international roughness index and present serviceability rating, Al-Omari and Darter developed a model that was predictive for current serviceability rating as a function of international roughness index that could be applied to different types of surfaces, including 
rigid, composite and pavements. The data found gave a nonlinear model that fit the prevailing boundary conditions and the data. The equation obtained was formulated as,

$$
P S R=5 * e^{-0.0041 * I R I}
$$

Where IRI is in inches per mile.

In addition, Al-Omari and Darter (1995) further considered the correlation of the international roughness index and the distress in different types of surfaces. When measuring the effect of asphalt surfaces distress on the international roughness index and the present serviceability rating, Al-Omari and Darter derived the equation

$$
I R I=136.19 * S D-116.36
$$

where IRI is in centimeters per kilometer,

based on this formula, a correlation was found to average the rut depth and the rut depth standard deviation where R2 of 0.80 was observed. A correlation-based on manufactured profile analysis gave a value of present serviceability rating value of $4.54(\mathrm{IRI}=37.5 \mathrm{~cm} / \mathrm{km})($ Al-Omari and Darter, 1995). When examining transverse cracking, it was established that the IRI value increased linearly with the number of cracks. The correlation of IRI and distress in concrete pavements was established. Precisely, Al-Omari and Darter established $\mathrm{R} 2=0.5$ as a linear function based on this function,

$$
I R I=147+27.95 * F
$$

In addition, there is a criterion that is followed when selecting critical levels of the international roughness index for the purposes of rehabilitation. It is further asserted that with lower rigorousness levels and an assortment of other distresses, the longitudinal profile has a probability of not being affected greatly unless a considerably huge amount of pavement deterioration occurs. From this review, it is evidently observed that the mean rating of panel rideability can easily be predicted in a reasonable way and in a 
wide range of conditions based on the international roughness index. The serviceability rating currently used to refer to the mean user panel rideability rating is normally put on a scale that ranges from 0 to 5 , where zero is rated as very poor, while five is put on a scale of very good. Furthermore, the relationship between the international roughness index on the different types of surfaces such as concrete, asphalt, and concrete was found to be affected by different conditions such as potholes and traverse cracks. It was further found that different types of distress affect the international roughness index in different ways.

\subsection{Pavement Roughness Measurement Methods}

Judging the quality of the road depends on its roughness or the ride quality. Therefore, pavement roughness is a major concern of many pavement engineers and road users. This section describes the different methods used to measure pavement roughness.

\subsubsection{BPR Roughometers}

The Bureau of Public Roads pavement measurement instrument needs no introduction because it is a popular device in this profession. Roughometers are used in several states in the US, including South Dakota, Tennessee, Indiana, and Minnesota. Some advanced Roughometers have electronic and mechanical devices to record measurements (Yoder and Milhous, 1965). Other Roughometers, such as the one owned by Michigan State Highway Department, are modified to include accelerometers on the frame. 


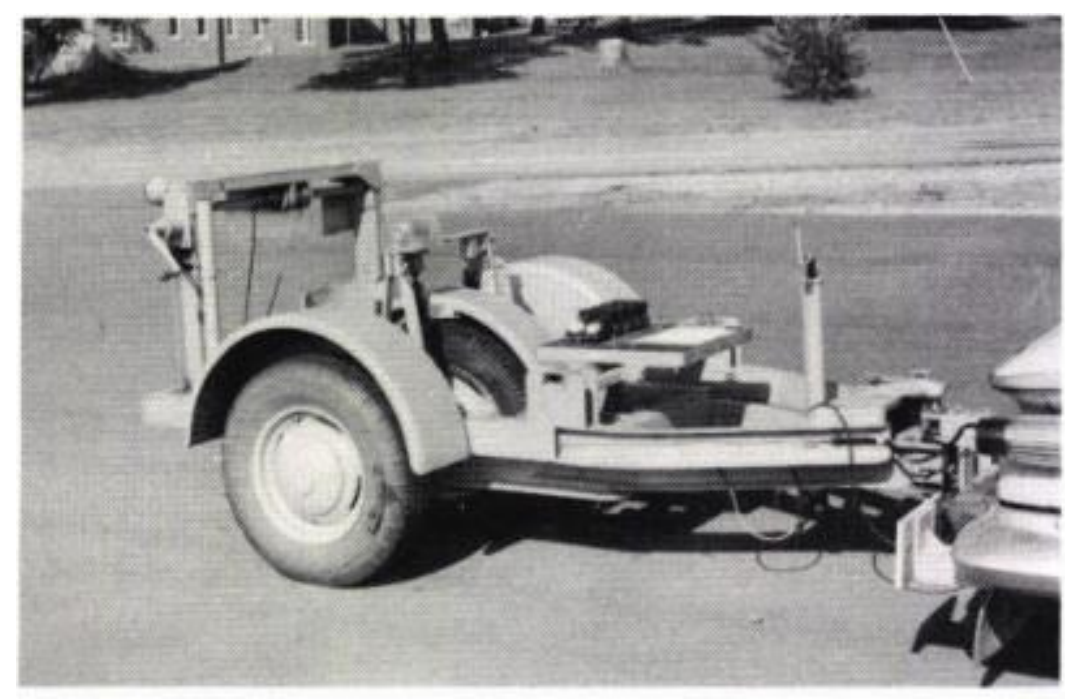

Figure 2-2: BPR Roughometer (Yoder and Milhous, 1965)

\subsubsection{AASHO Slope Profilometer}

This pavement measurement instrument is attached with two small wheels used to measure the slope variance as given in the equation below:

$$
S V=\frac{\sum Y^{2}-\frac{1}{n}\left(\sum Y\right)^{2}}{n-1}
$$

where $\mathrm{Y}$ is the difference between two elevations 1 foot apart, and $\mathrm{n}$ is the number of elevation readings,

The instrument was mainly used by individuals working for the Bureau of Public Roads. The road test profilometer that contains a horizontal reference was mainly applied to test bulk roughness. However, one shortcoming about this instrument is that the device's output varies from the truth when it is operated over an undulating pavement of different frequencies. Nonetheless, the chances of error are significantly low, thus might not affect the readings (Carey et al., 1962). This instrument was used throughout the AASHO test period, but many complained about its slow speed. Additionally, the 
maintenance costs were quite high; as such, although it was useful for the road tests in special-purpose research for highway projects, it could not be applied to routine evaluation of pavements.

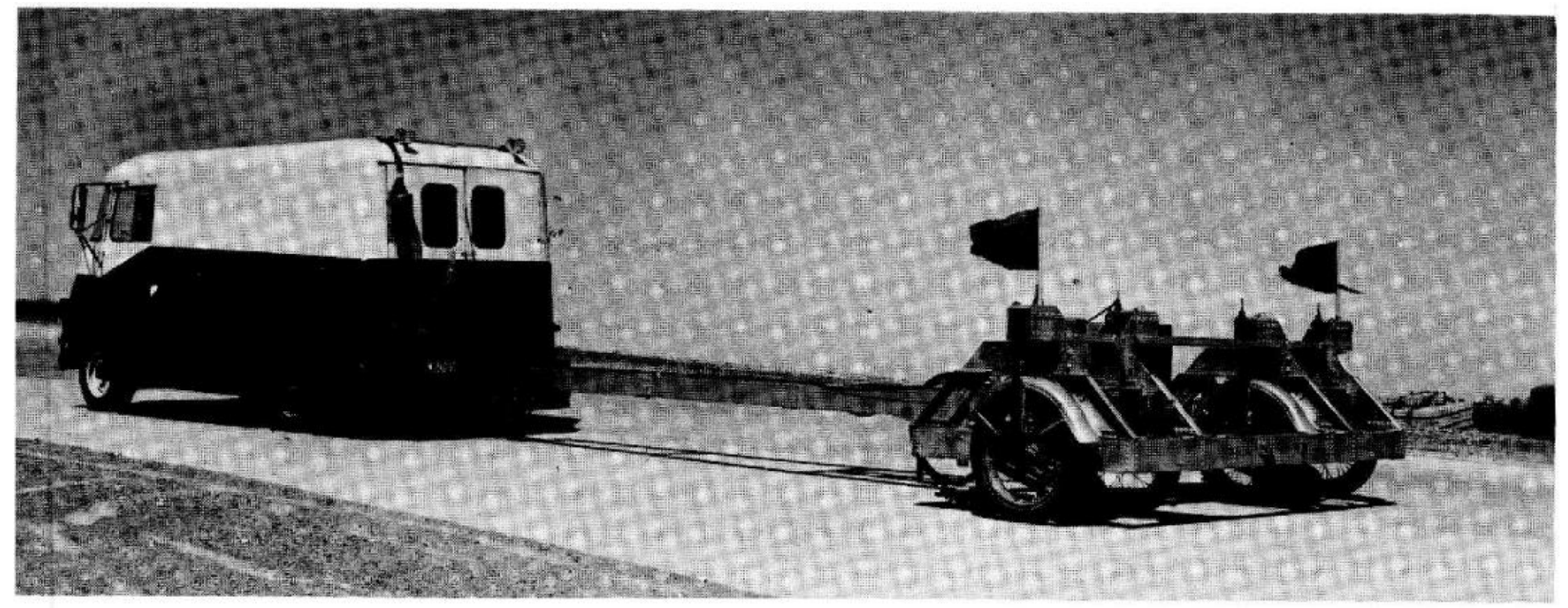

Figure 2-3: AASHO Road Test Profilometer (Carey et al., 1962)

\subsubsection{CHLOE Profilometer}

The CHLOE Profilometer was modified from the AASHO Slope Profilometer. This pavement measurement instrument digitizes slope variance at 6-inch intervals electronically along the surface of a pavement. The instrument is attached with slope wheels, which are needed to rerun the profilometer over the pavement and alternate between the right and left wheel paths as the observer travels along a pavement. In a study conducted by Potter et al. (1987), the CHLOE profilometer was alternated between the inner and outer paths, and the slope variance obtained was an average of both wheel paths. This differs from the Roughometers, which were towed over pavement, and in the outer wheel path. Additionally, this instrument belonged to the Bureau of Public Roads, but it was used by personnel from Texas Highway Department. Figure 2-4 below illustrates a CHLOE Profilometer. 


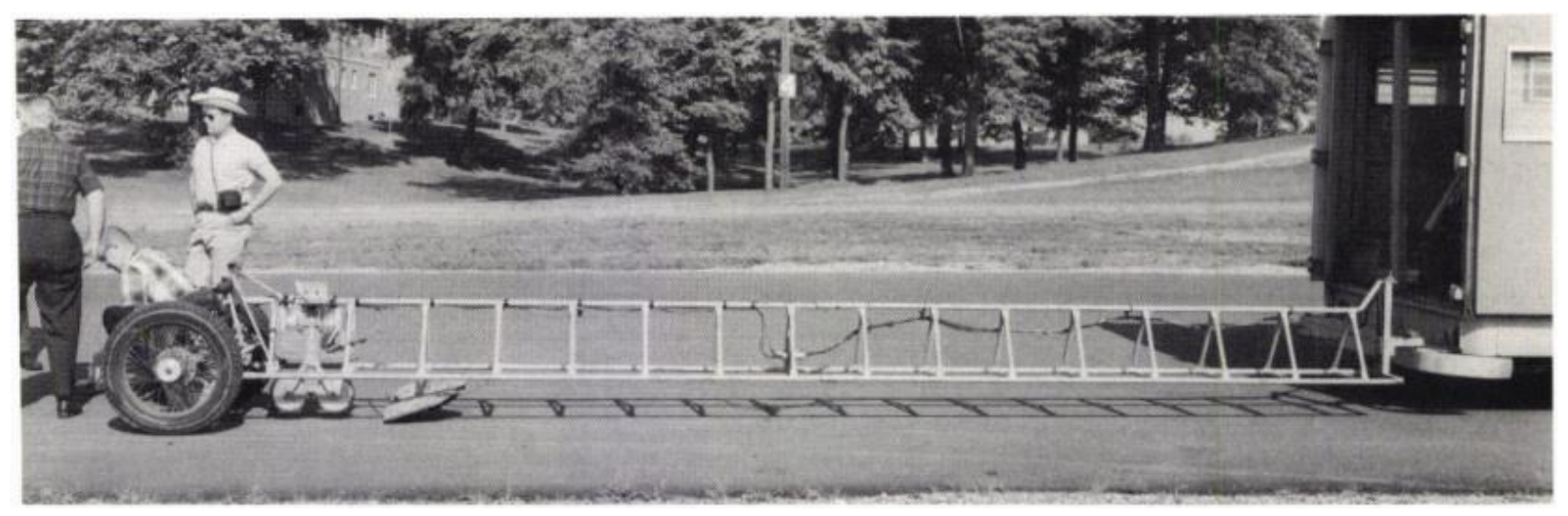

Figure 2-4: CHLOE Profilometer (Potter et al., 1987)

The observes using AASHO testing equipment found that it is too expensive to measure the variation in long-distance pavements. Consequently, they opted for simpler and less expensive equipment known as the CHLOE Profilometer. This instrument was named after engineers who designed it, namely Carey, Huckins, Leathers, and other engineers. The lowa state road agency first purchased it in 1964 (Potter et al., 1987). The test data collected by this instrument is more reliable than the previous AASHO instrument. Additionally, since it operates at a speed of $5 \mathrm{mph}$, it is the best calibration device compared to an inventory tool. Nonetheless, one major disadvantage about this instrument is that it is prone to electrical and mechanical breakdowns, especially since it has been operated on for more than two decades.

\subsubsection{Texas Texture Meter}

This instrument was developed by Hudson and Scrivner and was used to collect measurements in each test pavement. The instrument uses a series of prongs to measure the microrelief of pavement and give out the indentations and surface roughness (Scullion et al., 1997). Engineers from Texas discovered the CHLOE Profilometer might have some errors as regards slope variance, especially when considering roughtextured surface treatments. Figure 2-5 below illustrates the Texas Rough Texture instrument. 


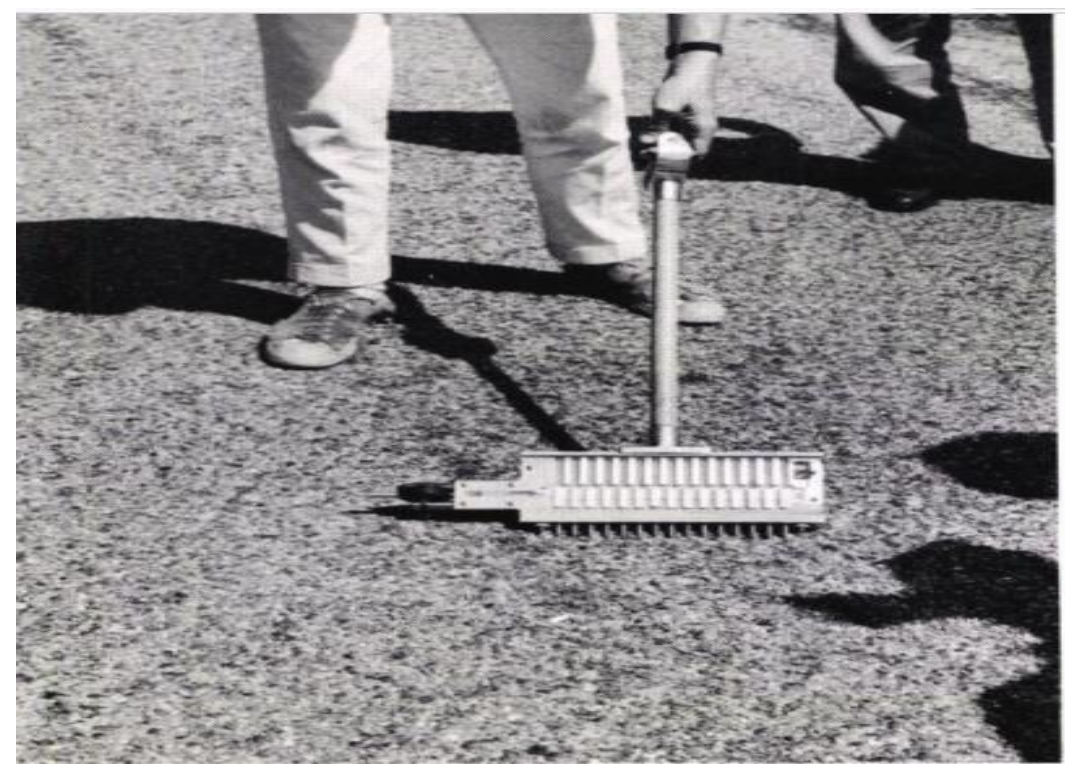

Figure 2-5: Texas Rough Texture instrument (Yoder and Milhous, 1965)

Observes used this instrument to measure roughness level on a pavement, and it is combined by the International Roughness Index (IRI) (Zuniga et al., 2016). This indicator is used to summarize the longitudinal surface profile on the traveled path, which entails the standardized roughness measurement. Observers combine the readings of the Texas Texture calculation instrument and the IRI equation to determine the quality and serviceability of a pavement.

\subsubsection{Kentucky Accelerometers}

Engineers from Kentucky designed a pavement measurement instrument used to collect roughness estimates upon the acceleration experienced by a passenger in their vehicle. The engineers first had to determine the number that would be used to describe the characteristics of a pavement surface. They performed a double integration and used it to obtain a passenger's displacement. They also devised another approach which included measuring the total acceleration arbitrarily (Yoder and Milhous, 1965). This was the method adopted by the engineer, and they stated that the toughness index is acquired by 
measuring the average acceleration in the vertical direction. The observes used this instrument to conduct several tests, and they drove the test vehicle over the pavements at three different speeds.

\subsubsection{University of Michigan profilometer}

The University of Michigan developed a profilometer mounted on a truck to assess pavement profiles. The truck is attached with equipment that traces and records each wheel's profile on the pavement. Two sets of bogey wheels are fitted at the front of the truck and sue to measure vertical displacement by recording each wheel midway between them. The observers collect pavement recordings on a continuous chart, which enables them to collect a detailed profile of the wheel paths. The roughness index, in this case, is estimated as the cumulative vertical displacement in each mile. Figure 2-6 below illustrates the Michigan Profilometer.

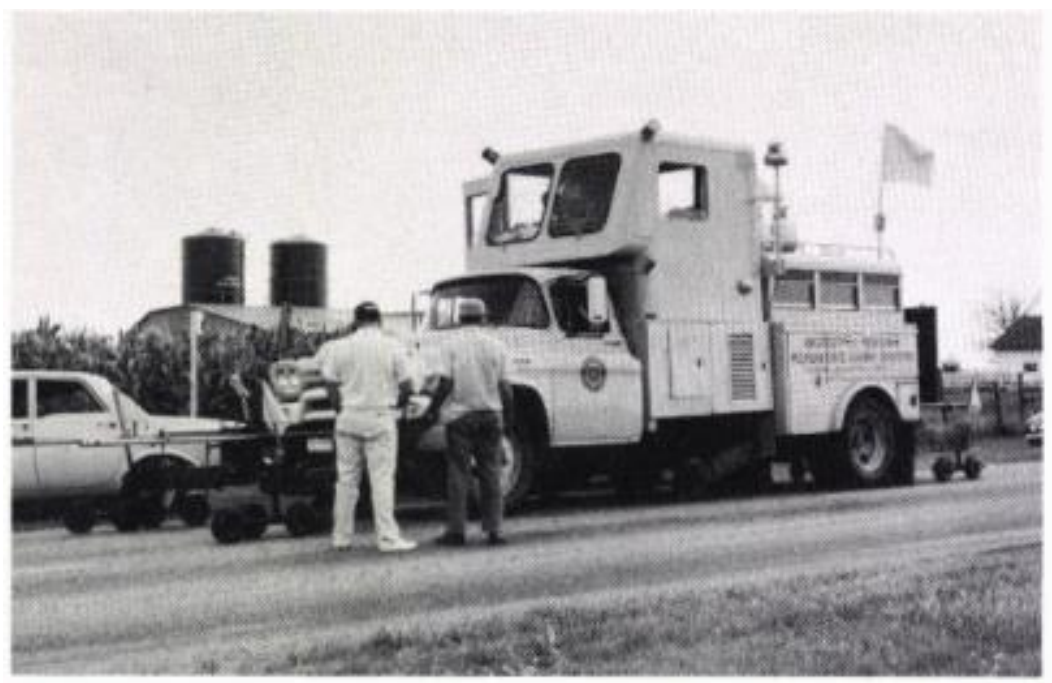

Figure 2-6: Michigan Profilometer (Yoder and Milhous, 1965) 


\subsubsection{General Motors Device}

Observers use this instrument to determine the pavement profile by observing a wheel on an inertial platform. The instrument has accelerometers mounted to indicate the movement of the platform relative to the surface of the pavement. The platform on which the accelerometer is mounted maintains a relatively fixed position through a hydraulic actuator and an electrohydraulic valve. The pavement profile is then placed on a magnetic tape, and readings are collected by plotting the road amplitude as a distance function along the pavement. Figure 2-7 below illustrates the General Motors Pavement measurement device.

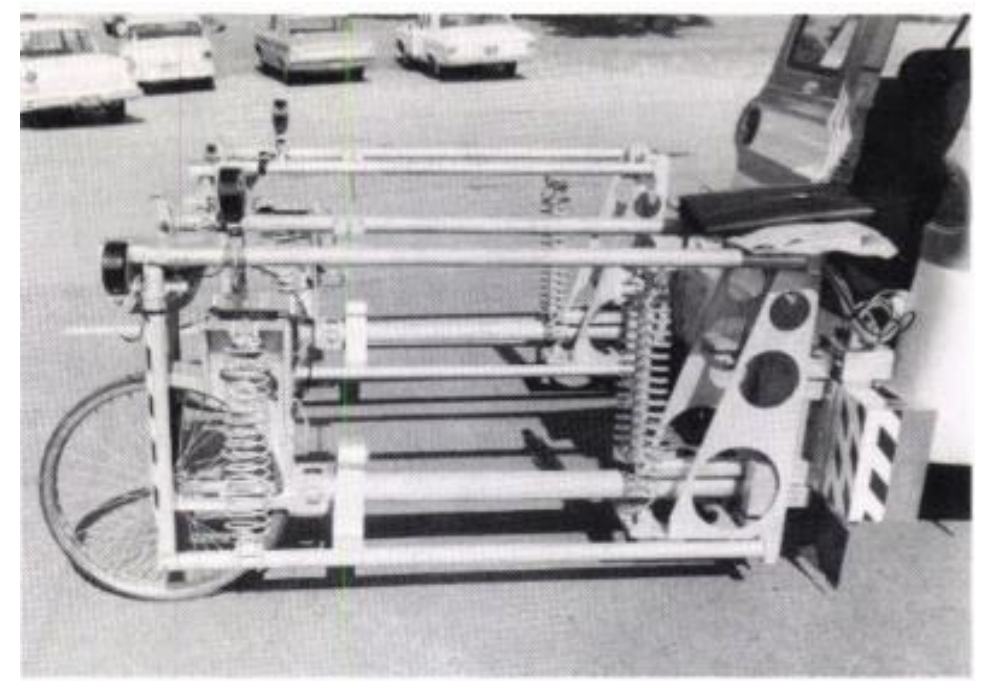

Figure 2-7: General Motors Pavement measurement device (Yoder and Milhous, 1965)

The techniques used to measure roughness can be categorized into four broad classes, as revealed in Table 2-3 below.

Table 2-3: Techniques Used to measure roughness

\begin{tabular}{|c|c|}
\hline Equipment/Technique & Complexity \\
\hline $\begin{array}{c}\text { Road and Level Survey } \\
\text { Dipstick Profiler }\end{array}$ & Simplest \\
\hline Profilographs & Simple \\
\hline Response Type Road Roughness Meters (RTRRMs) & Simple \\
\hline Profiling Devices & Complex \\
\hline
\end{tabular}


The discussions below with few modifications were acquired from the Pavement Condition Data Collection Equipment. These techniques are discussed below:

\section{a) Dipstick Profiler}

This technique is used to collect small quantities of measurements to calculate roughness and pavement quality. The approach consists of an inclinometer that is enclosed in a case supported by two legs. Two monitors are attached, one at each end of the surface. Each monitor measures the elevation of the legs relative to the elevation of the other leg (Ferreira et al., 2011). The observers using this technique or instrument walk it down a pavement alternately, pivoting the instrument on each side. The observers then take readings in a sequential manner as they go through each pre-marked section. The device is used to collect about 15 minutes per mile, and the software analysis provides an accurate reading up to +/$0.127 \mathrm{~mm}$. A single operation can survey a strip in about half the time that traditional equipment can.

\section{b) Profilographs}

Profilographs have been used for several decades, and they have existed in different forms and configurations. However, observers cannot use this instrument in network condition surveys but can only be used to collect pavement readings, quality control and acceptance. There are different types of Profilographs, and the main difference between these types entails the procedures used to assess pavement rigidity and the wheel configuration (Hosseini et al., 2021). Most observers use Profilographs with a sensing wheel, which enables them to move vertically. The motion of the sensing wheel and the deviation measurement is recorded against the Profilograph's frame. This instrument is effective as it enables to collect slight pavement deviations of about 20 feet in length. Figure 2-8 below illustrates a profilograph. 


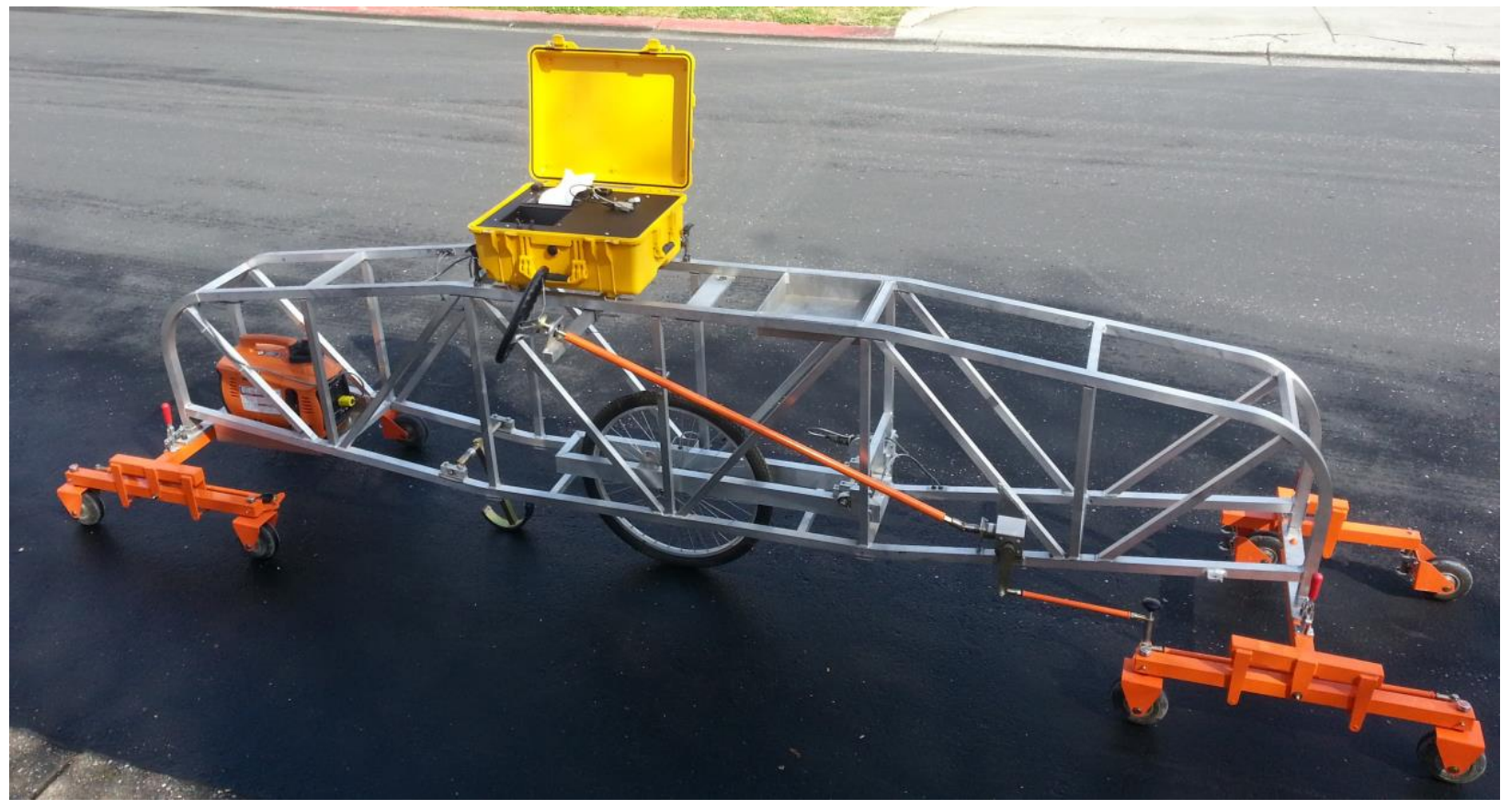

Figure 2-8: Profilograph (Hosseini et al., 2021)

c) Response Type road Roughness Meters (RTRRMs)

Pavement roughness is measured using multiple techniques, whereby RTRRMs is one of the main methods. This instrument is often referred to as a road meter, and it is used to monitor pavement networks to provide a general picture of the condition of a network (Gupta et al., 2014). The measurements enable managers to get a general indication of a network's overall condition and maintenance needs. Road Meters measure the vertical movement of the axle of a trailer relative to the frame of a vehicle. Attachment of meters on the passenger car and the middle of the vehicle enables observers to detect small changes in axle motion, in reference to the body of a vehicle. Nonetheless, critics such as Abed has argued against this instrument because they argue that roughness measures have not been stable and have not been transported. The critics argue that the measures taken today cannot be compared with those taken a few years ago. Additionally, the measures collected by one instrument 
cannot be compared with measures taken by a different road meter. Consequently, observes today prefer profiling devices to road meters.

\section{d) Profiling Devices}

Observers apply the profiling devices to obtain accurate measurements of pavements. Observers use devices of different forms, and the calibrations used are in meters. There are three main profiling systems used today: straight edge, low-speed systems, and inertial reference systems. The straight edge system is mounted on a wheel, and it creates a profilograph (Wang et al., 2017). CHLOE are examples of the slowspeed instruments towed at about $8 \mathrm{kph}$. This equipment is used by observes to prevent dynamic response measurement as an observer takes different pavement measurements. Some agencies use this equipment for calibration on a road meter. Lastly, the Inertial reference system is the most sophisticated of the three (Litzka et al., 2008). This instrument measures and computes longitudinal profiles by creating an inertial reference. The instrument uses accelerometers mounted on the body of a measuring vehicle and depends on the motion to take readings. A contact sensor is used to assess the measurements between an accelerometer and a pavement profile. As such, the profiling devices are mounted on equipment used to measure pavement roughness, but they vary in effectiveness and size.

The pavement's profile is measured using the profiling devices, whereby the readings are directly collected using contact systems. Most agencies in the United States use vans attached with non-contact sensors, with microcomputers to collect and process the data collected (Wadalkar et al., 2018). The initial profiling devices mainly used contact systems, but observers today use more advanced devices to collect and process data. The non-contact systems use light to assess the difference in pavement surfaces (Khattak et al., 2009). For example, the road observers in South Dakota collect data using the non-contact sensors attached to the center and wheel path. The data collected is then used to estimate the pavement 
roughness and rutting specified in intervals. A more advanced or hybrid South Dakota observer combines three ultrasonic sensors with two laser sensors. Table 2-4 below illustrates a summary of the measurement devices used to estimate pavement roughness.

Table 2-4: Summary of measurement devices used. (Khattak et al., 2009)

\begin{tabular}{|c|c|c|c|c|c|c|c|}
\hline $\begin{array}{l}\text { Roughness } \\
\text { Data } \\
\text { Collection } \\
\text { Device }\end{array}$ & $\begin{array}{c}\text { Principle of } \\
\text { Measurement }\end{array}$ & $\begin{array}{c}\text { Relative } \\
\text { Initial } \\
\text { Cost }\end{array}$ & $\begin{array}{l}\text { Relative } \\
\text { Data } \\
\text { Collection } \\
\text { Cost } \\
\text { (Network) }\end{array}$ & $\begin{array}{l}\text { Relative } \\
\text { Degree } \\
\text { of } \\
\text { Accuracy }\end{array}$ & $\begin{array}{l}\text { Approximate } \\
\text { Decade of } \\
\text { Development }\end{array}$ & $\begin{array}{l}\text { Extent of } \\
\text { Current } \\
\text { Use }\end{array}$ & $\begin{array}{l}\text { Projected } \\
\text { Extent of } \\
\text { Use }\end{array}$ \\
\hline Dipstick & $\begin{array}{c}\text { Direct } \\
\text { Differential } \\
\text { Measurement }\end{array}$ & Low & Impractical & $\begin{array}{l}\text { Very } \\
\text { High }\end{array}$ & $1980 \mathrm{~s}$ & $\begin{array}{l}\text { Limited, } \\
\text { Used for } \\
\text { Calibration }\end{array}$ & $\begin{array}{c}\text { Same as } \\
\text { Current } \\
\text { Use }\end{array}$ \\
\hline Profilographs & $\begin{array}{l}\text { Direct Profile } \\
\text { Recordation }\end{array}$ & Low & Impractical & Medium & $1960 \mathrm{~s}$ & $\begin{array}{l}\text { Extensive } \\
\text { for } \\
\text { Constant } \\
\text { Acceptance }\end{array}$ & $\begin{array}{l}\text { Same as } \\
\text { Current } \\
\text { Use }\end{array}$ \\
\hline $\begin{array}{c}\text { BPR } \\
\text { Roughometer } \\
\end{array}$ & $\begin{array}{c}\text { Device } \\
\text { Response }\end{array}$ & Low & Low & Medium & $1940 \mathrm{~s}$ & Limited & None \\
\hline Mays Meter & $\begin{array}{c}\text { Vehicle } \\
\text { Response }\end{array}$ & Low & Low & Medium & $1960 \mathrm{~s}$ & Extensive & $\begin{array}{l}\text { Decreasing } \\
\text { Continously }\end{array}$ \\
\hline $\begin{array}{l}\text { South Dakota } \\
\text { Road Profiler }\end{array}$ & $\begin{array}{l}\text { Direct Profile } \\
\text { Recordation }\end{array}$ & Medium & Low & High & $1980 \mathrm{~s}$ & Growing & $\begin{array}{c}\text { Rapidly } \\
\text { Increasing }\end{array}$ \\
\hline $\begin{array}{l}\text { Contact } \\
\text { Profiling } \\
\text { Device }\end{array}$ & $\begin{array}{l}\text { Direct Profile } \\
\text { Recordation }\end{array}$ & High & Medium & $\begin{array}{l}\text { Very } \\
\text { High }\end{array}$ & 1970s & Limited & Decreasing \\
\hline $\begin{array}{l}\text { Non-Contact } \\
\text { Lasers }\end{array}$ & $\begin{array}{l}\text { Direct Profile } \\
\text { Recordation }\end{array}$ & High & Medium & $\begin{array}{l}\text { Very } \\
\text { High }\end{array}$ & 1980s & Medium & Increasing \\
\hline
\end{tabular}

\subsubsection{Multiple Roles of Pavement Performance Indicators}

The terms performance measurement and management are used in similar contexts to mean the same thing. Nonetheless, performance management covers a larger scope, as it includes performance measurement, determination of the appropriate performance level, the performance information, and the relevant information obtained to evaluate the actual level of performance against the desired level (Perez et al., 2019). Some of the pavement performance indicators, including IRI, RCI, PCl, and DMI, are 
vital to assess the current or future pavement conditions. Additionally, they affect the economic analyses of long-term maintenance and rehabilitation treatments. Some indicators enable road agencies to acquire information on the pavement structural condition evaluation. Other indicators enable agencies to understand pavement functionality in regard to the quality of service and road safety. According to Ningyuan, performance indicators are used as the standards to assess the extent to which the above objectives are attained regarding the construction of pavements. When applied in pavement management, these indicators are used to assess the economic and technical aspects. Therefore, performance indicators use relevant information to evaluate the quality, safety, and maintenance needs of pavements.

Performance assessment is mostly done in different activities, including health, engineering, and economics. According to Karlaftis et al. (2012), performance may be described as the measure of successful attainment of a goal in an operation, system, or task function. Consequently, it helps one to assess and initiate improvements to the characteristics and operations of a given infrastructure or a process. Karlaftis et al. (2012) provided a comprehensive definition of performance measurement in the context of pavement quality, stating that it entails assessing whether the predetermined goals have been attained. These predetermined goals include quality, reliability, and client satisfaction. In the road sector, performance is measured from different perspectives and for different reasons. One of the main reasons is to evaluate the current and future conditions of pavement and other parameters such as road quality, safety, productivity, and cost-effectiveness, among others. The construction of roads involves different stakeholders, often with varying goals (Karlaftis et al., 2012). This challenge creates the need to understand different dimensions of performance in the area of road construction. Figure 2-9 below illustrates the varying perspectives. 


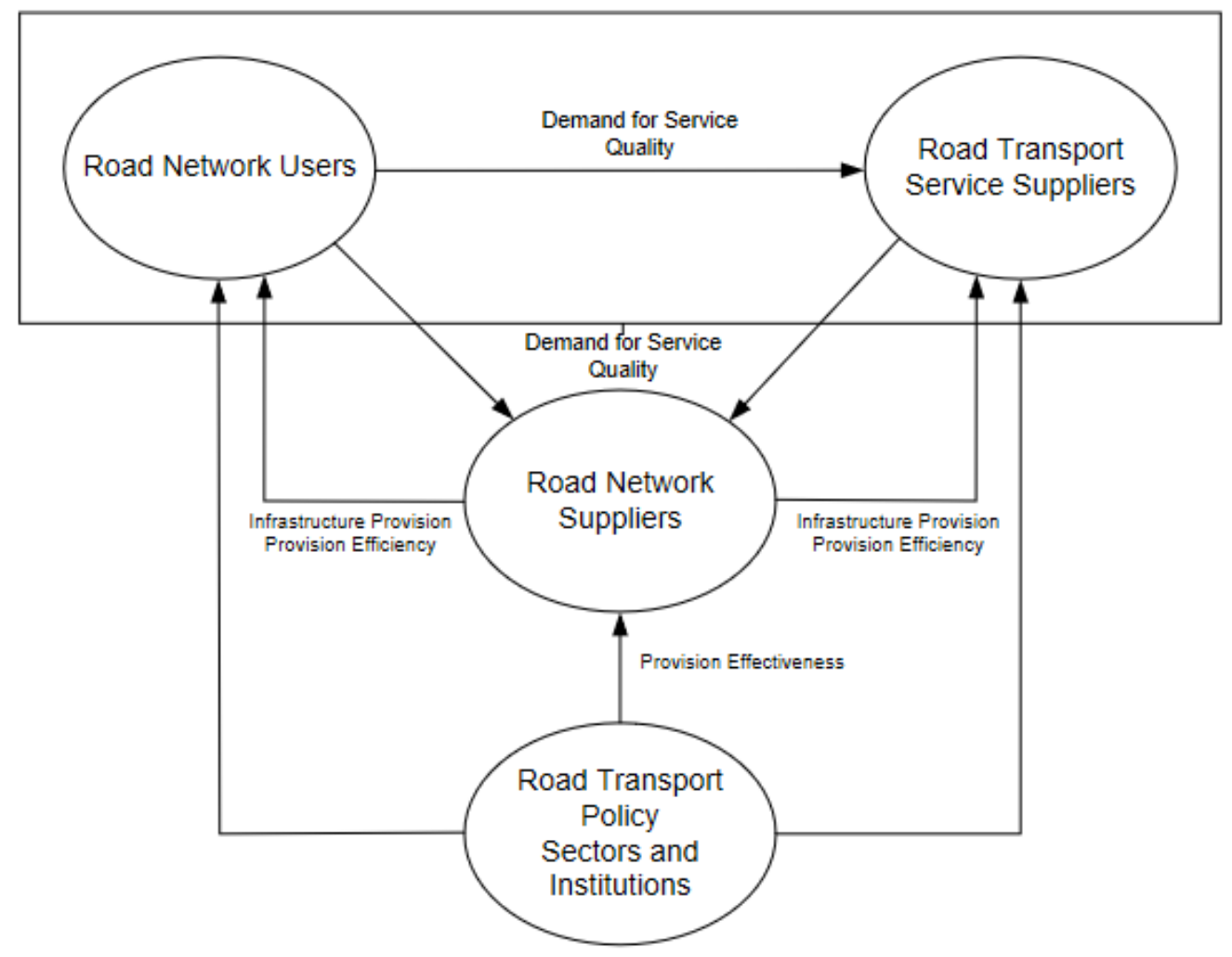

Figure 2-9: Perspectives (Karlaftis et al., 2012)

Service providers include the road users, who demand high-quality services that encompass comfort, safety, affordable usage, adequate environment for the drivers. The suppliers seek to offer customer satisfaction and attain high productivity and effectiveness. The policymakers are mainly interested in allocating the best resources to road networks and complying with road network-related rules. The suppliers of road networks play a vital role in measuring the performance and exploiting relevant findings. As put forward by Karlaftis et al. (2012), performance measures mainly involve three questions that need to be answered by the administrators. These questions include:

- $\quad$ Are the road administrators doing things right? (efficiency)

- Are the road administrators doing the right things? (effectiveness)

- What external factors affect the road sector? 


\subsection{Existing PSI Equations for PSR}

The PSI equations to estimate PSR are estimated using data from the IRI measurements in different studies. Pavement quality and the relationships between PSI, PSR, and IRI are discussed in this section to give a better understanding of how previous equations were generated.

\subsubsection{Pavement Quality}

The pavement quality index, also known as the pavement condition index, is developed and applied using existing procedures. According to Reza et al. (2005), the Ohio department of transportation uses a measure of pavement distress, namely the Pavement Condition Rating (PCR), to regularly check pavement conditions. Although the roughness and friction measurements are taken, they are independent considerations, and they are not used as pavement measures. The recent discourse regarding roughness on pavements has continued to gain traction because of its importance in pavement serviceability decisions. One disadvantage of the PCR performance indicator is that it does not correlate with user satisfaction (Sarwar et al., 2016). For instance, a distressed pavement with a low PCR will not provide the required quality. In this case, the challenges are reduced because the rehabilitation of the same to address the PCR also improves ride quality. The other issue is also more problematic (Rahman et al., 2017). Under the current operating procedures of many transportation and road departments, including the Ohio department, there are no provisions to identify the pavement that needs rehabilitation. As such, road users would continue feeling dissatisfied with the road quality and safety. This challenged prompted the department to introduce the Pavement Quality Index, which uses PCR to assess distress characterization and International Roughness Index. The implementation of this performance indicator would not require the purchase of any new equipment (Piryonesi et al., 2021). Other indicators used to measure roughness include IFI and FN; the latter uses the speed constant of $60 \mathrm{kph}$. This measure is mainly calculated using the locked-wheel test. Users should understand the level of friction on pavement to ensure their cars are 
well maintained and also to safely drive their cars in lateral and longitudinal directions. As such, the application of the PCR method alone would leave users dissatisfied because it fails to deal with roughness, which is a vital part of pavement measures.

\subsubsection{Linear PCR with IRI Function}

The equation applied in this case is based on the IRI concept as a deduction from the PCR indicator. The equation is shown below.

$$
P Q I=-P C R a(I R I)^{b}
$$

where $a=0.0000371642597$ and $b=2.49128114$,

To apply in all priority systems, the threshold for failure was set at a PCl of 65 . The stakeholders involved in this exercise wanted a flat curve until IRI exceeds $60 \mathrm{in} / \mathrm{mi}$, which meant that one of the points on the curve of $\mathrm{PCl}$ of 65 should be (PCR=66, IRI=60). One should note that the PCR that corresponded to the IRI had to be slightly higher than 65 to ensure that the function had a maximum at a point (Reza et al., 2005). The maximum allowable IRI was applied because it can be used in new pavements using effective models. Consequently, an additional curve point of PQI-65 entails an IRI of 250 and a PCR of 100 . The IRI of 250in/mi was accepted as the threshold for ride quality, which means that pavements with a PCR value of 100 would drop their PQI to 65 if its IRI reached $250 \mathrm{in} / \mathrm{mi}$. Nonetheless, it is impossible for a pavement with such quality would exist, but this does not mean that construction companies should create new pavements with such a level of IRI because any smoothness specification is expected to hold new construction to a much higher standard, such as $95 \mathrm{in} / \mathrm{mi}$. 
The graph representing $P Q I=65$ is shown in Figure $2-10$ below, which also contains $P Q I=75$ and 90 . The values, in this case, were selected because they represent vital points for maintenance and overlay actions (Tsai et al., 2020). From Figure 2-10 shown below, one can observe that the curve representing the PQI is flat, up until the IRI curve reaches $60 \mathrm{in} / \mathrm{mi}$. After this point, the curve reaches to a non-linear point. To develop an equation that represents IRI $60 \mathrm{in} / \mathrm{mi}$, one would need a mathematically intractable formula.

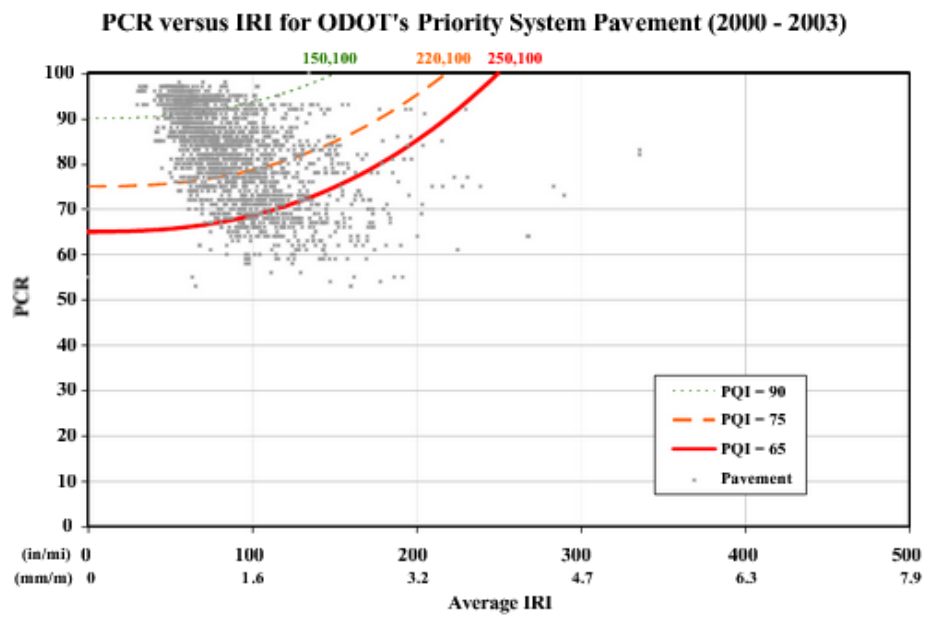

Figure 2-10: PCR vs. IRI (Reza et al., 2005)

\subsubsection{Pavement Serviceability Rating}

The Pavement Serviceability (PSR) refers to the judgment made by an observer revealing the current ability of pavement to serve the targeted traffic (Chu et al., 2008). Observers did several road tests and rated the quality of their ride using the equations below to generate Road Test PSR scores.

For Rigid pavements:

$$
p=5.41-1.78 \log (1+S V)-0.09 \sqrt{C+P}
$$

For Flexible pavements:

$$
p=5.03-1.91 \log (1+S V)-0.01 \sqrt{C+P}-1.38(R D)^{2}
$$

where 
- $\quad$ SV=Slope Variance

- $\quad$ C=Major Cracking, in ft per 1000 sq ft of area

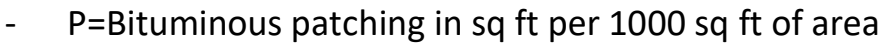

- $\quad \mathrm{RD}=$ Average rut depth of both wheelpaths in inches

\subsubsection{Correlations between IRI and PSR}

The IRI formal is directly related to the condition of pavements, which is mainly based on the PSR system. The PSR system runs on a scale of 0.0 to 5.0. The main factors considered in determining the PSR for pavement are the quality and roughness of the ride regarding the IRI average rut depth and the age of the pavement surface (Arambula et al., 2011). The IRI average and values rut depth is taken directly from data provided by an observer. Figure 2-11 below shows data from the IRI experiment relating to PSI to IRI. The rate of serviceability mainly entails the vehicle ride perception, and a close relationship with the IRI roughness is expected.

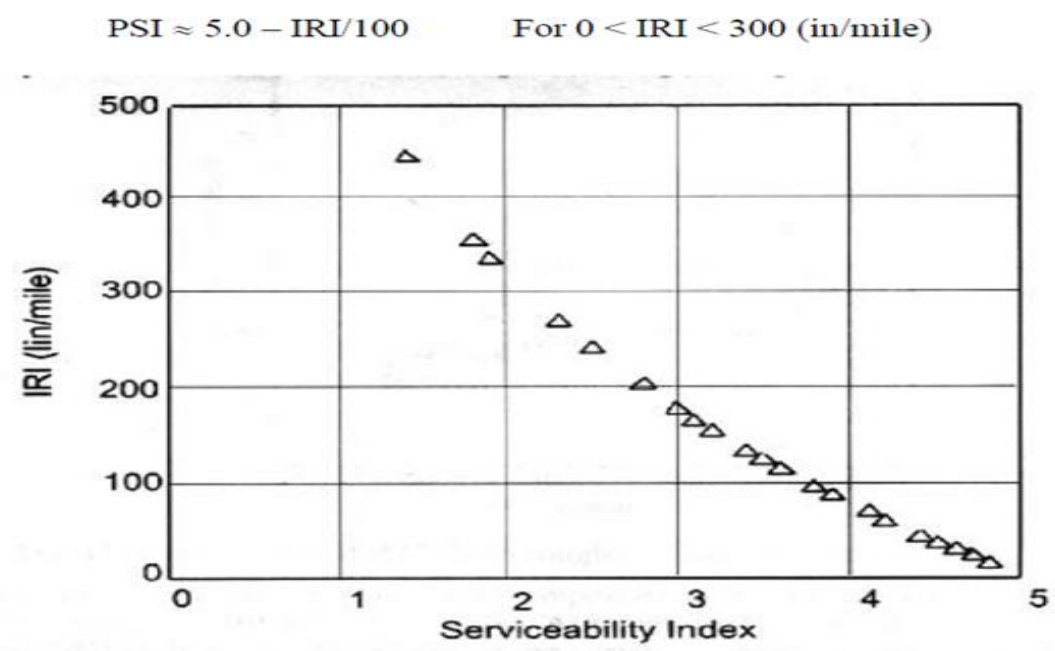

Figure 2-11: IRI vs. PSI (Arambula et al., 2011) 


\subsubsection{PSR and Ride Quality}

PSR values of pavements may be determined using the ride quality concepts. Al-Khateeb et al. (2020) illustrated ride quality based on common pavement rating, as shown in Figure 2-12.

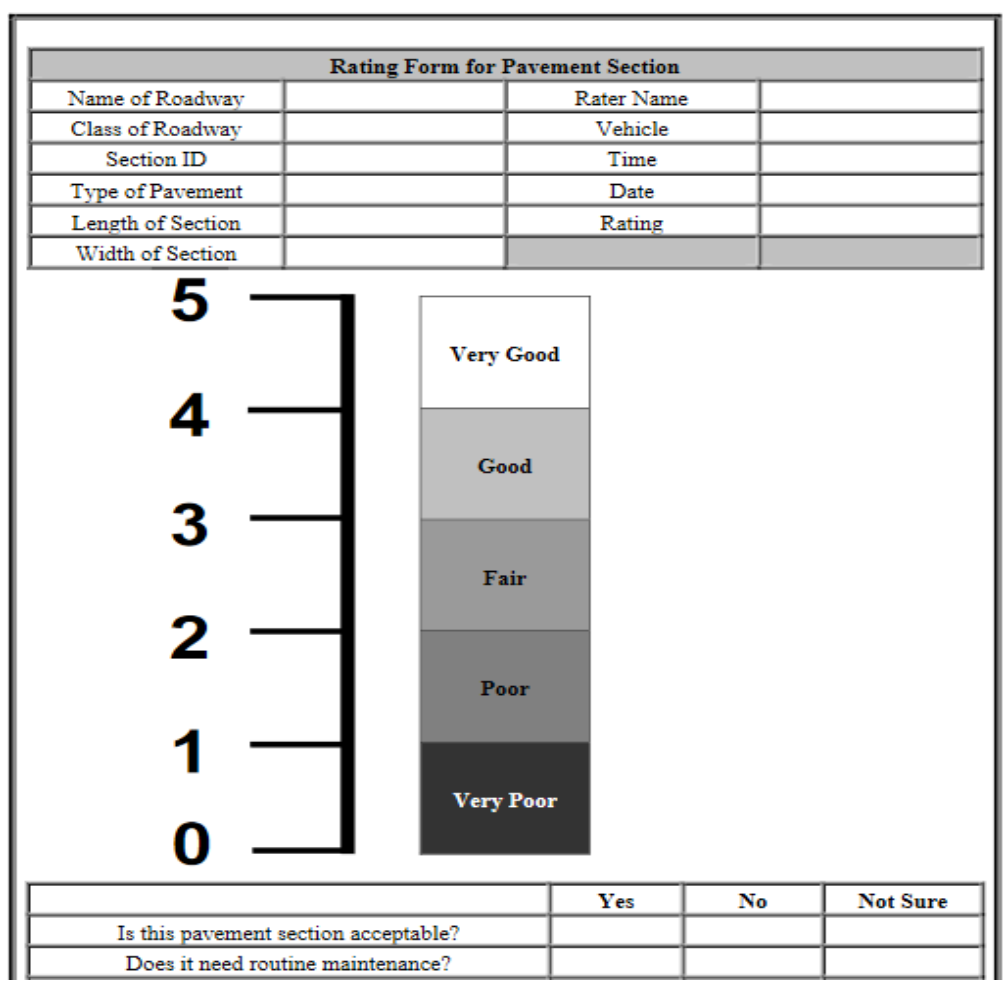

Figure 2-12: Ride quality based on common pavement rating (Al-Khateeb et al., 2020)

Data collection in the study involved a standard passenger car with remarkable dynamic and mechanical conditions, whereby Independent ratings from each engineer helped minimize the bias in pavement rating. Moreover, road users with large trucks, semi-trailers, and single-unit trucks were involved in the study. The ratings enabled the researchers to validate all the engineers' data because it was an objective study. The researchers then compared the relationship between both sets of ratings to find out the goodness of fit. The attained linear model and $r^{2}$ coefficient was 0.70 . Figure 2-13 below illustrates the results of the PSR by engineers and road users. 


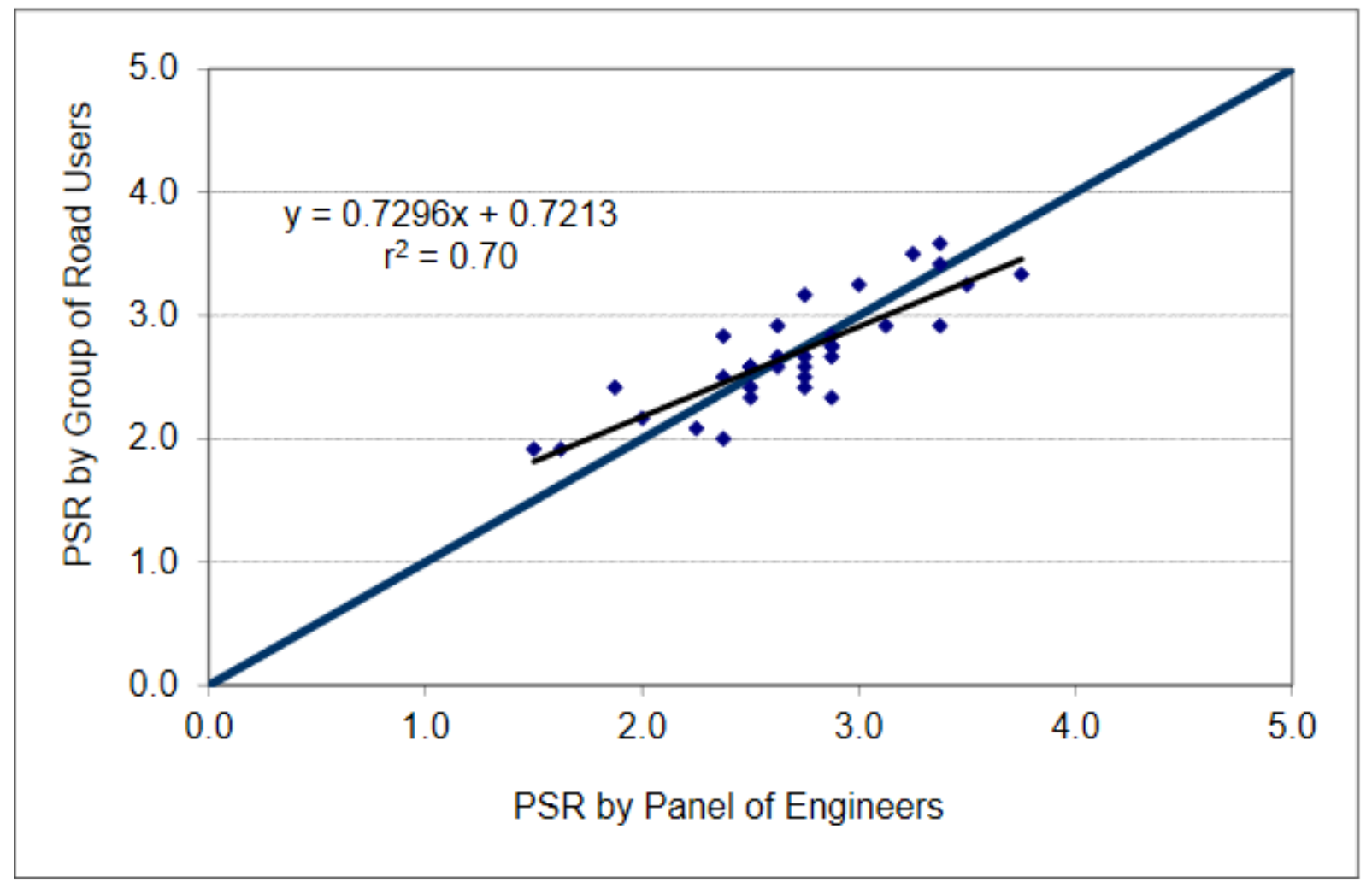

Figure 2-13: PSR by Road User vs. PSR by Panel of Engineers (Al-Khateeb et al., 2020)

$$
S V=\frac{\sum_{i=1}^{n}\left(S_{i}-\bar{S}\right)^{2}}{n-1}
$$

Where

- $\quad$ SV=Slope Variance

- $\quad S_{i}=$ Slope I

- $\quad \bar{S}=$ Mean of slopes

- $\quad n=N u m b e r$ of observations 
The distress that was measured in this case used the following symbols:

- $\quad$ Rut depth -RD

- $\quad$ Linear Cracking-LC

- $\quad$ Fatigue Cracking- FC

- Patching and Raveling-PR

- Potholes-H

- Deboning-DB

The RD was measured using a straightedge, and the average ten RD measurements collected across the instrument were assumed to represent the RD on the surface. Measurements for the RD were collected in five different intervals, and the LC was measured by length, while the $\mathrm{DB}, \mathrm{FC}$, and PR were measured by surface area (Al-Khateeb et al., 2020). Additionally, the statistical models based on distress for the PSI were developed. The above independent variables that represent roughness and distress were also considered in a multiple regression analysis. The PSI model for the PSR acquired in this investigation is shown below.

$$
P S I=k_{0}+k_{1} f(S V)+k_{2} f(R D)+k_{3} f(L C)+k_{4} f(F C)+k_{5} f(P R)+k_{6} f(H)+k_{7} f(D B)
$$

where $k_{0}, k_{1}, k_{2}, k_{3}, k_{4}, \ldots$ and $k_{n}$ are regression constants.

\subsubsection{Selecting Appropriate Correlation Functions}

The relationship between each independent variable and PSR was also investigated. This exercise was conducted to select the most appropriate function $(f)$ to illustrate the relationship. In this study, two independent variables were combined, consequently representing one variable and the formulation helped to acquire accurate outcomes. A scatter plot for used in one case, and the final PSI's expression is shown in the following equation:

$$
P S I=k_{0}+k_{1}(S V)+k_{2} \log (R D)+k_{3} \log (L C)^{2}+k_{4}(P R+F C)^{0.5}+k_{5} f(D B+P H)^{0.5}
$$




\subsubsection{Developing Distress-based PSI Models}

A non-linear regression analysis may be conducted using the STATISTICA package. According to the results obtained in the study, the best PSI model was only attained with a higher coefficient $\left(r^{2}\right)$, and the application of Slope Variance (SV). The PSI model in the test cases were SV $>=500$, and $S V<500$. The outcome depicts that PSR is inversely correlated to the SV values, whereby latter results indicate pronounced effect of SV variations on PSR. The expression for SV $>=500$ is presented below in the PSI equation.

$$
\begin{aligned}
& P S I=3.974-0.000106(S V)-0.11971 \log (R D)-0.308 \log (L C)^{2}-0.0309(P R+F C)^{0.5}- \\
& 0.227(D B+P H)^{0.5}
\end{aligned}
$$

On the other hand, the PSI equation for the SV $<500$ was developed and is shown below.

$$
\begin{gathered}
P S I=2.676+0.000417\left(\frac{1 \times 10^{6}}{S V^{2}}\right)-0.4971 \log (R D)-0.0914 \log (L C)^{2}-0.0780(P R+F C)^{0.5} \\
-0.2(D B+H)^{0.5}
\end{gathered}
$$

The PSI models based on the distress-base are developed mainly for pavements covered with asphalt and estimated through the non-linear regression techniques. SV $>=500$ and $S V<500$ PSI value ranges helped to attain best results in the models. Furthermore, the SV variation lacks any impact on the pavement rating after a specified period because the PSR's correlates inversely to the SV. In this case, the prediction of PSI and the obtained PSR had a 95\% confidence level. Moreover, rough pavements, $(S V<500),(D B+H)$ is the main factor for all the rough pavements as used in PSI estimations. RD (PR+FC), SV, and the LC comes next in the list, whereby further investigations have suggested that SV gives a higher effect on PSI values in smooth pavements than in rough pavements $(S V<500)$ and $S V>=500$ respectively. 


\section{Chapter 3. Research Methodology}

The research hypothesis is that drivers in modern vehicles might feel more comfortable on the highways in the condition same as the time the equation was developed due to advanced vehicle suspension systems. Therefore, the research methodology to calibrate the current IRI- based PSI equation is designed to include the steps, such as data collection for panel ratings and pavement roughness profiles from field testing and quarter-car parameters, IRI calculation code transition, the calibration of the current PSI equation, and the evaluation of the calibrated PSI equation. Figure 3-1 illustrates the steps required for this research.

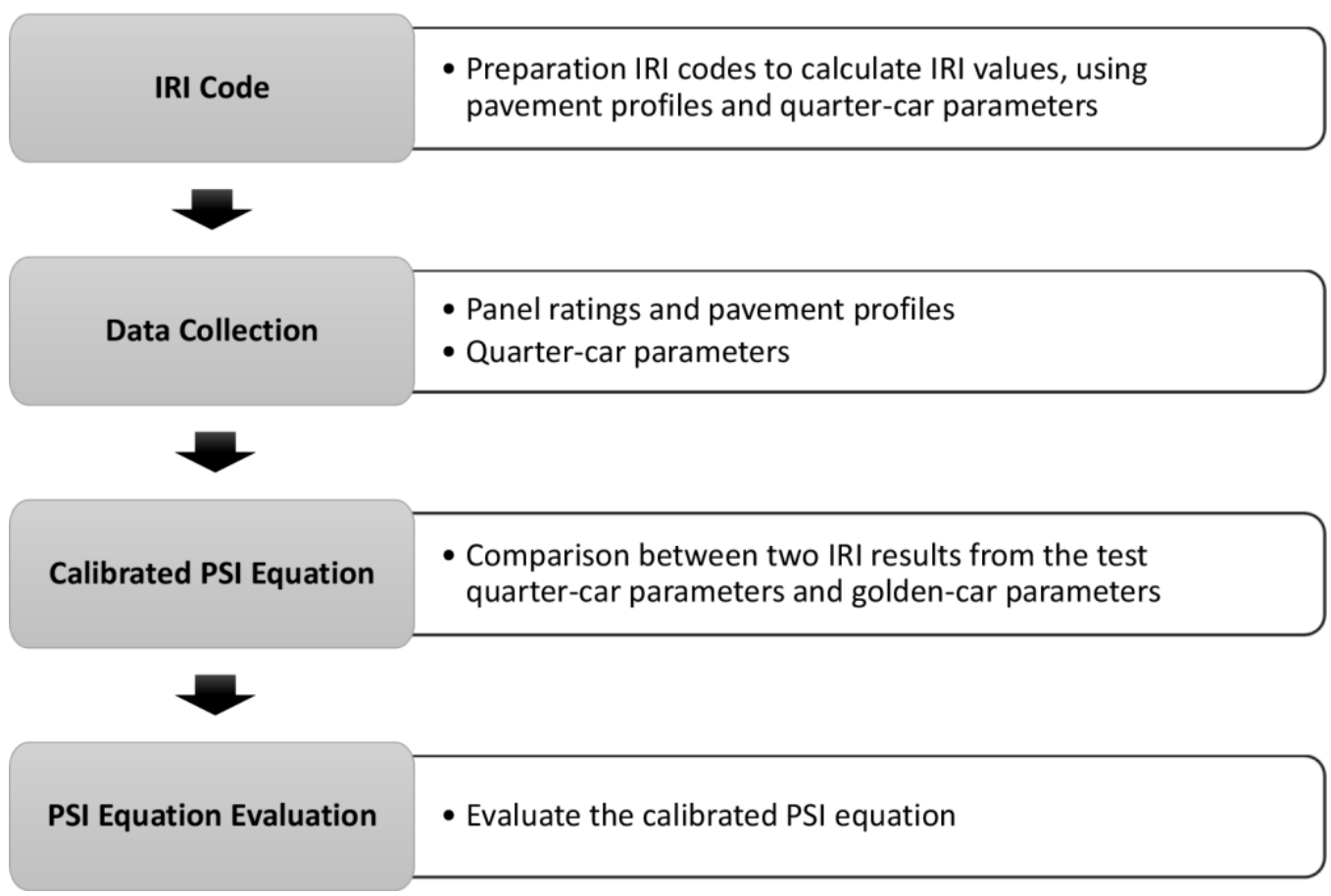

Figure 3-1. Steps for the Research Methodology 


\section{Step 1: IRI Codes}

The preparation of the codes for IRI calculation is essential to transform road profile data into IRI values, considering the parameters of a quarter-car model. A road profile data is a measurement of a pavement surface roughness along a continuous imaginary longitudinal line (Sayers and Karamihas, 1998). Responsetype equipment and profilometers are the types of equipment widely used to measure pavement profiles (Janoff et al., 1985). The profile data are processed to profile index (PI) that is defined as the root mean square (RMS) of profile in a specified frequency (e.g., one-third octave band). That is, the processes for PI follows: first, the average value of raw profiles is calculated; second, the average value is subtracted from the raw profiles; and, finally, the mean square of the subtracted profiles is computed, which is then square-rooted for RMS. PI is represented as a length unit (e.g., inches or millimeters).

A quarter-car model is the most common suspension system designed for passenger vehicles (Loizos and Plati, 2008; Liu et al., 2021). The lane IRI calculation is based on a quarter-car model that simulates a single wheel to measure longitudinal road profiles at a constant speed of $80 \mathrm{~km} / \mathrm{h} \quad(=49.7 \mathrm{mph})$. The model simulates the dynamic responses of a vehicle to uneven pavement surfaces, involving the parameters such as sprung mass, unsprung mass, suspension spring rate, tire spring rate, and suspension damping coefficient (Múčka, 2017). Figure 3-2 shows the parameters of a quarter-car model, where $m_{s}-$ sprung mass, $m_{u}$ - unsprung mass, $k_{s}$ - suspension spring rate, $k_{t}-$ tire spring rate, and $c_{s}-$ suspension damping coefficient. The sprung mass is the portion of a car body mass supported by one wheel and affects the body resonance (Gillespie et al., 1980; Sayers and Karamihas, 1996). The unsprung mass is the mass of the wheel and tire as well as the half of the axle/suspension moving up and down together while traveling over bumpy roads. The suspension spring rate, also called suspension stiffness, is one of the major factors for the motion control of a car body at the rate designed (Yagiz and Yuksek, 2001; Romero and Lozano, 2006). The tire spring rate, also called the stiffness of unsprung mass, is the ratio of the vertical load 
change to the tire deflection and interferes with the road excitation at the wheel to the vertical vibration of the unsprung mass (Koulocheris and Papaioannou, 2015). Lastly, the suspension damping coefficient is deduced in compression and rebound conditions of a vehicle's suspension system (SenthilKumar et al., 2009).

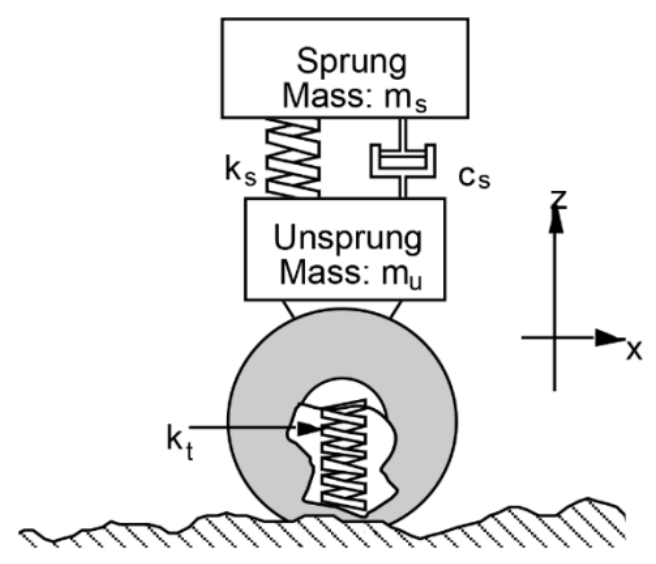

Figure 3-2. Quarter-Car Model (Sayers and Karamihas, 1996)

\section{Step 2: Data Collection}

The data types required for the approach in the research methodology are panel ratings and road profiles collected concurrently through field testing as well as the quarter-car parameters of modern vehicles. The data sources for the panel ratings and road profiles are the two NCHRP reports 275 and 308 that are the only resources publicly accessible from open sources. On the other hand, various quarter-car parameters need to collect through an extensive discovery search. The data types for the parameters, as stated in Step 1, include sprung mass, unsprung mass, suspension spring rate, tire spring rate, and suspension damping coefficient of passenger vehicles. The data collection step contains data cleaning and data evaluation activities to secure a quality set of raw data to generate reliable data analysis results. The data cleaning removes missing and noisy data points while the data evaluation checks the validity of data (i.e., whether the data are well-grounded or not). The choice to apply either the data cleaning or the data 
evaluation depends on data types. For example, the data cleaning can be suitable for panel ratings and road profiles while the data evaluation for quarter-car parameters. The data collection for quarter-car parameters applies search criteria to pinpoint target data saving time. These criteria can include publication years, search engines, and vehicle categories.

\section{Step 3: Calibration of the Current PSI Equation}

The calibration of the current PSI equation needs to compare the difference between the IRI values estimated from the golden-car parameters and the test quarter-car parameters that are the average of the quarter-car parameters collected through a discovery search in Step 2. As the NCHRP research revealed no effect of different pavement surface types on panel ratings, which was also reassured by AlOmari and Darter (1994), the calibration targets the current PSI equation for any of the pavement types in Equation 2.9. The NCHRP reports of the data sources show the panel ratings (i.e., MPR) associated with a wide range of PIs from 0.009 to 0.269 by increasing about 0.001 . Thus, there is a need to use PI groups that are similar to the concept of histogram bins as the comparisons in all PI values are not required. The number of PI groups should be determined in consideration of a number of data points enough to identify the trend of a calibrated PSI equation and PI counts in each PI group. Once IRI values for both the test and golden-car parameters at each PI group, the IRI values are translated into PSI values using Equation 2.9. Then, the PSI values of the test parameters are coordinated to the IRI values of the golden-car parameters in the same PI groups. Finally, the coordinated PSI values are fitted into a trend line that is a calibration of the current PSI equation. 


\section{Step 4: Calibrated PSI Equation Evaluation}

The calibration of the current PSI equation needs an evaluation for its applicability to replace the current PSI equation. As this research was motivated due to the reasons such as the current equation developed more than 20 years and the disparity between IRI and PSI requirements for new construction, two evaluation aspects were conceived to address the motivation. Also, as it is expected that a calibrated PSI equation produces better PSI values given the same IRI values than the current PSI equation, one more evaluation aspect was added. Thus, the three evaluation aspects for a calibrated PSI equation include:

- Similarity between two PSI equations, current and calibrated

- $\quad$ IRI requirements for new pavements, the present serviceability rating (PSR) definitions

- $\quad$ Acceptable ride quality of National Highway System (NHS)

\section{Chapter 4. Calibration of IRI-based PSI Equation}

The calibration of the IRI-based PSI equation was conducted, following the steps of the research methodology such as the translation of the IRI calculation codes to the Matlab codes, data collection for IRI calculation and quarter-car parameters, calibration of PSI equation, and compatibility evaluation of the calibrated PSI equation. The details of the calibration steps were presented in the subsequent subchapters from 4.1 to 0 .

\subsection{Translation of the IRI Calculation Codes}

The original IRI calculation codes used for the conversion were retrieved from the technical paper of Sayers (1995) and Syaers and Karamihas (1996). The Fortran language was used to program the codes that consist of four subroutines, such as IRI, SETABC, SETSTM, and STFILT, collectively working on calculating 
IRI. The IRI subroutine is the main part of converting an array of profile height values to an average IRI. Profile height values are longitudinal pavement profiles measured through the vertical movements of a vehicle at a speed of $80 \mathrm{~km} / \mathrm{h}$ (Loizos and Plati, 2008). The IRI subroutine calls the three other subroutines in order of the SETABC, SETSTM, and STFILT subroutines. The SETABC subroutine sets the model matrices for the quarter-car model parameters, road input through tire spring, and suspension motion as output. The SETSTM subroutine sets the state transition matrices given the matrices for the quarter-car model parameters and road input. The STFILT subroutine filters profiles using the state transition matrices from the SETSTM subroutine and the suspension motion matrix. The details of the original codes can be found in the referred source papers. 
The programming platform used to translate the original Fortran codes is MATLAB. Similar to the Fortran codes design, the IRI calculation codes in MATLAB consist of the IRI script that calls the three functions of SETABC, SETSTM, and STFILT. Figure 4-1 is the script to calculate IRI from road profile data given the input variables such as DX, BASE, and UNITSC as well as quarter-car parameters (see the red box in Figure 4-1).

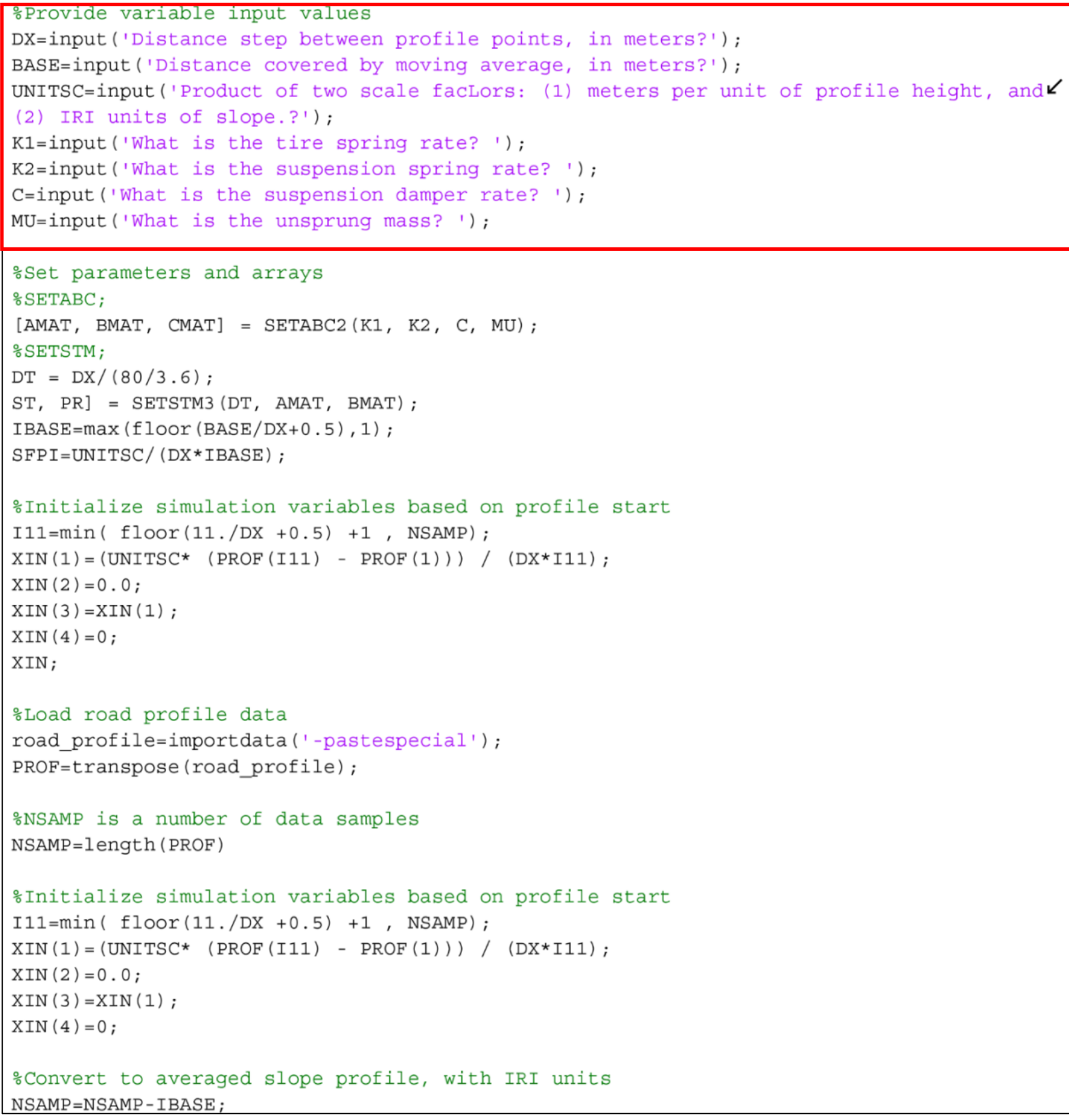

Figure 4-1. The Script to Compute Average IRI 


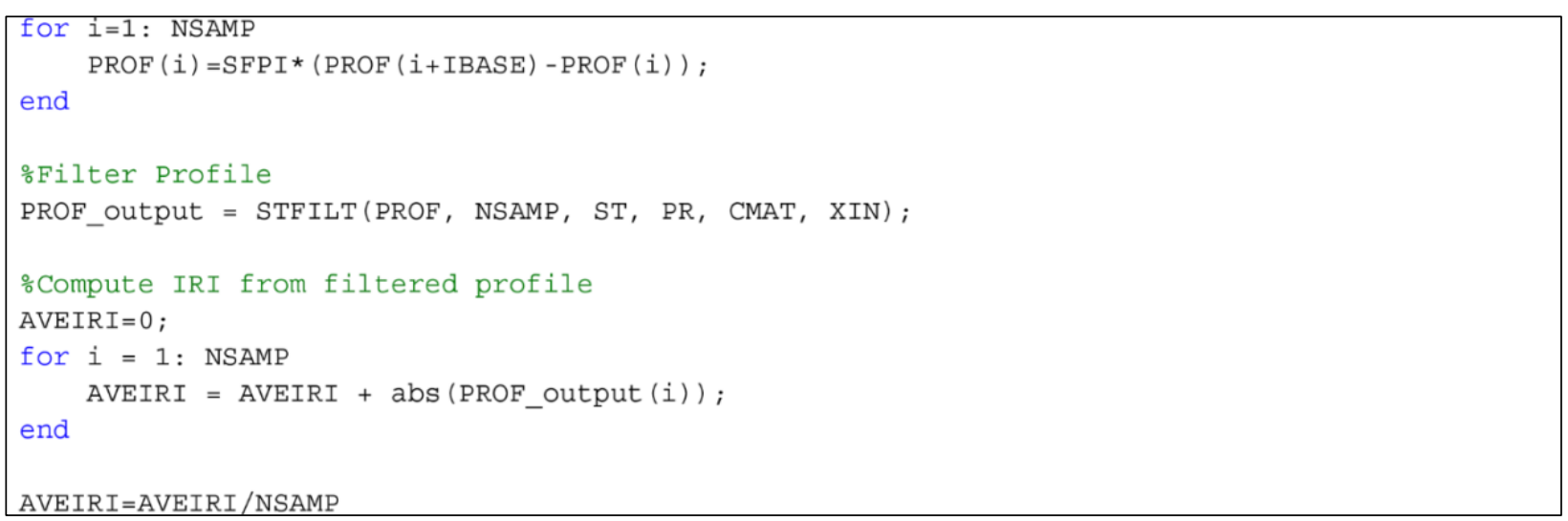

Figure 4-2. The Script to Compute Average IRI (continued)

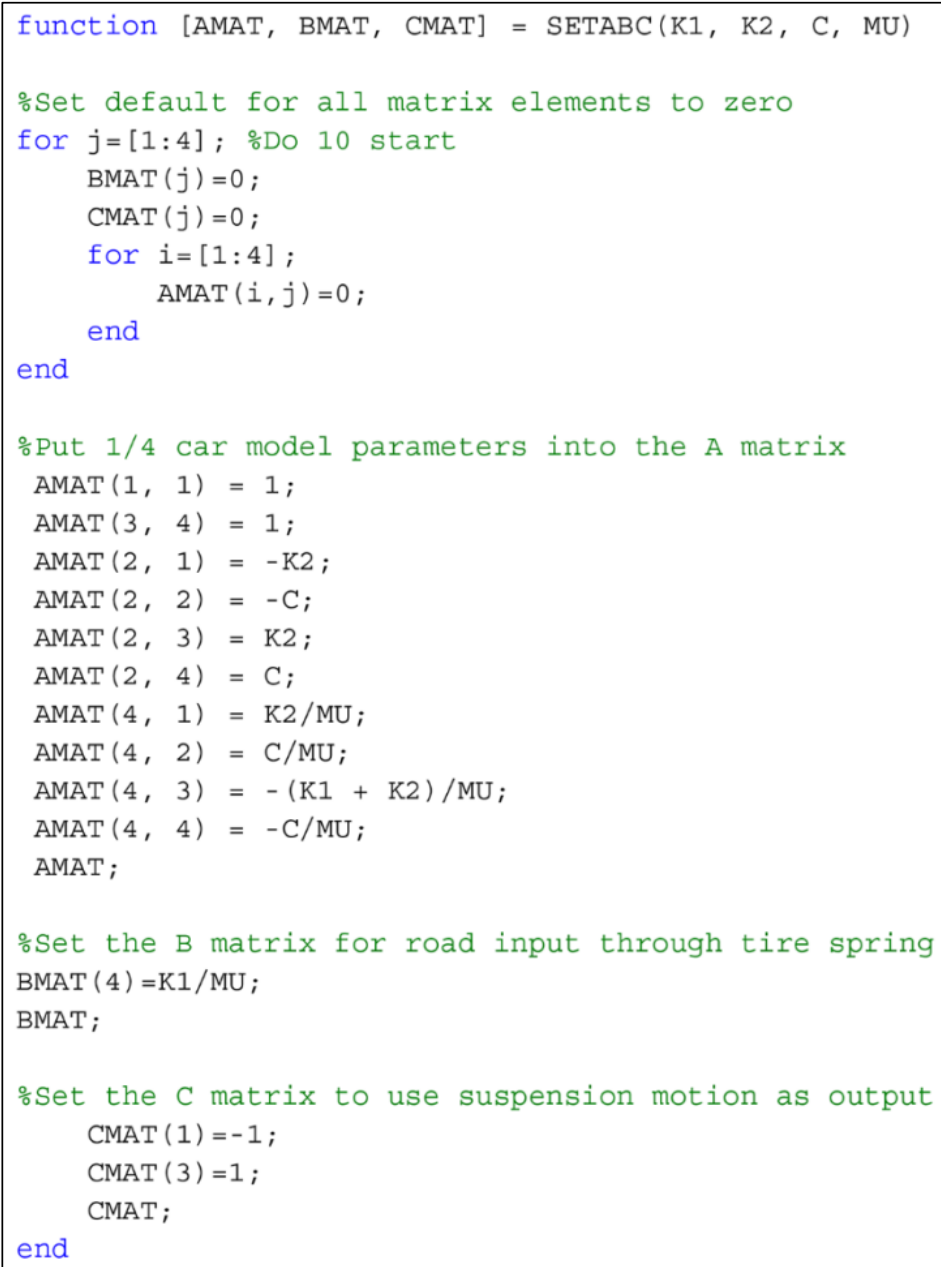

Figure 4-2. Function to Set the Model Matrices 
Figure 4-2 through Figure 4-4 show the three functions needed to calculate IRI in Figure 4-1. The variables such as AMAT, BMAT, and CMAT in Figure 4-2 represent the matrices for the quarter-car model parameters, road input, and suspension motion, respectively. The codes in Figure 4-3 are grouped into two main parts to calculate the state transition and partial response matrices. The notes starting "Do" are the remarks to match the ones to the Fortran codes. The filtered profiles as the outputs from Figure 4-4 are returned to the absolute values for summation and divided by the number of samples (NSAMP) to estimate an average IRI for the test section finally.

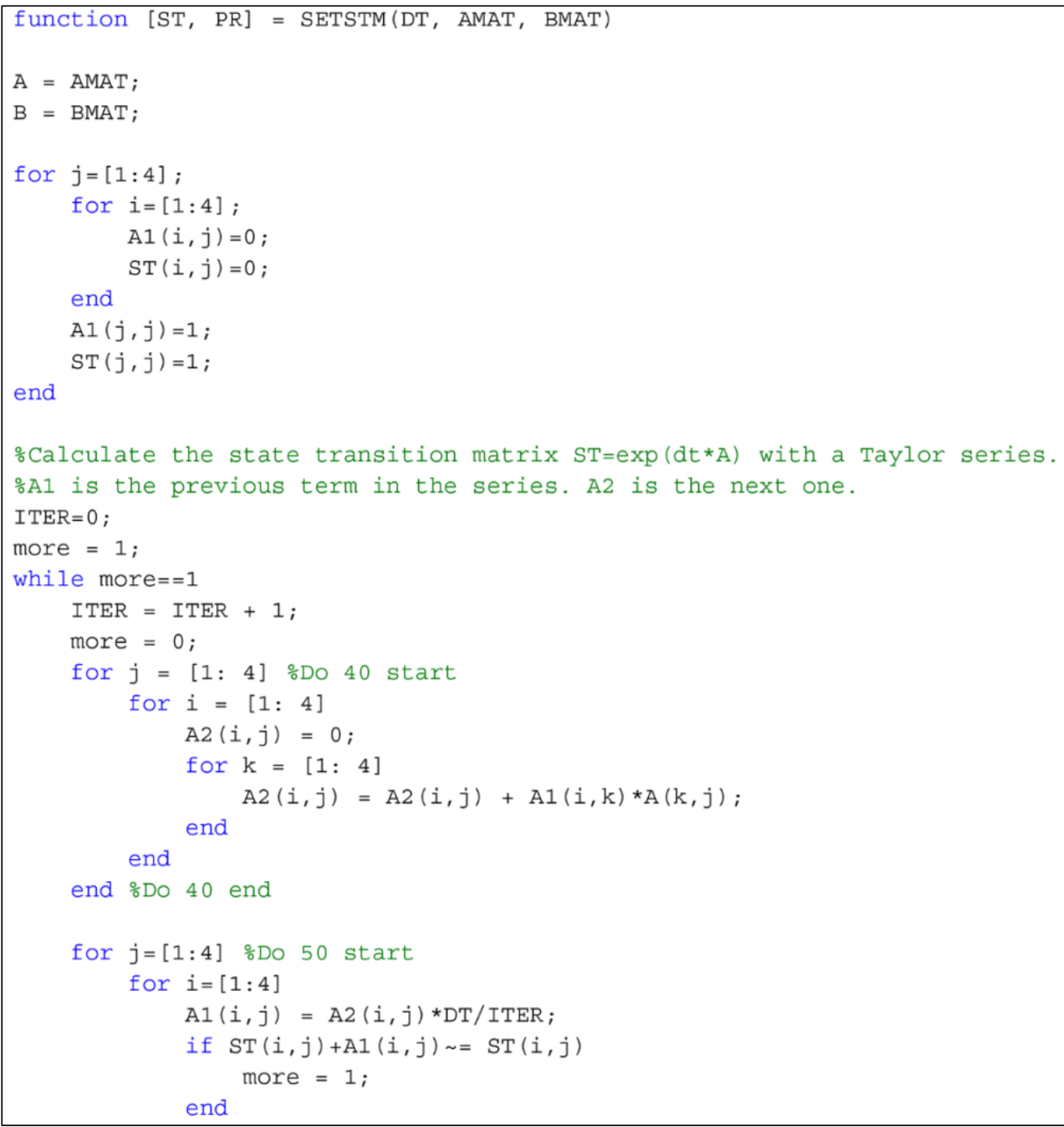

Figure 4-3. Function to Set the State Transition Matrices 


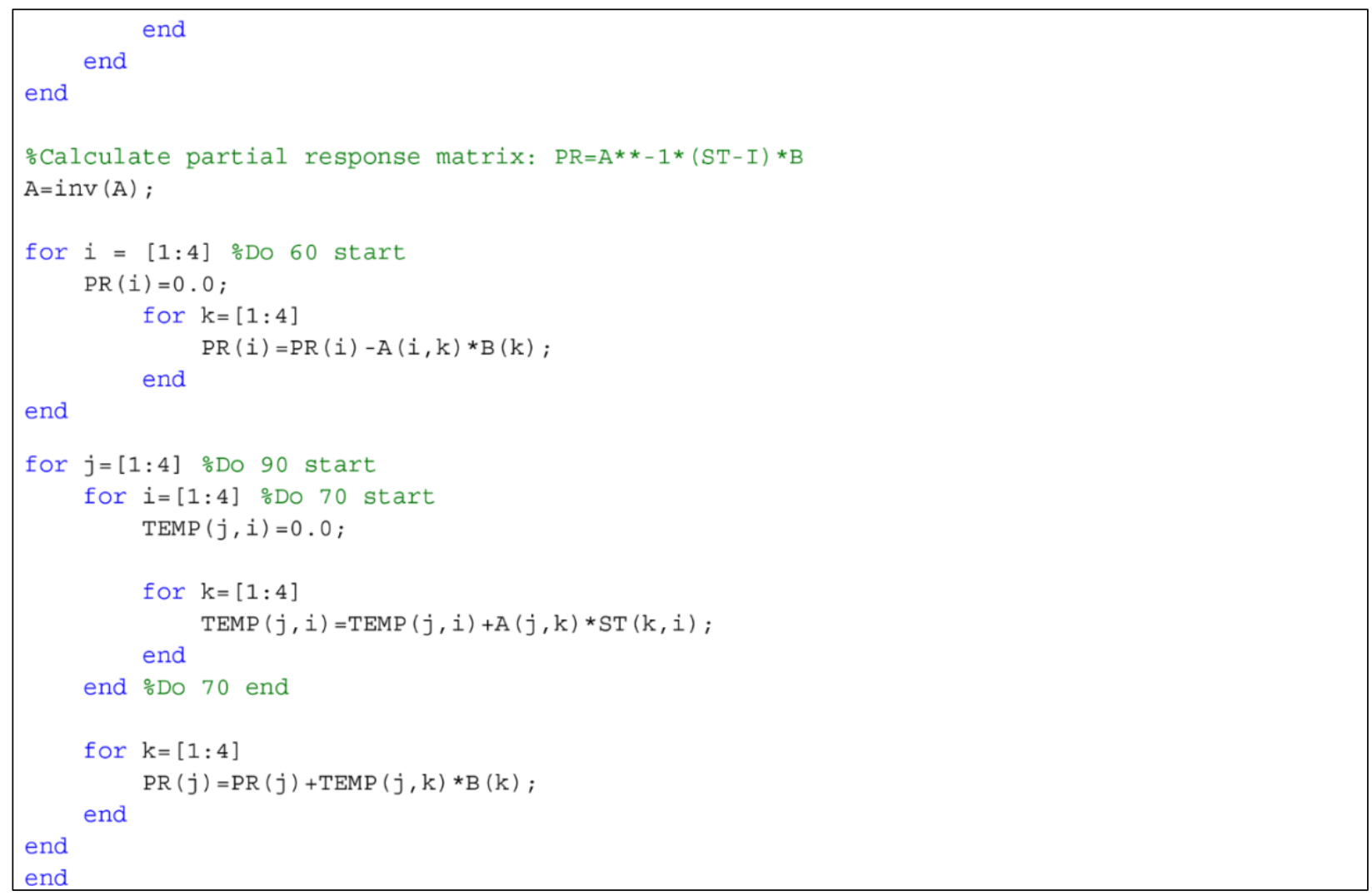

Figure 4-4. Function to Set the State Transition Matrices (continued)

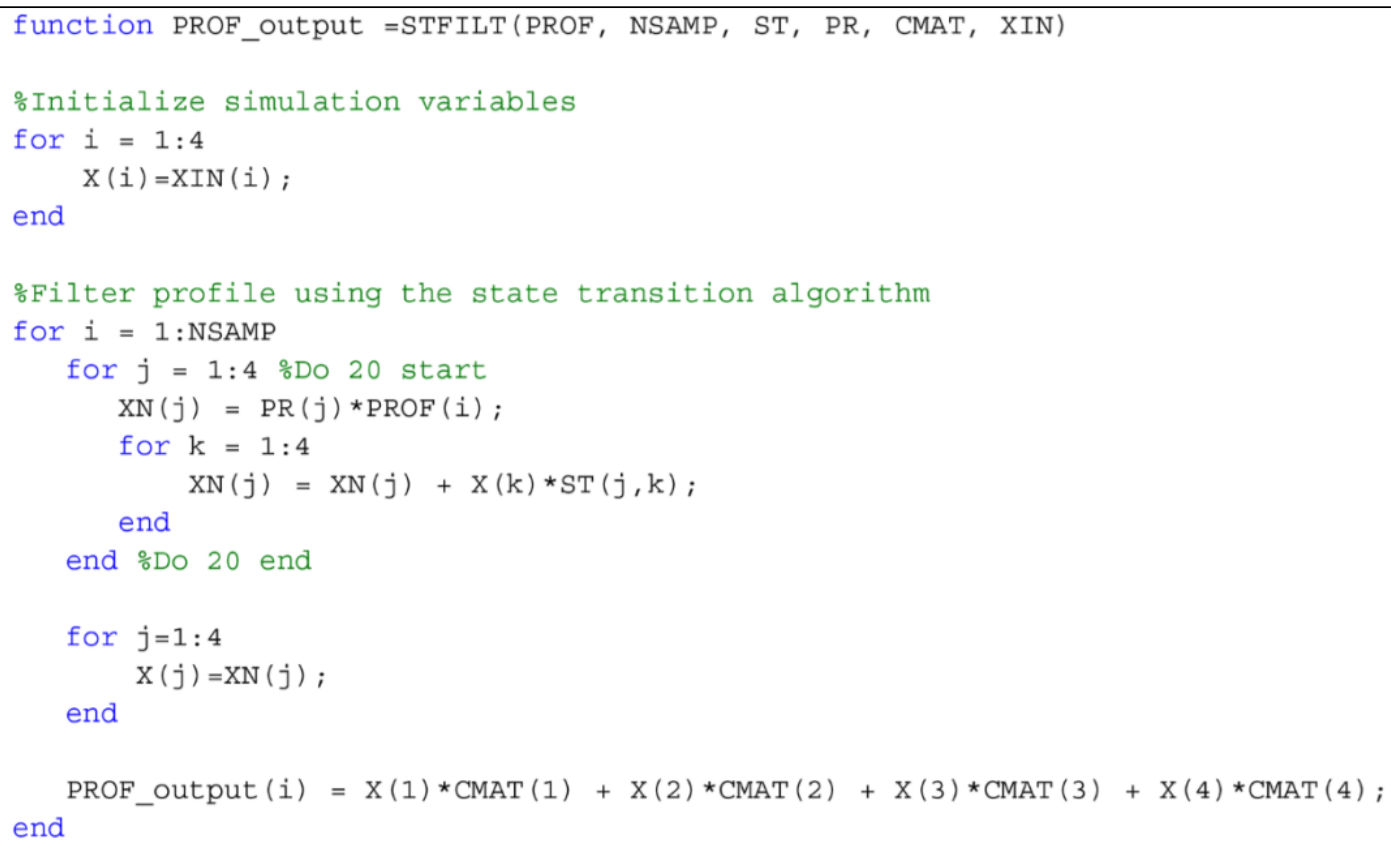

Figure 4-4. Function to Filter Profiles 


\subsection{Data Collection for the Calibration of PSI Equation}

The data types required to calibrate the current PSI equation that is derived from IRI were the panel ratings and pavement roughness profiles measured concurrently as well as the quarter-car parameters of passenger vehicles. The measurement data, MPR and PI, were retrieved from the NCHRP Report 308 (Janoff, 1988) where Al-Omari and Darter (1994) obtained most of the data to develop the current PSI equation. The report includes a total of 317 data points from the three different surface types (e.g., BC, PCC, and COMP) in the five selected states that include New Jersey, Michigan, New Mexico, Louisiana, and Ohio. The data points with missing PI values were not retrieved, which left out 36 data points. As a result, a total of 281 data points (e.g., 109 BC, 98 PCC, and 74 Composite) were retrieved, as shown in Table 4-1. The outlier evaluation for the retrieved data points as a whole was required for a quality data analysis. Figure 4-5 is a scatterplot of two variables, MPR and PI, and shows two data points circled that was suspected of outliers. The point at the top-left looks far from the fitted line (log function) so that the data point was removed from the data analysis. However, the point at the bottom-right was not removed as it was almost on the fitted line, indicating that the data point was not influential as an outlier. Appendix A lists the data points of MPR and PI retrieved from the NCHRP Report 308 and the highlighted one for the data point removed from the data analysis. It should be noted that the number of the PCC data points for Louisiana in Table 4-1 includes one outlier that was removed from the data analysis.

Table 4-1. Data Points retrieved from NCHRP Report 308

\begin{tabular}{|c|c|c|c|}
\hline State & BC & PCC & COMP \\
\hline New Jersey & 15 & 21 & 10 \\
\hline Michigan & 21 & 26 & 20 \\
\hline New Mexico & 41 & 10 & 13 \\
\hline Louisiana & 14 & 24 & 14 \\
\hline Ohio & 18 & 17 & 17 \\
\hline Total & 109 & 98 & 74 \\
\hline
\end{tabular}




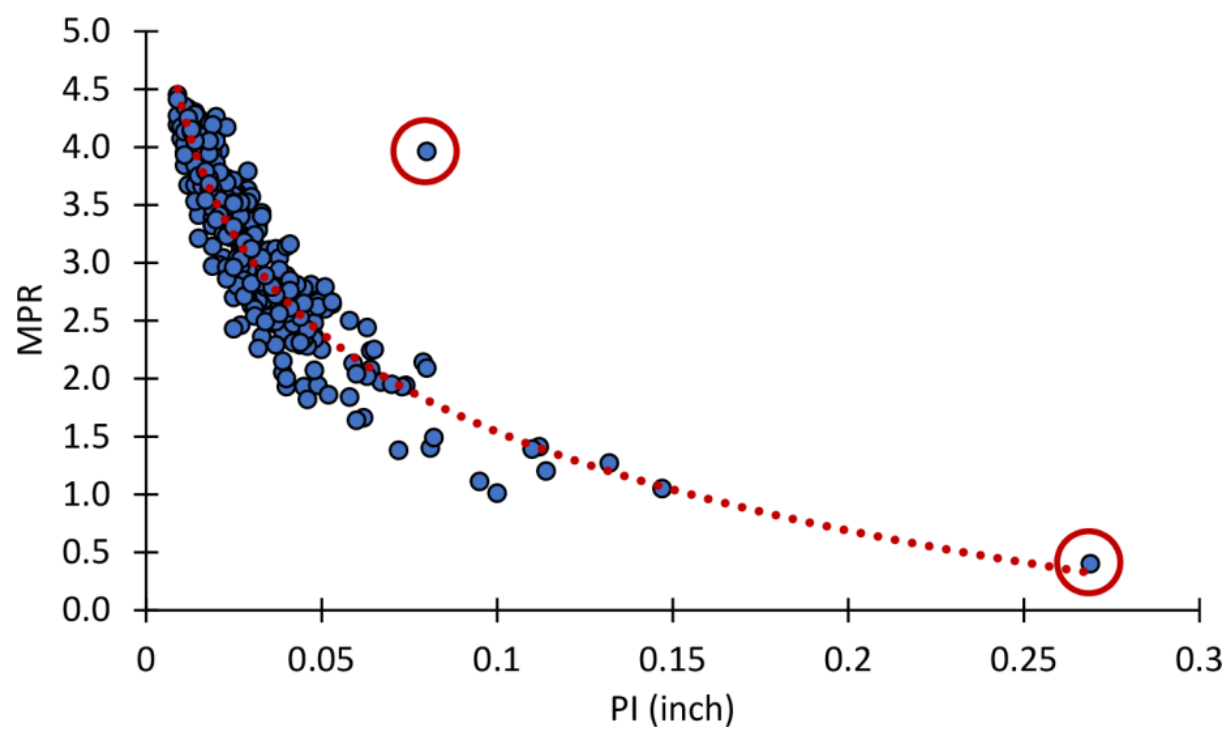

Figure 4-5. MPR vs. PI to Detect Outliers

The quarter-car parameters of passenger cars were collected through an extensive discovery search. The quarter-car parameters used to compute the IRI values for the current PSI equation were the golden-car parameters normalized by the sprung mass as follows:

$$
c_{s} / m_{s}=6.0 \quad k_{t} / m_{s}=653 \quad k_{s} / m_{s}=63.3 \quad m_{u} / m_{s}=0.15
$$

The golden car is not designated as a specific passenger car but a reference vehicle showing the most common response to pavement profiles (Lafarge et al., 2016). The vehicle sizes used to collect the panel data for NCHRP studies (e.g., Project 1-23 and 1-23(2)) ranged from compact (e.g., Chrysler Horizon) to full-size vehicles (e.g., Ford LTD), while K-car was the main vehicle for most data collection. However, the studies concluded that the panel ratings were not subjective to vehicle sizes. Therefore, the discovery search for the quarter-car parameters data was conducted based on the data search criteria set by this research as follows:

- Parameters from the publications after 2005 to consider relatively modern technologies for vehicle suspension systems since 2002. The three-year gap was derived from the time difference 
between research kick-off and publication. However, the parameters that were cited from other sources before 2005 were not considered.

- Vehicle sizes from mini to heavy, according to the passenger vehicle categories that the U.S. National Highway Traffic Safety Administration (NHTSA) separates, considering the curb weight of a vehicle as follows (NHTSA, 2021).

○ Passenger cars mini: $1,500-1,999$ lbs. $(680-907 \mathrm{~kg})$

○ Passenger cars light: $2,000-2,499$ lbs. $(907-1,134 \mathrm{~kg})$

○ Passenger cars compact: 2,500-2,999 lbs. (1,134-1,360 kg)

- Passenger cars medium: $3,000-3,4900$ lbs. $(1,361-1,587 \mathrm{~kg})$

- Passenger cars heavy: 3,500 lbs. $(1,588 \mathrm{~kg})$ and over

- Quarter-car parameters from explicit vehicle size classifications from data sources (e.g., small family, compact, and mid-size)

The reliability of the data was evaluated by different sources obtained from a supplementary discovery search, which assured the sprung and unsprung masses mostly due to the limited availability of other data types. As a result, a total of the nine mechanical properties for the different vehicle classes was obtained from the extensive discovery search, as shown in Table 4-1. Also, Table 4-2 shows both the vehicle classes indicated by the data sources and reclassified according to the NHTSA vehicle class categories considering vehicle curb weights. The NHTSA vehicle classes were codified for convenient, effective use in the following calibration steps. The data point marked as the asterisk $\left({ }^{*}\right)$ are the values estimated based on the additional information available at the data sources or the assumptions as follows:

- The distribution of a vehicle curb weight between front and rear is $56 \%$ to $44 \%$ (Allen et al., 2003), which was used to estimate the missing sprung masses and curb weights. For example, the curb weight of the upper-class from the data source of Schramm et al. (2014) was estimated by: 


$$
\text { Curb weight }=(401+48) \times 2 \div 0.56=1,603 \mathrm{~kg}
$$

The estimated curb weight is within the NHTSA category of a heavy passenger car.

- The proper damping ratios suggested for conventional passenger cars equipped with passive suspensions range from 0.2 to 0.4 to provide a good ride in the literature (Ivers and Miller, 1989; Dixon, 2008; Zhang and Cai, 2020). Thus, the medium of the range was considered to estimate the damping coefficient values, using Eq. 4.2, where $\mathrm{z}$ is a damping ratio, $c_{\text {crit }}$ is a critical damping coefficient, and $m$ is a total sprung mass of a vehicle, was the equation used to estimate the damping coefficient. For example, the damping coefficient of the European middle-class from the data source of Calvo et al. (2009), where denoted the total sprung mass of the class as $1,527 \mathrm{~kg}$, was estimated at 3,810 by $0.3 \times 2 \sqrt{1,527 \times 26,400}$.

$$
\zeta=\frac{c_{s}}{c_{\text {crit }}}=\frac{c_{s}}{2 \sqrt{m k_{s}}}
$$

\begin{tabular}{|c|c|c|c|c|c|c|c|c|}
\hline \multirow{2}{*}{$\begin{array}{c}\text { Vehicle Class from } \\
\text { Source }\end{array}$} & \multirow{2}{*}{$\begin{array}{c}\text { Vehicle Class } \\
\text { by NHTSA }\end{array}$} & \multirow[b]{2}{*}{ Code } & \multicolumn{5}{|c|}{ Quarter-Car Parameters } & \multirow{2}{*}{$\begin{array}{c}\text { Curb } \\
\text { Weight } \\
\text { (kg) }\end{array}$} \\
\hline & & & $\begin{array}{c}m_{s} \\
(\mathrm{~kg})\end{array}$ & $\begin{array}{l}m_{u} \\
(\mathrm{~kg})\end{array}$ & $\begin{array}{c}k_{s} \\
(\mathrm{~N} / \mathrm{m})\end{array}$ & $\begin{array}{c}k_{t} \\
(\mathrm{~N} \cdot \mathrm{s} / \mathrm{m})\end{array}$ & $\begin{array}{c}c_{s} \\
(\mathrm{~N} \cdot \mathrm{s} / \mathrm{m})\end{array}$ & \\
\hline Upper-Class $^{1)}$ & Heavy & $\mathrm{H} 1$ & 401 & 48 & 28,426 & 235,000 & 2,836 & $1,603^{*}$ \\
\hline Compact $^{2)}$ & Light & L1 & $253^{*}$ & 36.5 & 18,700 & 184,000 & $1,960^{*}$ & 1,065 \\
\hline $\begin{array}{l}\text { European Middle- } \\
\text { Class }^{3)}\end{array}$ & Heavy & $\mathrm{H} 2$ & 428 & 50 & 26,400 & 220,000 & $3,810^{*}$ & 1,707 \\
\hline Small Size ${ }^{4)}$ & Light & L2 & 265 & 35 & 30,000 & 180,000 & 2,000 & 1,070 \\
\hline Medium Size ${ }^{4)}$ & Medium & M1 & 397.4 & 45 & 40,000 & 250,000 & 2,200 & 1,580 \\
\hline Small(5) & Compact & $\mathrm{C} 1$ & $298^{*}$ & 30 & 12,800 & 97,500 & 850 & 1,174 \\
\hline Compact $^{6)}$ & Light & L3 & 256 & 31 & 20,200 & 128,000 & 1,140 & $1,025^{*}$ \\
\hline Compact $^{7)}$ & Compact & $\mathrm{C} 2$ & $334^{*}$ & $43^{*}$ & 46,800 & 200,000 & 3,000 & 1,349 \\
\hline Small(8) & Mini & MN1 & 231 & 17 & 12,800 & 150,000 & $970^{*}$ & $886^{*}$ \\
\hline
\end{tabular}

Table 4-2. Mechanical Properties of the Representative Vehicle Classes

Data sources:

1) Schramm et al. (2014), 2) Ersanilli (2015), 3) Calvo et al. (2009), 4) Başlamişli and Ünlüsoy (2009), 5) Wakeham and Rideout (2011), 6) Kang et al. (2020), 7) March and Shim (2007), 8) Islam and Ahmed (2005)

* Estimated values 
The mechanical properties in Table 4-2 were normalized by the sprung masses for the quarter-car parameters, as shown in Table 4-3. The quarter-car parameters were averaged to a test quarter-car parameter that was used to calculate IRI values in Chapter 4.3. The mechanical properties in Table 4-2 were reordered by the codes and classes from lighter to heavier in Table 4-3.

Table 4-3. Quarter-Car Parameters derived from Table 4-2

\begin{tabular}{|c|c|c|c|c|}
\hline \multirow{2}{*}{ Code } & \multicolumn{4}{|c|}{ Quarter-Car Parameters } \\
\cline { 2 - 5 } & $m_{u} / m_{s}$ & $k_{s} / m_{s}$ & $k_{u} / m_{s}$ & $c_{s} / m_{s}$ \\
\hline MN1 & 0.07 & 55.41 & 649.35 & 4.20 \\
\hline L1 & 0.14 & 73.91 & 727.27 & 7.75 \\
\hline L2 & 0.13 & 113.21 & 679.25 & 7.55 \\
\hline L3 & 0.12 & 78.91 & 500.00 & 4.45 \\
\hline C1 & 0.10 & 42.95 & 327.18 & 2.85 \\
\hline C2 & 0.13 & 140.12 & 598.80 & 8.98 \\
\hline M1 & 0.11 & 100.65 & 629.09 & 5.54 \\
\hline H1 & 0.03 & 20.14 & 166.48 & 2.01 \\
\hline H2 & 0.12 & 61.7 & 514.00 & 8.90 \\
\hline Test Parameter & 0.11 & 76.33 & 532.38 & 5.80 \\
\hline
\end{tabular}

\subsection{Calibration of the Current PSI Equation}

The PI data collected from the NCHRP Report 308 (Janoff, 1988) are the square root of the mean square of the profile height. On the other hand, the IRI calculation codes presented in Section 4.1 require road profile heights as inputs. This research tried to obtain the actual profile heights through an internet search and personal contacts involved in the NCHRP study. However, none of these efforts was successful, so the profile heights were randomly generated, assuming the normality of the raw data. The random generation of the profile heights got grounded from the fact that "measured records of roughness or profile data are recognized as random signals of finite durations" (Janoff et al., 1985). Another basis supporting the integrity of the random generation was from the research approach that calibrates the current PSI equation by analyzing the difference between two IRI measures derived from the golden-car parameters 
and new test quarter-car parameter. Therefore, random profile heights were generated for the 12 groups of $\mathrm{PI}$ as follows: $0.01,0.015,0.02,0.025,0.03,0.035,0.04,0.045,0.05,0.06,0.07$, and 0.08 . The number of PI groups was selected considering the data points enough to identify a PSI-IRI tendency for calibration and the counts of the PI data showing very little after 0.05 (see Figure 4-6).

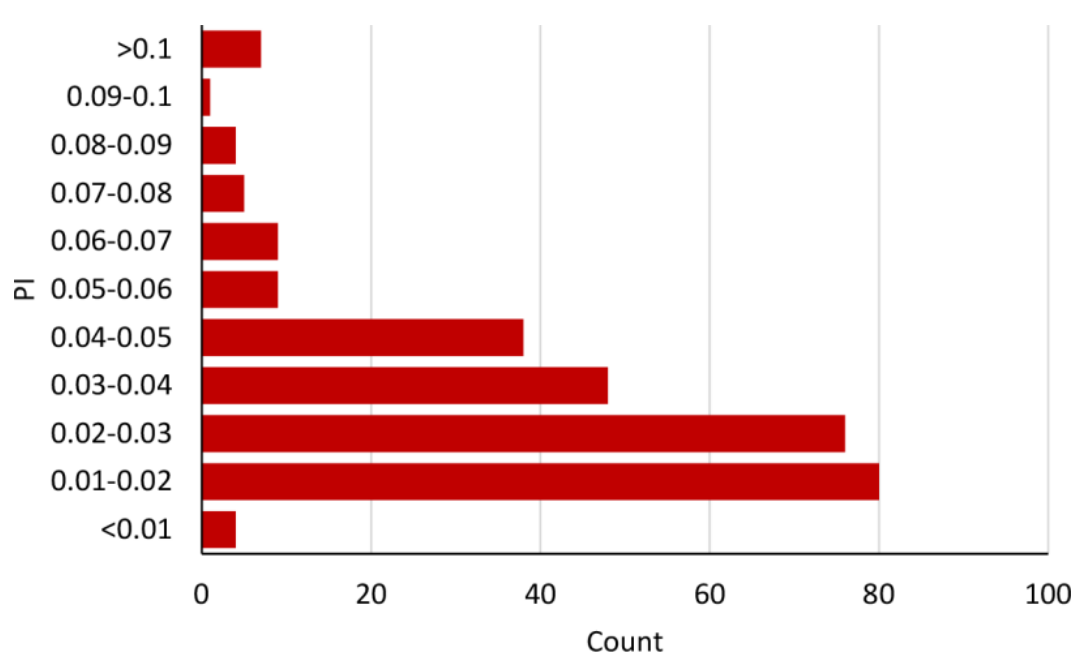

Figure 4-6. Counts of PIs

The number of the profile heights for each PI group was 1,024, considering the sample spacing of 6 inches at a one-tenth mile section. Then, the randomly generated profile heights were filtered for the frequencies outside 0.125 cycles/ft -0.630 cycles/ft that was found as the band of frequencies highly correlated with MPRs (Janoff et a., 1985 and Janoff, 1988). The NCHRP studies clearly concluded that using total roughness across all frequencies was not a good predictor of a PSI (Janoff et al., 1985). The filtered profile heights were processed to obtain adjusted profile heights matching each PI group. Finally, the filtered profile heights were entered into the IRI calculation codes that produced the IRI values for the golden-car and test parameters. While producing the IRI values, a temporary input variable was added to the codes to generate the IRI values in a reasonable range at each PI group. The original IRI values resulted from the codes were too low compared to expected IRI values, as the profile heights were generated at random, 
although they were adjusted to the PI groups. Therefore, the original IRI values needed to be amplified, considering the reasonable IRI values expected for the PI groups. For example, based on the MPRs in Appendix A, the IRI values were estimated using the current PSI equation (see Equation 2.9), and the estimated IRI values were averaged for the PI groups (see Figure 4-7), except for the PI group of 0.08 that was not able to calculate an average due to a wide range of PIs so assumed as 300.0 inches $/ \mathrm{mi}$. Then, the average IRI value at each PI group was used as a reference to adjust the temporary input variable, so the IRI values close to the actual IRI values could be generated. However, it should be noted that this adjustment does not compromise the integrity of the IRI values estimated as they were not used for developing any new formula but measuring the difference between the two IRI values from the goldencar and test parameters.

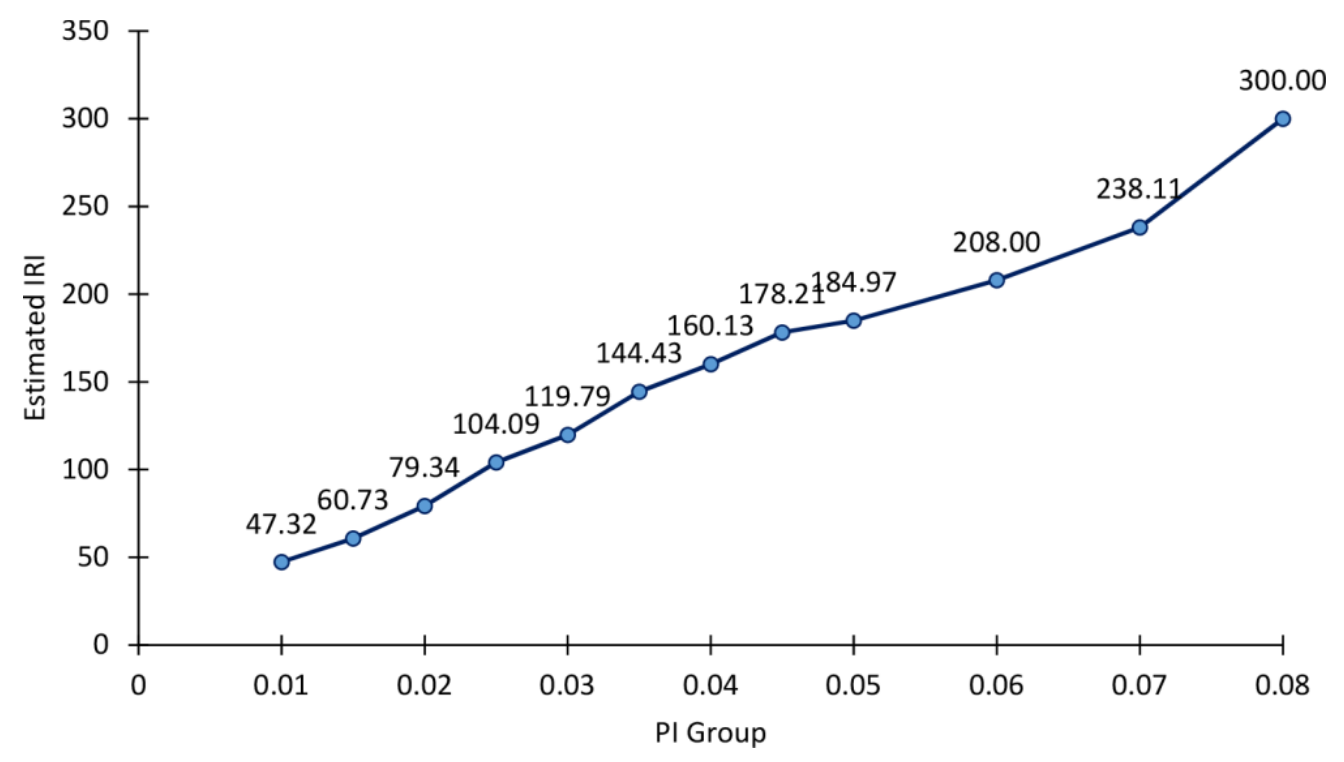

Figure 4-7. IRI Values estimated from MPR using the PSI Equation 
Each PI group generated 30 paired IRI values because the profile heights used for comparison were not actual data, so that there was a need to consider different road profile conditions given the PI. Also, the number is a minimum data point generally accepted for the t-test. The t-test was conducted for this research to evaluate the difference between the two sets of IRI results from the golden-car and test parameters. The tables in Appendix B include all the IRI results used for the data analysis. Table 4-4 shows the t-test results. As the IRI values from the test parameter were always less than the golden-car parameters, a one-tailed t-test was conducted at the $95 \%$ confidence level. The null hypothesis was that the mean values of the two datasets from the golden-car and test parameters were the same. The null hypothesis should be rejected when the t-value is greater than the t-critical value, or the p-value is less than the significance level. The t-critical value for 30 data samples (i.e., the degree of freedom $=29$ ) at a 95\% confidence level is 1.699 . The t-values for all PI groups are far greater than the t-critical value, which are represented as extremely low p-values. Thus, it concluded that the two datasets from the golden-car and test parameters for all PI groups were different, which indicated that the IRI results from the test parameters might need to calibrate the current PSI equation.

Table 4-4. One-tailed t-Test Results

\begin{tabular}{|c|c|c|}
\hline PI Group & t-value & $p$-value \\
\hline 0.01 & 13.432 & $2.79 \mathrm{E}-14$ \\
\hline 0.015 & 15.946 & $3.43 \mathrm{E}-16$ \\
\hline 0.02 & 15.497 & $7.23 \mathrm{E}-16$ \\
\hline 0.025 & 14.057 & $8.85 \mathrm{E}-15$ \\
\hline 0.03 & 14.257 & $6.18 \mathrm{E}-15$ \\
\hline 0.035 & 12.842 & $8.58 \mathrm{E}-14$ \\
\hline 0.04 & 12.043 & $4.15 \mathrm{E}-13$ \\
\hline 0.045 & 11.561 & $1.11 \mathrm{E}-12$ \\
\hline 0.05 & 9.8278 & $4.89 \mathrm{E}-11$ \\
\hline 0.06 & 11.635 & $9.55 \mathrm{E}-13$ \\
\hline 0.07 & 11.545 & $1.15 \mathrm{E}-12$ \\
\hline 0.08 & 10.560 & $9.45 \mathrm{E}-12$ \\
\hline
\end{tabular}


The calibration of the current PSI equation first calculated the average IRI values for both datasets at each PI group. Figure 4-8 shows the comparison of the average IRI values from the two datasets at each PI group. The average IRI values from the test quarter-car parameters clearly indicate that a driver in a modern passenger vehicle would feel better than IRI values being measured by state DOTs. The average IRI values of the test parameters were applied to Equation 2.9 to derive the PSI values, which were then associated with the average IRI values of the golden-car parameters at the same PI groups. For example, the PSI of the average IRI value for the test parameters at the PI group of 0.015 was 4.15 (= $\left.5 \times e^{-0.0041 \times 45.429}\right)$, while the PSI of the average IRI value for the golden-car parameters was $4.11(=$

$\left.5 \times e^{-0.0041 \times 48.072}\right)$. The PSI value of the test parameters was associated with the IRI value of the goldencar parameters (i.e., 48.072). Finally, a calibrated PSI equation was identified, fixing the initial PSI value at 5.0, as shown in Figure 4-9.

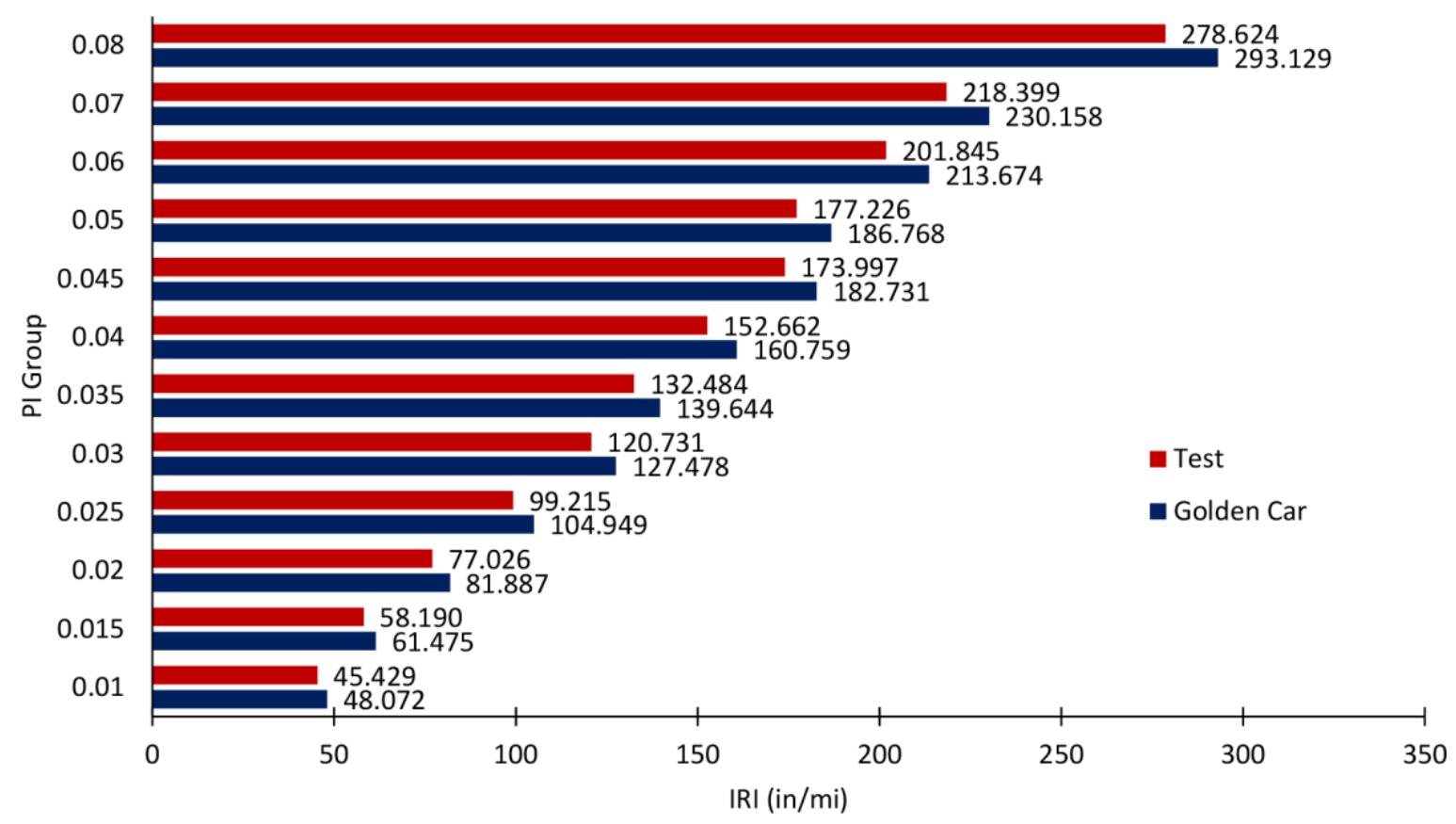

Figure 4-8. Comparison of Average IRI Values at each PI Group 


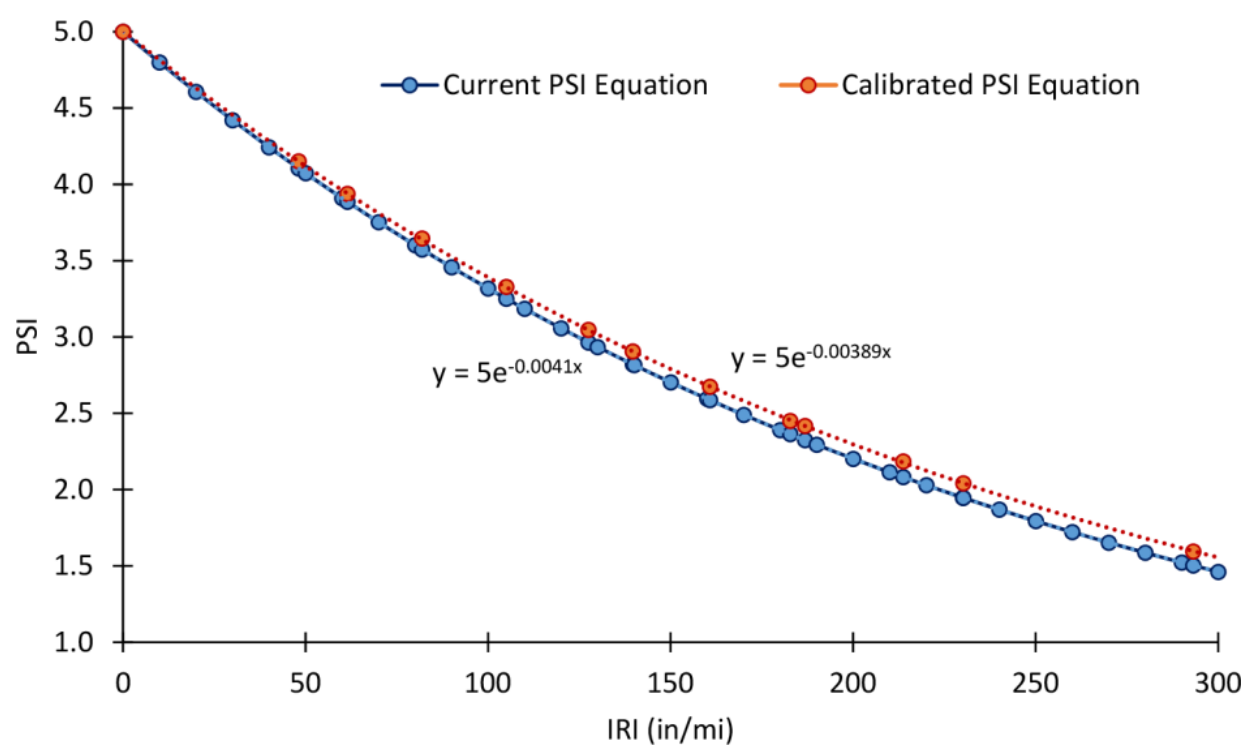

Figure 4-9. Calibration of the Current PSI Equation

\subsection{Evaluation of the Calibrated PSI Equation}

As the first aspect, the similarity evaluation between the current and calibrate PSI equations was done using cosine similarity, ranging from 1 to 0 . The smaller the cosine similarity value, the greater the dissimilarity between the two PSI-IRI graphs. Eq. 4.3 shows the function to calculate a cosine similarity. The variables $x$ and $y$ in Eq. 4.3 represent two vectors (i.e., data points in the IRI-PSI coordinator for the current and calibrated equations) for comparison.

$$
C S=\frac{x \cdot y}{\|x\|\|y\|}
$$

As a result, the cosine similarity was 0.655 , which this research interprets as a relatively high similarity.

The second evaluation aspect investigated the consistency between IRI requirements for new pavements and the FHWA PSR definitions. According to the survey conducted by Merritt et al. (2015), the average IRI limits of many states for new asphalt and concrete pavements are 65.9 inches/mile (typical acceptable IRI values range: 52 - 66 inches/mi) and 71.7 inches/mile (typical acceptable IRI values range: 57 - 72 
inches/mi), respectively. On the other hand, Federal Highway Administration (FHWA) defines a PSR within $4.0-5.0$ as only new (or nearly new) superior pavements with no need for any maintenance, while pavements with a PSR below 4.0 show visible signs of surface deterioration (FHWA, 2014). Using the current PSI equation, the average IRI limits for asphalt and concrete are translated to 3.81 PSI and 3.72 PSI, which indicates that the new pavements might have a maintenance need the year when they are constructed. The calibrated PSI equation estimates the average IRI limits as 3.87 PSI and 3.78 PSI, which are a little better than the current PSI equation but still show an inconsistency between the IRI acceptance limits for new pavements and the FHWA definitions for PSR values. It indicates that the calibrated PSI equation is still not good enough to solve the inconsistency.

FHWA criterion considers an IRI of 170 inches/mi as acceptable ride quality on NHS (FHWA, 2018). The most recent IRI statistics reported in 2019 showed that the percentage of the NHS miles with acceptable ride quality was $88.4 \%$ in 2018 (FHWA, 2021). The IRI values in the statistics were measured based on the golden-car parameters. The IRI of 170 inches/mi at $2.5 \mathrm{PSI}$ is equivalent to 178.2 inches/mi by the calibrated PSI equation as shown in Figure 4-10. It indicates that additional pavement miles between the IRI values of $170-178.2$ inches/mi can be classified as acceptable ride quality when the calibrated PSI equation is used. For example, the IRI statistics in 2019 reported a total of 217,026 miles on the NHS and 194,492 miles with a reported IRI less than or equal to 170 inches/mi. Also, the statistics recorded 6,941 miles in an IRI range of 171-194 inches/mi. Assuming the NHS miles in the range were equally distributed, the increased IRI of 178.2 can rate an additional $31.3 \%(=(178.5-171) \div(194-171) \times 100 \%)$ of the NHS miles in the range as acceptable ride quality. As a result, the percentage of the NHS miles with acceptable ride quality could be $90.6 \%(=(194,492+6,941 \times 0.313) \div 217,026)$, which is $2.2 \%$ increase from $88.4 \%$ at the IRI of 170 inches/mi. Also, when state DOTs consider 2.5 PSI as one of the measures to trigger pavement rehabilitation, the calibrated PSI equation saves about $\$ 592,957,200$ for a rehabilitation per 
year, as estimated in Table 4-5. It concludes that the calibrated PSI equation is worthwhile to use in terms of the third evaluation aspect.

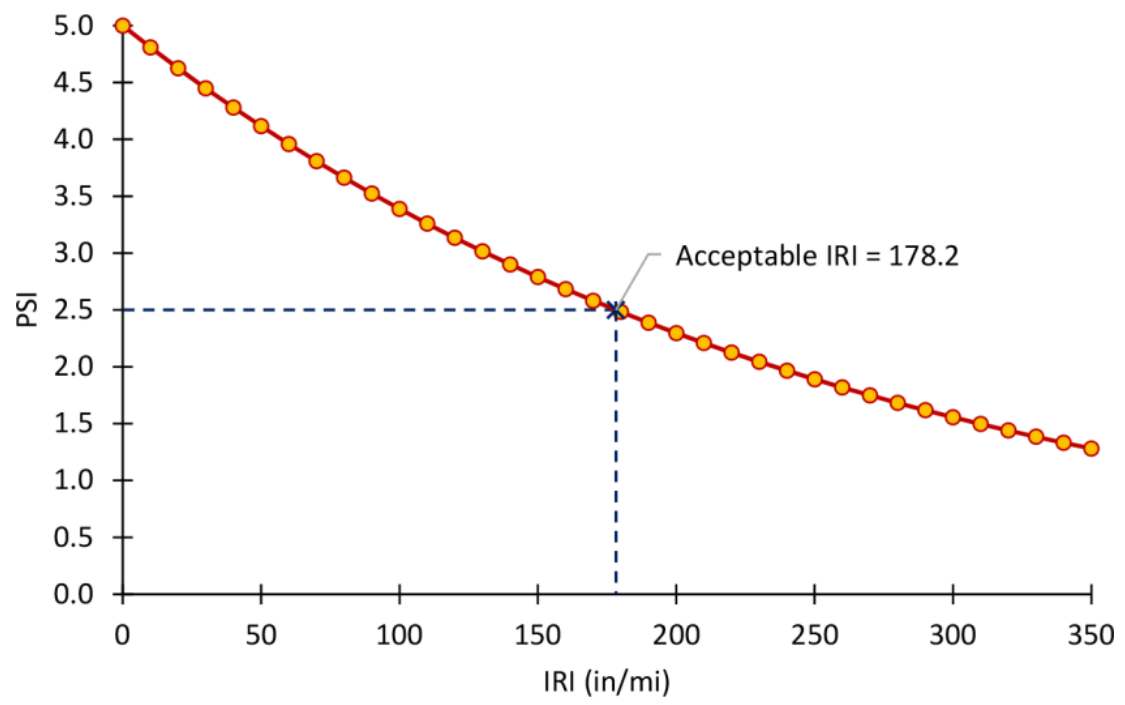

Figure 4-10. IRI Value at PSI $=2.5$

Table 4-5. Rehabilitation Cost Saving due to the Increased IRI

\begin{tabular}{|l|l|r|l|}
\hline \multicolumn{1}{|c|}{ Item } & Unit & \multicolumn{1}{c|}{ Cost (\$) } & \multicolumn{1}{c|}{ Note } \\
\hline Rehabilitation Cost & $\mathrm{yd}^{2}$ & 11 & \multicolumn{1}{c|}{ Source: FHWA (2017) } \\
\hline Rehabilitation Cost & $\mathrm{mi}^{2}$ & $34,078,000$ & \\
\hline Cost-saving & & $592,957,200$ & $\begin{array}{l}\text { Additional NHS miles: } 6,941 \text { miles } \times 31.3 \% \\
\text { Average lanes per mile: } 3.54 \text { lanes } / \mathrm{mile} \\
\text { Width per lane: } 12 \text { feet } \\
\text { Additional NHS area: } 17.4 \mathrm{mi}^{2}\end{array}$ \\
\hline
\end{tabular}

Chapter 5. Conclusions and Recommendations

\subsection{Conclusions}

State DOTs and FHWA use the IRI and PSI indices to administer the quality and serviceability of roads. The IRI and PSI values are applied in making decisions for pavement design and management practices along with other metrics, but there exists a demand for adjusting the PSI equation to accommodate the disparities between IRI-based design requirements and PSI values estimated from IRI. Hence, this study 
was motivated to provide a newly adjusted PSI equation, hypothesizing that the suspension systems of modern passenger cars have evolved to make drivers on pavements feel more comfortable today. The research approach used was the comparison between the IRI results from the quarter-car parameters of a golden-car that were used to develop the current PSI equation and the parameters identified through a comprehensive discovery search in this research. As a result, a newly calibrated PSI equation was formulated and examined by three evaluation aspects presented in Chapter 3 . The evaluation results show that the calibrated PSI equation is different from the current PSI equation but is not highly significant in terms of the coefficient of the cosine similarity of 0.655 . Although the calibrated PSI equation reduces the inconsistency between the PSI values estimated from the IRI acceptance limits for new pavements and the FHWA definitions for PSR values, it is not good enough to solve the inconsistency issue. However, the calibrated PSI equation presents a higher cut-off IRI limit to rating national highway systems as acceptable ride quality, estimating about $\$ 6$ million cost-savings for rehabilitation. 
Based on the research results, the contributions of this thesis can be summarized as follows:

- The calibrated PSI equation has the potential to replace the current PSI equation for state DOTs to survey their national highway systems for good and acceptable ride quality.

- Assuming the availability and accessibility of road profile data and the quarter-car parameters of passenger vehicles, this thesis still values the research approach as a cost-effective way to calibrate the current PSI equation with no need for field studies.

- The primary research approach, the comparison of the IRI values from different quarter-car parameters if applicable, can be applied for state DOTs to adjust quarter-car parameters in their IRI measurement equipment.

- The evaluation aspects devised in this thesis can be considered in future research that seeks to update the current PSI equation. 


\subsection{Limitations and Recommendations}

While conducting this research, the major limitation was collecting the data required to calibrate the current PSI equation. Many studies indicated that there had been enormous advancement in vehicle suspension systems to enhance ride comfortability and safety for drivers, which was the basis to build the hypothesis of this thesis. However, the collection of the main data types, quarter-car parameters of modern passenger vehicles and road profile data used to develop the current PSI equation was almost impossible by any means, such as open search spaces and personal contact to car manufacturers and researchers in the past studies. The primary reason for the difficulty in obtaining the road profile data was the NCHRP research conducted too long ago (i.e., more than 30 years). Also, the data of quarter-car parameters for various vehicle models were not so open for public access. The limitations encountered in this research lead to recommend the following future work:

- Investigation of the quarter-car parameters of modern passenger vehicles for IRI measurement equipment being used by state DOTs

- Another new field study like the NCHRP, Project 1-23, to re-find the relationship between IRI measurements and panel ratings (PSR), with technological advancements, not limited to suspension systems, in enhancing ride comfort

- Overall review of current design standards related to PSI and IRI metrics for new construction and rehabilitation of pavement projects 


\section{Work Cited}

Abed, Ahmed, Nick Thom, and Luis Neves. "Probabilistic prediction of asphalt pavement performance." Road Materials and Pavement Design 20.sup1 (2019), pp. 247-264. https://nottinghamrepository.worktribe.com/preview/2004066/Probabilistic\%20prediction\%20of\%20asphalt\%20pavement \%20performance\%20\%28002\%29.pdf

Abulizi, Nueraihemaitijiang, et al. “Measuring and Evaluating of Road Roughness Conditions With a Compact Road Profiler and ArcGIS." Journal of Traffic and Transportation Engineering, vol. 3, no. 5, 2016, pp. 1-14. doi:10.1016/j.jtte.2016.09.004

Ahmed, Namir G. et al. "Prediction the Effect of Maintenance Alternative on Pavement Performance Indicators." Civil and Environment Research, vol. 8, no. 12, 2016, pp. 44-49. www.iiste.org/Journals/index.php/CER/article/view/34429. Accessed on 28 April 2021.

Al-Khateeb, Ghazi \& Al-Smadi, Riyada. (2013). PSI Models for Urban Highway Flexible Pavements in Jordan.

Al-Khateeb, Ghazi G., and Nagham Y. Khadour. "Distress-based PSI Models for Asphalt Pavements of Rural Highways." Jordan Journal of Civil Engineering $14.2 \quad$ (2020), pp.1-13. https://www.proquest.com/openview/bdb3c1fb7a17a5170ff8b318d4e27275/1?pqorigsite=gscholar $\& \mathrm{cbl}=2035891$

Al-Omari, Bashar, and Darter I. Darter. "Effect of pavement deterioration types on IRI and rehabilitation." Transportation Research Record 1505 ,1995, pp.57-65.

Al-Omari, Bashar, and Michael I. Darter. "Relationships between International Roughness Index and Present Serviceability Rating." Transportation Research Record, Vol.1435, No.1, 1994, pp.130-136.

Aleadelat, Waleed, \& Khaled, Ksaibati. "Estimation of Pavement Serviceability Index Through Android-Based Smartphone Application for Local Roads." Transportation Research Record: Journal of the Transportation Research Board, no. 2639, 2017, pp. 129-135. doi:10.3141/2639-16 
Allen, R. W., Klyde, D. H., Rosenthal, T. J., \& Smith, D. M. (2003). Estimation of passenger vehicle inertial properties and their effect on stability and handling. SAE transactions, 1032-1050.

Arambula, Edith, et al. "Development and validation of pavement performance models for the state of Maryland." $\begin{array}{llllll}\text { Transportation } & \text { research } & \text { record } & 2225.1 & \text { (2011), } & \text { pp. }\end{array}$ https://journals.sagepub.com/doi/abs/10.3141/2225-04

Arellana, Julián, et al. "Multivariate analysis of user perceptions about the serviceability of urban roads: case of Barranquilla." International Journal of Pavement Engineering, vol. 22, no. 1, 2021, pp. 54-63.

Arhin, Stephen A., et al. "Predicting Pavement Condition Index Using International Roughness Index in a Dense Urban Area." Journal of Civil Engineering Research, vol. 5, no. 1, 2015, pp. 10-17. doi: 10.5923/j.jce.20150501.02

Arianto, T., M. Suprapto and I. Syafi'. "Pavement Condition Assessment Using IRI from Roadroid and Surface Distress Index Method on National Road in Sumenep Regency." International Conference on Advanced Materials for Better Future 2017. IOP Publishing, 2017, pp. 1-7. https://doi.org/10.1088/1757899X/333/1/012091.

Başlamişli, S. C., \& Ünlüsoy, Y. S. (2009). Optimization of speed control hump profiles. Journal of transportation engineering, 135(5), 260-269.

Botha, G. "Measuring Road Traffic Safety Performance." Proceedings of the 24th South African Transport Conference (SATC). Department of Transport, Pretoria, 2005, pp. 515-529. https://repository.up.ac.za/bitstream/handle/2263/6580/055.pdf?sequence=1.

Bryce, James M. "A Pavement Structural Capacity Index for Use in Network-Level Evaluation of Asphalt Pavements." Thesis, 18 January 2012. vtechworks.lib.vt.edu/bitstream/handle/10919/76970/etd01202012-105452_Bryce_JM_T_2012_2.pdf?sequence=1. Accessed on 2 May 2021. 
Bryce, James, et al. "Relating Pavement Condition Index and Present Serviceability Rating for Asphalt-Surfaced Pavements." Transportation Research Record: Journal of the Transportation Research Board, vol. 2673, no. 3, 2019, pp. 208-312. doi:10.1177/0361198119833671

Cai, Xu, Duanyi Wang and Jiangmiao Yu. "Evaluation of the Functional Performance of Paving Materials Based on the Driving Wheel Pavement Analyzer." Applied Sciences, vol. 10, no. 2410, 2020, pp. 1-16. https://doi.org/10.3390/app10072410.

Carey Jr, W. N., H. C. Huckins, and R. C. Leathers. "Slope Variance as a Measure of Roughness and the CHLOE Profilometer." HRB Spec. Rept 73 (1962), pp. 1-12.

Chamorro, Alondra, et al. "Development of Distress Guidelines and Condition Rating to Improve Network Management in Ontario, Canada." Transportation Research Record Journal of the Transportation Research Board, no. 2093, 2009, pp. 128-135. http://dx.doi.org/10.3141/2093-15.

Chang, Jia-Ruey, et al. "Evaluating the Structural Strength of Flexible Pavements in Taiwan Using the Falling Weight Deflectometer." International Journal of Pavement Engineering, vol. 3, no. 3, 2002, pp. 1-28. https://doi.org/10.1080/1029843021000067854.

Chen, Shong-Loong, et al. "Research on the International Roughness Index Threshold of Road Rehabilitation in Metropolitan Areas: A Case Study in Taipei City." Sustainability, Vol.12, No.24, 2020, pp.1-18.

Chu, Chih-Yuan, and Pablo L. Durango-Cohen. "Empirical comparison of statistical pavement performance models. "Journal of Infrastructure Systems 14.2 (2008), pp.1-12. https://www.researchgate.net/profile/PabloDurango-

Cohen/publication/238532601_Empirical_Comparison_of_Statistical_Pavement_Performance_Models/l inks/5408b9370cf2187a6a6cb079/Empirical-Comparison-of-Statistical-Pavement-PerformanceModels.pdf

Coenen, Tom B. et al. “A Review on Automated Pavement Distress Detection Methods.” Cogent Engineering, vol. 4, no. 1, 2017, pp. 1-23. doi:10.1080/23311916.2017.1374822 
Comprehensive Truck Size and Weight Limits Study: Pavement Comparative Analysis Technical Report. CTS\&W Limits Study: Pavement Comparative Analysis Technical Report - Chapter 4: Scenario Impacts. (2017, February22).

https://ops.fhwa.dot.gov/freight/sw/map21tswstudy/technical_rpts/pcanalysis/04_scen_impacts.htm.

Determination of the International Roughness Index. Engineering Policy Guide. (n.d.). https://epg.modot.org/index.php/106.3.2.59_TM59,_Determination_of_the_International_Roughness_I ndex.

Dixon, J. C. (2008). The shock absorber handbook. John Wiley \& Sons.

Ersanilli, V. (2015). Automotive Tyre Fault Detection (Doctoral dissertation, Coventry University).

Ferreira, Adelino, et al. "Selection of pavement performance models for use in the Portuguese PMS." International $\begin{array}{llllll}\text { Journal of } & \text { Pavement } & \text { Engineering } & 12.1 & \text { (2011), } & \text { pp. }\end{array}$ https://www.tandfonline.com/doi/abs/10.1080/10298436.2010.506538

Flintsch, Gerardo W., et al. "Evaluation of International Friction Index Coefficients for Various Devices." Transportation Research Record Journal of the Transportation Research Board, vol. 2094, 2009, pp.136143. http://dx.doi.org/10.3141/2094-15.

Flora, William Fredrick, Ghim Ping and Kumares C. Sinha. "Development of a Structural Index as an Integral Part of the Overall Pavement Quality in the INDOT PMS." Technical Summary FHWA/IN/JTRP-2010/11, 2010. https://docs.lib.purdue.edu/cgi/viewcontent.cgi?article=2609\&context=jtrp.

Fuentes, Luis G. et al. “Determination of Pavement Macrotexture Limit for Use in International Friction Index Model." Transportation Research Record: Journal of the Transportation Research Board, vol. 2306, no. 1, 2012, pp. 138-143. doi:10.3141/2306-16

Fuentes, Luis, et al. "Modelling pavement serviceability of urban roads using deterministic and probabilistic approaches." International Journal of Pavement Engineering, vol. 22, no. 1 , 2021, pp. 77-86.

Gillespie, T. D. (1980). Calibration of response-type road roughness measuring systems. 
Gulen, Sedat, et al. "Correlation of present serviceability ratings with international roughness index." $\begin{array}{lllll}\text { Transportation } & \text { Research } & \text { Record } & 1435 & \text { (1994), }\end{array}$ http://onlinepubs.trb.org/Onlinepubs/trr/1994/1435/1435.pdf\#page=35

Gupta, Ankit, Praveen Kumar, and Rajat Rastogi. "Critical review of flexible pavement performance models." KSCE Journal of Civil Engineering 18.1 (2014), pp. 1-7. https://www.researchgate.net/profile/Rajat-Rastogi5/publication/259636755_Critical_review_of_flexible_pavement_performance_models/links/0c960536 37b8c45296000000/Critical-review-of-flexible-pavement-performance-models.pdf

Hall, J.W., et al. "Guide for Pavement Friction." Contractor's Report for NCHRP Project 01-43. 2009. https://www.massenza.ru/wp-content/themes/massenza/downloads/publications/nchrp w108.pdf.

Highway Statistics 2019. U.S. Department of Transportation/Federal Highway Administration. (2021, April 15). https://www.fhwa.dot.gov/policyinformation/statistics/2019/.

Hosseini, Seyed Amirhossein, and Omar Smadi. "How prediction accuracy can affect the decision-making process in pavement management system." Infrastructures $6.2 \quad$ (2021), pp.1-17. https://res.mdpi.com/d_attachment/infrastructures/infrastructures-0600028/article_deploy/infrastructures-06-00028-v2.pdf.

Hu, C., Gao, H., Guo, J., Taghavifar, H., Qin, Y., Na, J., \& Wei, C. (2019). RISE-based integrated motion control of autonomous ground vehicles with asymptotic prescribed performance. IEEE Transactions on Systems, Man, and Cybernetics: Systems.

Irfan, Muhammad, Muhammad Bilal Khurshid, and Samuel Labi. "Determining the service life of thin hot-mix asphalt overlay by means of different performance indicators." Transportation research record 2108.1 (2009), pp. 37-45. https://journals.sagepub.com/doi/abs/10.3141/2108-04

Islam, A. S., \& Ahmed, A. K. W. (2005). Comparative performance study of magneto-rheological fluid based damper for vehicle suspension. In Proceedings of the International conference on mechanical engineering. 
Ivers, D. E., \& Miller, L. R. (1989). Experimental comparison of passive, semi-active on/off, and semi-active continuous suspensions (No. 892484). SAE Technical Paper.

Janoff, M. S., Nick, J. B., Davit, P. S., \& Hayhoe, G. F. (1985). Pavement roughness and rideability. NCHRP Report, (275).

Janoff, Michael S. Pavement Roughness and Rideability Field Evaluation. No. 308. 1988.

Kang, M., Chen, R., \& Li, Y. (2020, December). Adaptive Tube-based Model Predictive Control for Vehicle Active Suspension System. In 2020 4th CAA International Conference on Vehicular Control and Intelligence (CVCI) (pp. 720-725). IEEE.

Karim, Fareed M. A. et al. "The Road Pavement Condition Index (PCI) Evaluation and Maintenance: A Case Study of Yemen." Organization, Technology and Management in Construction: An International Journal, vol. 8, no. 1, 2016, pp. 1446-1455. doi:10.1515/otmcj-2016-0008

Karlaftis, Matthew, and Konstantinos Kepaptsoglou. "Performance measurement in the road sector: a crosscountry review of experience." International Transport Forum Discussion Paper, 2012, pp. 1-53. https://www.econstor.eu/bitstream/10419/68806/1/728780895.pdf

Khattak, Mohammad Jamal, Gilbert Y. Baladi, and Xiaoduan Sun. Development of index based pavement performance models for pavement management system (PMS) of LADOTD. No. FHWA/LA. 08/460. Louisiana Transportation $\quad$ Research $\quad$ Center, 2009, pp. 1-933. https://rosap.ntl.bts.gov/view/dot/20282/dot_20282_DS2.pdf

Khoshnoud, F., Zhang, Y., Shimura, R., Shahba, A., Jin, G., Pissanidis, G., ... \& De Silva, C. W. (2015). Energy regeneration from suspension dynamic modes and self-powered actuation. IEEE/ASME Transactions on Mechatronics, 20(5), 2513-2524.

Koulocheris, D., \& Papaioannou, G. (2015, April). Dynamic analysis of the suspension system of a heavy vehicle through experimental and simulation procedure. In 25th JUMV International Automotive Conference “Science and Motor Vehicles (Vol. 13, pp. 187-199). 
Lafarge, Barbara, et al. "From Functional Analysis to Energy Harvesting System Design: Application to Car Suspension." International Journal on Interactive Design and Manufacturing (IJIDeM), Vol.10, No.1, 2016, pp.37-50.

Litzka, Johann, et al. The Way Forward for Pavement Performance Indicators across Europe. COST Action 354: Performance Indicators for Road Pavements. 2008, pp.1-112. https://trid.trb.org/view/1153371

Liu, C., Wu, D., Li, Y., \& Du, Y. (2021). Large-scale pavement roughness measurements with vehicle crowdsourced data using semi-supervised learning. Transportation Research Part C: Emerging Technologies, 125, 103048.

Llopis-Castello, David, et al. "Influence of Pavement Structure, Traffic, and Weather on Urban Flexible Pavement Deterioration." Sustainability, vol. 12, 2020, pp. 1-20. doi:10.3390/su12229717

Loizos, A. and Plati, C. (2008). Evolutional process of pavement roughness evaluation benefiting from sensor technology. International Journal on Smart Sensing and Intelligent Systems, vol.1, no.2, 370-387.

Loprencipe, Giuseppe, \& Zoccali, Pablo. “Ride Quality Due to Road Surface Irregularities: Comparison of Different Methods Applied on a Set of Real Road Profiles." Coatings, vol. 7, no. 5, 2017, pp. 1-16. doi:10.3390/coatings7050059

Marcelino, Pedro, Maria de Lurdes Antunes and Eduardo Fortunato. “Comprehensive performance indicators for road pavement condition assessment." Structure and Infrastructure Engineering, vol. 14, no.7, 2018, pp.113. http://dx.doi.org/10.1080/15732479.2018.1446179.

Marcelino, Pedro, et al. "Machine learning approach for pavement performance prediction." International Journal $\begin{array}{lllll}\text { of } & \text { Pavement } & \text { Engineering } & \text { 341-354. }\end{array}$ https://www.tandfonline.com/doi/abs/10.1080/10298436.2019.1609673

March, C., \& Shim, T. (2007). Integrated control of suspension and front steering to enhance vehicle handling. Proceedings of the Institution of Mechanical Engineers, Part D: Journal of Automobile Engineering, 221(4), 377-391. 
Merritt, D. K., Chang, G. K., and Rutledge, J. L. (2015). Best practices for achieving and measuring pavement smoothness: A synthesis of state-of-practice. Rep. No. FHWA/LA.14/550, Louisiana Transportation Research Center, Baton Rouge, LA.

Moreira, André V., et al. "An application of Markov chains to predict the evolution of performance indicators based on pavement historical data." International Journal of Pavement Engineering 19.10 (2018), pp. 118. https://www.researchgate.net/profile/Andre-Moreira11/publication/308135615_An_application_of_Markov_chains_to_predict_the_evolution_of_performa nce_indicators_based_on_pavement_historical_data/links/59c8e387aca272c71bcdc700/An-applicationof-Markov-chains-to-predict-the-evolution-of-performance-indicators-based-on-pavement-historicaldata.pdf

Mubaraki, Muhammad, and Hossam Sallam."The most effective index for pavement management of urban major roads at a network level."Arabian Journal for Science and Engineering, vol. 46, no.5, 2021, pp.4615-4626.

Múčka, Peter. "International Roughness Index Specifications Around the World." Road Materials and Pavement Design, Vol.18, No.4, 2017, pp.929-965.

Múčka, Peter. "Influence of Profile Specification on International Roughness Index." Journal of Infrastructure Systems, vol. 25, no. 2, 2019, pp. 1-14. doi:10.1061/(asce)is.1943-555x.0000478

Newstead, Brett, Leila Hashemian and Alireza Bayat. "A Study on Pavement Network Condition and Reporting in the Province of Alberta Through a Questionnaire Survey." Research Report, 2018. https://www.tacatc.ca/sites/default/files/conf_papers/newsteadb-a_study_on_pavement.pdf.

Nguyen, Long Hoang. "Research on the Correlation Between International Roughness Index (IRI) and Present Serviceability Index (PSI), Recommendations on Evaluation Rates in Vietnam's Conditions." International Journal of Engineering Research \& Technology (IJERT), vol. 6, no. 9,2017, pp. 266-271. https://www.ijert.org/research/research-on-the-correlation-between-international-roughness-index-iri- 
and-present-serviceability-index-psi-recommendations-on-evaluation-rates-in-vietnams-conditionsIJERTV6IS090128.pdf.

Ningyuan, Li, Tom Kazmierowski and Apple Koo. "Key Pavement Performance Indicators and Prediction Models Applied in a Canadian PMS." 8th International Conference on Managing Pavement Assets. 2011, pp.1-13. https://citeseerx.ist.psu.edu/viewdoc/download?doi=10.1.1.655.5081\&rep=rep1\&type=pdf.

Osorio-Lird, Aleli, et al. "Application of Markov chains and Monte Carlo simulations for developing pavement performance models for urban network management." Structure and Infrastructure Engineering 14.9 (2018), pp. 1169-1181. https://www.tandfonline.com/doi/abs/10.1080/15732479.2017.1402064

Papagiannakis, Athanassios, et al. "Pavement Scores Synthesis." Technical Report Documentation (Report No. FHWA/TX-09/0-6386-1). 2009. https://static.tti.tamu.edu/tti.tamu.edu/documents/0-6386-1.pdf.

Park, Kyungwon, et al. "Applicability of the International Roughness Index as a Predictor of Asphalt Pavement Condition." Journal of Transportation Engineering, vol. 133, no. 12, 2007, pp. 706-709. doi:10.1061/(asce)0733-947x(2007)133:12(706)

Pavement Condition Index 101. hawaiiasphalt.org/wp/wp-content/uploads/PCl-101.pdf. n.d. Accessed on 2 May 2021.

Pavements. U.S. Department of Transportation/Federal Highway Administration. (2018, September 25). https://www.fhwa.dot.gov/pavement/smoothness/.

Pérez-Acebo, Heriberto, et al. "Rigid pavement performance models by means of Markov Chains with half-year step time." International Journal of Pavement Engineering 20.7 (2019), pp. 830-843. https://www.tandfonline.com/doi/abs/10.1080/10298436.2017.1353390

Piryonesi, S. Madeh, and Tamer E. El-Diraby. "Examining the relationship between two road performance indicators: Pavement condition index and international roughness index." Transportation Geotechnics 26 (2021), pp. 1-441. https://www.sciencedirect.com/science/article/abs/pii/S2214391220303299

Potter, Charles J. Iowa's CHLOE Profilometer Correlation Procedure. No. MRL-87-10. 1987, pp. 1-47. 
Rada, Gonzalo R., et al. "Relating Ride Quality and Structural Adequacy for Pavement Rehabilitation and Management Decisions." Transportation Research Record: Journal of the Transportation Research Board, vol. 2304 , no. 1 , 2012, pp. 28-36. doi:10.3141/2304-04

Ragnoli, Antonella, et al. "Pavement Distress Detection Methods: A Review." Infrastructures, vol. 3, no. 4, 2018, pp. 1-19. doi:10.3390/infrastructures3040058

Rahman, Mostaqur, et al. "Pavement Performance Evaluation Models For South Carolina." KSCE Journal of Civil Engineering, vol. 21, no. 7, 2017, pp. 1-12. doi:10.1007/s12205-017-0544-7

"Ratings - How does NHTSA categorize vehicles?". National Highway Traffic Safety Administration. Retrieved May $31,2021$.

Reza, F., K. Boriboonsomsin and S. Bazlamit. "Development of a Pavement Quality Index for the State of Ohio." 85th Annual Meeting of the Transportation Research Board, 2006. https://escholarship.org/uc/item/3w68q7z6\#author.

Reza, Farhad, Kanok Boriboonsomsin, and Subhi M. Bazlamit. Development of a composite pavement performance index. No. ST/SS/05-001. Ada, OH: Department of Civil Engineering, Ohio Northern University, 2005, pp.1-93. https://www.researchgate.net/publication/311385878_Development_of_a_Composite_Pavement_Perf ormance_Index

Romero, J. A., \& Lozano, A. (2006). Effect of truck suspension and tire properties on pavement damage spatial distribution. Transportation research record, 1949(1), 148-154.

Sarwar, M. Tawfiq, and Panagiotis C. Anastasopoulos. "Three-stage least squares analysis of postrehabilitation pavement performance." Transportation Research Record 2589.1 (2016), pp. 1-22. https://www.researchgate.net/profile/Md-Tawfiq-Sarwar/publication/305801395_ThreeStage_Least_Squares_Analysis_of_Postrehabilitation_Pavement_Performance/links/593b1e1daca272c4 d9330a2c/Three-Stage-Least-Squares-Analysis-of-Postrehabilitation-Pavement-Performance.pdf 
Sayers, M. W. (1995). On the calculation of international roughness index from longitudinal road profile. Transportation Research Record, (1501).

Sayers, M. W., \& Karamihas, S. M. (1996). Interpretation of road roughness profile data (No. FHWA-RD-96-101).

Sayers, M. W. and Karamihas, S. M. (1998). The little book of profiling: basic information about measuring and interpreting road profiles. University of Michigan, Ann Arbor, Transportation Research Institute.

Schramm, D., Hiller, M., \& Bardini, R. (2014). Modeling and Analysis of Wheel Suspensions. In Vehicle Dynamics (pp. 101-141). Springer, Berlin, Heidelberg.

Scullion, Tom, and Timo Saarenketo. "Using suction and dielectric measurements as performance indicators for aggregate base materials." Transportation Research Record 1577.1 (1997), pp. 37-44. https://journals.sagepub.com/doi/abs/10.3141/1577-05

SenthilKumar, K., Shivhare, M. M., \& Gole, M. V. (2009). Analysis of Characteristics of Dampers of Hydrogas Suspension and the Effect of Damping Configuration on the Vibration Dynamics of a Light Tracked Vehicle (No. 2009-26-0068). SAE Technical Paper.

Shah, Yogesh U. et al. "Development of Overall Pavement Condition Index for Urban Road Network." Procedia Social and Behavioral Sciences, vol. 104, 2013, pp. 332-341. doi:10.1016/j.sbspro.2013.11.126

Sharma, Madhavendra et al."A review of pavement condition rating models for flexible pavements."International Research Journal of Engineering and Technology, vol. 6, no.6, 2019.

Smith, Robert. H. \& Waheed, Uddin. "A Rational Theory of Tire-Pavement Friction." Advances in Tribology, 2016, pp. 1-15. doi:10.1155/2016/4858317

Suspension Design for Ride \&amp; Handling. Mitostile Prototipo. (n.d.). https://sites.google.com/site/mitostile/vehicle-dynamics/technical-articles/chassis-suspensiontyres/suspension-design. 
Terzi, Serdal. "Modeling the pavement serviceability ratio of flexible highway pavements by artificial neural networks." Construction and Building Materials $21.3 \quad$ (2007), pp. 590-593. https://www.sciencedirect.com/science/article/abs/pii/S0950061805002916

Terzi, Serdal. "Modeling the Pavement Present Serviceability Index of Flexible Highway Pavements Using Data Mining." Journal of Applied Sciences, 6, 2006, pp. 193-197. https://dx.doi.org/10.3923/jas.2006.193.197.

Tighe, Susan, et al. "Incorporating Road Safety into Pavement Management." Transportation Research Record: Journal of the Transportation Research Board, vol. 1699, 2000, pp. 1-10. doi:10.3141/1699-01

Tools and Technology - Safety: Federal Highway Administration. Safety. (2014, October 15). https://safety.fhwa.dot.gov/tools/data_tools/mirereport/29.cfm.

Tsai, Yichang, and Zhongyu Yang. "New Pavement Performance Indicators using Crack Fundamental Elements and 3D Pavement Surface Data with Multiple-Timestamp Registration for Crack Deterioration Analysis and Optimal Treatment Determination." Transportation Research Record 2674.7 (2020), pp. 115-126. https://journals.sagepub.com/doi/abs/10.1177/0361198120920877

US Department of Transportation. "Measuring And Specifying Pavement Smoothness." Tech Brief, 2016. https://www.fhwa.dot.gov/pavement/pubs/hif16032.pdf.

Wadalkar, Shruti S., R. K. Lad, and R. K. Jain. "Study of Pavement Performance Indicators: RII Approach." Indian Journal of Science and Technology 8.1 (2018), pp.1-4. https://sciresol.s3.us-east2.amazonaws.com/IJST/Articles/2018/Issue-22/Article11.pdf

Wakeham, K. J., \& Rideout, D. G. (2011, January). Model complexity requirements in design of half car active suspension controllers. In Dynamic Systems and Control Conference (Vol. 54761, pp. 839-846).

Wang, Feng, et al. "Correlation of asphalt performance indicators and aging degrees: A review." Construction and $\begin{array}{lllll}\text { Building } & \text { Materials } & 250 & \text { (2020), } & \text { pp. }\end{array}$ https://www.sciencedirect.com/science/article/abs/pii/S0950061820308291 
Wang, Hui, et al. "Comparing of Data Collection for Network Level Pavement Management of Urban Roads and Highways." Journal of Advanced Transportation, 2015, pp. 1-11. doi.org/10.1155/2020/9237963

Wang, Junzhe, et al. "A Comparison of Network Level Pavement Condition Assessment in Road Asset Management." International Journal of Transportation Engineering and Technology, vol. 6, no. 3, 2020. pp. 95-101. doi: 10.11648/j.ijtet.20200603.14

Wang, Z., Qin, Y., Gu, L., \& Dong, M. (2017). Vehicle system state estimation based on adaptive unscented Kalman filtering combing with road classification. IEEE Access, 5, 27786-27799.

West Virginia Department of Transportation (WVDOT) - Division of Highways, Engineering Division. (2014). Design Directives. WVDOT, Charleston, WV.

Yagiz, N., \& Yuksek, I. (2001). Sliding mode control of active suspensions for a full vehicle model. International Journal of Vehicle Design, 26(2-3), 264-276.

Yoder, Eldon J., and Robert T. Milhous. "Comparison of different methods of measuring pavement conditions." (1965), PP. 1-39.

Yu, Miao et al. "Tire-Pavement Friction Characteristics with Elastic Properties of Asphalt Pavements." Applied Sciences, vol. 7, no. 11, 2017, pp. 1-16. doi:10.3390/app7111123

Zang, Kaiyue, et al. "Assessing and Mapping of Road Surface Roughness based on GPS and Accelerometer Sensors on Bicycle-Mounted Smartphones." Sensors, vol. 18, no. 3, 2018, pp. 1-17. doi:10.3390/s18030914

Zhang, D., \& Cai, Y. (2020, April). Simulation Analysis and Optimization of a Passenger Car Ride Comfort. In IOP Conference Series: Materials Science and Engineering (Vol. 811, No. 1, p. 012052). IOP Publishing.

Zuniga-Garcia, Natalia, and Jorge A. Prozzi. Contribution of micro-and macro-texture for predicting friction on pavement surfaces. No. CHPP Report-UTA\# 3-2016, pp. 1-106. 


\section{Appendix}

Appendix A. Measurement data retrieved from NCHRP Report 308

Table A-1. New Jersey Data

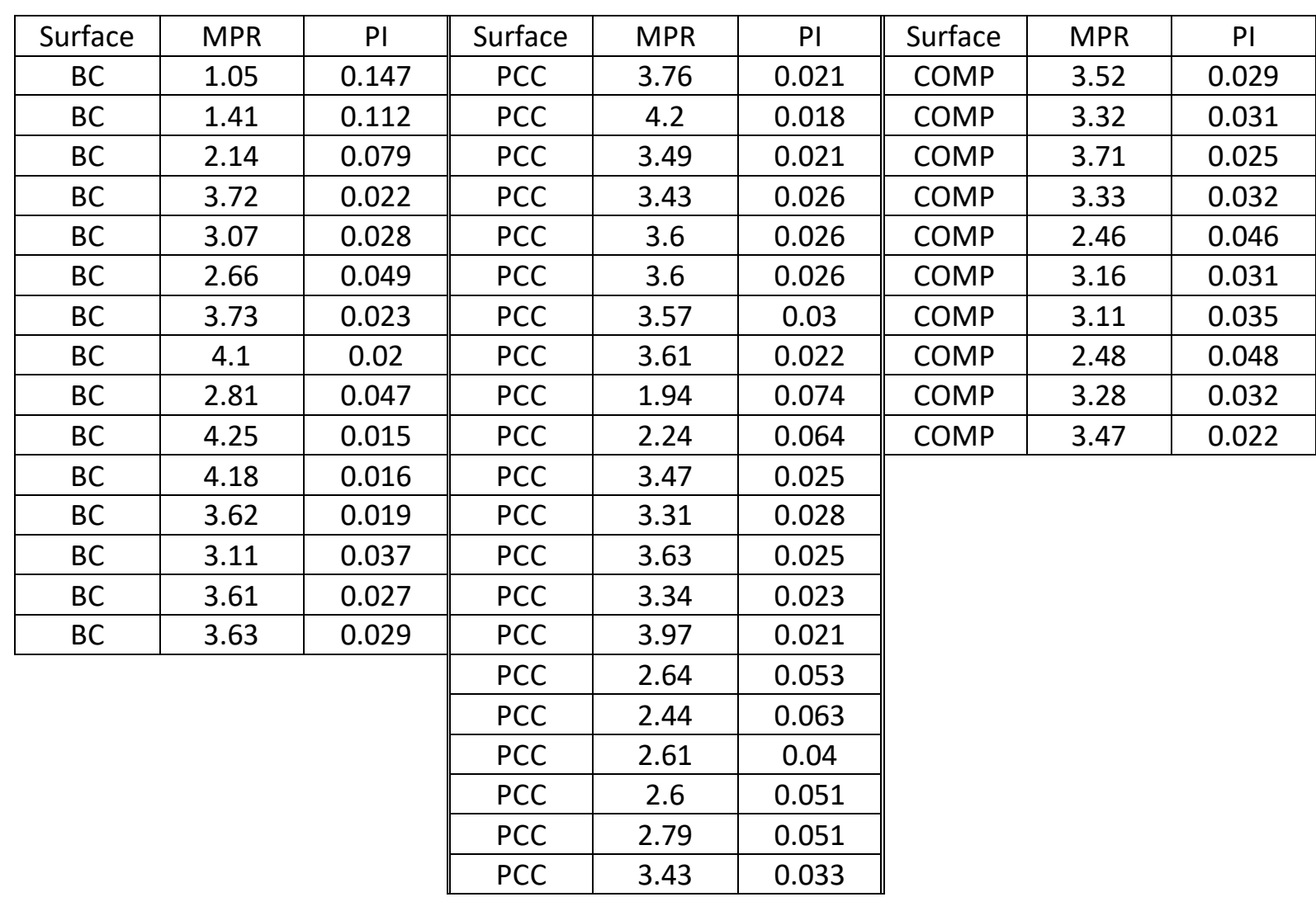


Table A-2. Michigan Data

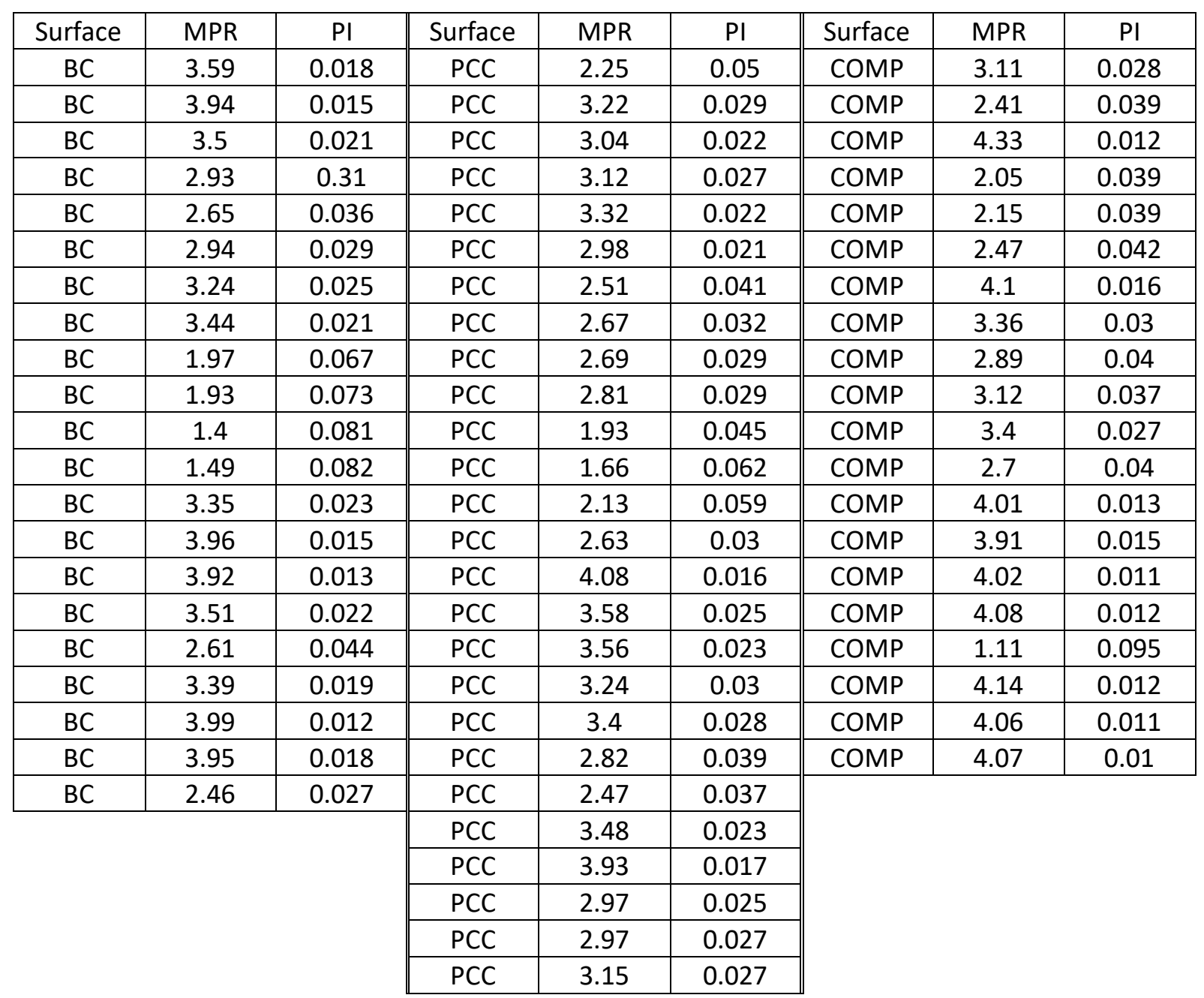


Table A-3. New Mexico Data

\begin{tabular}{|c|c|c|c|c|c|c|c|c|}
\hline Surface & MPR & $\mathrm{PI}$ & Surface & MPR & $\mathrm{PI}$ & Surface & MPR & $\mathrm{PI}$ \\
\hline $\mathrm{BC}$ & 2.36 & 0.048 & PCC & 2.36 & 0.033 & COMP & 3.32 & 0.019 \\
\hline$B C$ & 3.41 & 0.015 & PCC & 3.04 & 0.033 & COMP & 3.84 & 0.014 \\
\hline$B C$ & 3.75 & 0.018 & PCC & 3.04 & 0.026 & COMP & 3.9 & 0.014 \\
\hline$B C$ & 3.67 & 0.012 & PCC & 2.85 & 0.028 & COMP & 3.32 & 0.019 \\
\hline $\mathrm{BC}$ & 2.55 & 0.036 & PCC & 2.7 & 0.025 & COMP & 3.55 & 0.019 \\
\hline$B C$ & 1.95 & 0.07 & PCC & 2.8 & 0.026 & COMP & 4.01 & 0.014 \\
\hline $\mathrm{BC}$ & 1.39 & 0.11 & PCC & 2.97 & 0.019 & COMP & 4.06 & 0.014 \\
\hline BC & 2.71 & 0.04 & PCC & 2.96 & 0.023 & COMP & 4.07 & 0.012 \\
\hline$B C$ & 3.84 & 0.012 & PCC & 2.86 & 0.023 & COMP & 3.84 & 0.011 \\
\hline BC & 3.67 & 0.014 & PCC & 3.14 & 0.019 & COMP & 4.02 & 0.011 \\
\hline $\mathrm{BC}$ & 2.08 & 0.064 & & & & COMP & 3.86 & 0.016 \\
\hline BC & 4.22 & 0.012 & & & & COMP & 2.55 & 0.037 \\
\hline$B C$ & 2.29 & 0.044 & & & & COMP & 2.34 & 0.045 \\
\hline
\end{tabular}

\begin{tabular}{|l|l|l|}
\hline$B C$ & 2.34 & 0.048 \\
\hline
\end{tabular}

\begin{tabular}{l|l|l}
$B C$ & 4.27 & 0.011
\end{tabular}

\begin{tabular}{l|l|l} 
BC & 4.3 & 0.014
\end{tabular}

\begin{tabular}{l|l|l}
$B C$ & 4.29 & 0.012
\end{tabular}

\begin{tabular}{l|l|l}
\hline$B C$ & 2.28 & 0.046
\end{tabular}

\begin{tabular}{l|l|l} 
BC & 3.95 & 0.019
\end{tabular}

\begin{tabular}{l|l|l} 
BC & 4.19 & 0.009
\end{tabular}

\begin{tabular}{l|l|l}
$B C$ & 2.6 & 0.031
\end{tabular}

\begin{tabular}{l|l|l}
$B C$ & 2.29 & 0.037
\end{tabular}

\begin{tabular}{l|l|l}
$B C$ & 2.34 & 0.045
\end{tabular}

\begin{tabular}{l|l|l}
\hline$B C$ & 3.66 & 0.016
\end{tabular}

\begin{tabular}{|l|l|l|}
$B C$ & 3.83 & 0.014 \\
\hline
\end{tabular}

\begin{tabular}{l|l|l}
$B C$ & 2.79 & 0.034
\end{tabular}

\begin{tabular}{l|l|l}
$B C$ & 2.02 & 0.063
\end{tabular}

\begin{tabular}{l|l|l}
$B C$ & 2.83 & 0.033
\end{tabular}

\begin{tabular}{l|l|l}
$B C$ & 2.92 & 0.038
\end{tabular}

\begin{tabular}{l|l|l} 
BC & 3.69 & 0.021
\end{tabular}

\begin{tabular}{l|l|l} 
BC & 0.4 & 0.269
\end{tabular}

\begin{tabular}{l|l|l}
$B C$ & 3.53 & 0.014
\end{tabular}

\begin{tabular}{l|l|l}
$B C$ & 2.83 & 0.033 \\
\hline
\end{tabular}

\begin{tabular}{|l|l|l}
$B C$ & 3.39 & 0.019
\end{tabular}

\begin{tabular}{l|l|l}
$B C$ & 4.27 & 0.009
\end{tabular}

\begin{tabular}{l|l|l}
$\mathrm{BC}$ & 1.84 & 0.058
\end{tabular}

\begin{tabular}{l|l|l}
$B C$ & 3.95 & 0.011 \\
\hline
\end{tabular}

\begin{tabular}{l|l|l}
$B C$ & 4.35 & 0.011
\end{tabular}

\begin{tabular}{l|l|l}
$B C$ & 4.45 & 0.009
\end{tabular}

\begin{tabular}{l|l|l} 
BC & 3.52 & 0.027
\end{tabular}

\begin{tabular}{l|l|l}
$\mathrm{BC}$ & 2.77 & 0.036 \\
\hline
\end{tabular}


Table A-4. Louisiana Data

\begin{tabular}{|c|c|c|c|c|c|c|c|c|}
\hline Surface & MPR & $\mathrm{PI}$ & Surface & MPR & $\mathrm{PI}$ & Surface & MPR & $\mathrm{PI}$ \\
\hline$B C$ & 2.42 & 0.046 & PCC & 3.19 & 0.03 & COMP & 2.53 & 0.044 \\
\hline$B C$ & 4.09 & 0.016 & PCC & 3.04 & 0.038 & COMP & 2.81 & 0.043 \\
\hline $\mathrm{BC}$ & 4.17 & 0.01 & PCC & 3.69 & 0.023 & COMP & 2.62 & 0.049 \\
\hline$B C$ & 4.17 & 0.012 & PCC & 3.78 & 0.021 & COMP & 3.38 & 0.021 \\
\hline $\mathrm{BC}$ & 3.25 & 0.022 & PCC & 4.26 & 0.02 & COMP & 3.24 & 0.031 \\
\hline$B C$ & 1.2 & 0.114 & PCC & 4.17 & 0.023 & COMP & 2.5 & 0.058 \\
\hline$B C$ & 3.03 & 0.027 & PCC & 3.58 & 0.019 & COMP & 3.9 & 0.013 \\
\hline$B C$ & 2.31 & 0.042 & PCC & 3.4 & 0.033 & COMP & 4.28 & 0.014 \\
\hline$B C$ & 3.91 & 0.018 & PCC & 2.53 & 0.035 & COMP & 2.94 & 0.038 \\
\hline$B C$ & 2.71 & 0.028 & PCC & 2.96 & 0.025 & COMP & 2.04 & 0.06 \\
\hline$B C$ & 2.82 & 0.03 & PCC & 4.05 & 0.02 & COMP & 3.22 & 0.024 \\
\hline$B C$ & 4.03 & 0.019 & PCC & 4.19 & 0.019 & COMP & 4.13 & 0.013 \\
\hline $\mathrm{BC}$ & 4.13 & 0.011 & PCC & 3.94 & 0.018 & COMP & 2.65 & 0.045 \\
\hline $\mathrm{BC}$ & \multirow[t]{11}{*}{3.86} & \multirow[t]{11}{*}{0.02} & PCC & 2.65 & 0.038 & COMP & 3.52 & 0.025 \\
\hline & & & PCC & 3.79 & 0.029 & & & \\
\hline & & & PCC & 3.64 & 0.019 & & & \\
\hline & & & PCC & 3.72 & 0.018 & & & \\
\hline & & & PCC & 3.23 & 0.026 & & & \\
\hline & & & PCC & 2.63 & 0.04 & & & \\
\hline & & & PCC & 2.78 & 0.045 & & & \\
\hline & & & PCC & 3.14 & 0.04 & & & \\
\hline & & & PCC & 4.05 & 0.018 & & & \\
\hline & & & PCC* & 3.96 & 0.08 & & & \\
\hline & & & PCC & 3.16 & 0.041 & & & \\
\hline
\end{tabular}

*Data point removed from the data analysis 
Table A-5. Ohio Data

\begin{tabular}{|c|c|c||c|c|c||c|c|c|}
\hline Surface & MPR & PI & Surface & MPR & PI & Surface & MPR & PI \\
\hline BC & 3.2 & 0.027 & PCC & 2.85 & 0.041 & COMP & 4.41 & 0.009 \\
\hline BC & 2.26 & 0.032 & PCC & 3.31 & 0.025 & COMP & 3.12 & 0.03 \\
\hline BC & 1.01 & 0.1 & PCC & 3.42 & 0.021 & COMP & 3.21 & 0.015 \\
\hline BC & 2.25 & 0.065 & PCC & 1.93 & 0.04 & COMP & 2.49 & 0.034 \\
\hline BC & 2.09 & 0.08 & PCC & 3.73 & 0.018 & COMP & 2.89 & 0.034 \\
\hline BC & 3.18 & 0.028 & PCC & 2.76 & 0.041 & COMP & 3.93 & 0.011 \\
\hline BC & 4.05 & 0.014 & PCC & 2.72 & 0.037 & COMP & 1.86 & 0.052 \\
\hline BC & 1.94 & 0.049 & PCC & 2.79 & 0.036 & COMP & 2.66 & 0.053 \\
\hline BC & 3.54 & 0.021 & PCC & 2.56 & 0.04 & COMP & 3.68 & 0.018 \\
\hline BC & 3.81 & 0.015 & PCC & 2.49 & 0.037 & COMP & 4.25 & 0.012 \\
\hline BC & 2.54 & 0.031 & PCC & 3.47 & 0.019 & COMP & 4.15 & 0.013 \\
\hline BC & 1.64 & 0.06 & PCC & 3.75 & 0.015 & COMP & 3.54 & 0.017 \\
\hline BC & 1.38 & 0.072 & PCC & 3.63 & 0.018 & COMP & 3.37 & 0.02 \\
\hline BC & 2.31 & 0.044 & PCC & 3.51 & 0.025 & COMP & 2.61 & 0.041 \\
\hline BC & 1.82 & 0.046 & PCC & 3.79 & 0.017 & COMP & 2 & 0.04 \\
\hline BC & 1.27 & 0.132 & PCC & 3.41 & 0.021 & COMP & 2.56 & 0.038 \\
\hline BC & 3.23 & 0.023 & PCC & 2.07 & 0.048 & COMP & 2.43 & 0.025 \\
\hline BC & 3.84 & 0.014 & \multicolumn{1}{|l}{} & & & \\
\hline
\end{tabular}


Appendix B. IRI results generated from the golden-car and test parameters

Table B-1. IRI Results (1)

\begin{tabular}{|c|c|c|c|c|c|c|c|c|}
\hline \multirow{3}{*}{ Run } & \multicolumn{8}{|c|}{ PI Group } \\
\hline & \multicolumn{2}{|c|}{0.01} & \multicolumn{2}{|c|}{0.015} & \multicolumn{2}{|c|}{0.02} & \multicolumn{2}{|c|}{0.025} \\
\hline & Golden & Test & Golden & Test & Golden & Test & Golden & Test \\
\hline 1 & 44.4552 & 44.4552 & 61.8424 & 58.6265 & 81.1114 & 77.0818 & 95.0802 & 89.1933 \\
\hline 2 & 49.0507 & 45.2711 & 53.9591 & 50.4321 & 81.2505 & 77.0168 & 120.0066 & 109.4021 \\
\hline 3 & 48.7799 & 47.2138 & 70.4208 & 65.6096 & 68.5294 & 65.9471 & 104.3747 & 97.0047 \\
\hline 4 & 50.9422 & 47.4226 & 57.5404 & 54.849 & 83.7262 & 80.2288 & 108.9347 & 102.2573 \\
\hline 5 & 45.0822 & 43.8571 & 57.2149 & 53.9377 & 78.6828 & 75.973 & 96.7957 & 91.8681 \\
\hline 6 & 41.2009 & 39.7601 & 54.9483 & 51.4781 & 83.1964 & 77.0889 & 103.9744 & 99.6467 \\
\hline 7 & 41.9441 & 39.3315 & 60.5064 & 57.3405 & 87.3748 & 82.082 & 105.011 & 99.1437 \\
\hline 8 & 53.4331 & 49.7746 & 60.5009 & 55.8477 & 83.2905 & 77.8607 & 101.2739 & 95.9086 \\
\hline 9 & 50.7967 & 47.9321 & 58.3851 & 56.5231 & 85.9951 & 78.4367 & 106.0608 & 102.0032 \\
\hline 10 & 43.332 & 40.8251 & 61.7998 & 57.5538 & 82.5312 & 75.0006 & 100.1533 & 96.2523 \\
\hline 11 & 46.1377 & 43.9262 & 63.3269 & 58.398 & 96.6688 & 88.9419 & 112.274 & 107.4667 \\
\hline 12 & 49.1532 & 45.7159 & 53.5507 & 51.9439 & 83.5716 & 79.2998 & 98.2295 & 94.3334 \\
\hline 13 & 46.6079 & 44.382 & 60.1427 & 56.3373 & 79.6366 & 75.7547 & 115.3563 & 106.8516 \\
\hline 14 & 45.6758 & 43.4681 & 67.2193 & 64.1547 & 93.1371 & 86.4003 & 109.5881 & 106.2229 \\
\hline 15 & 54.544 & 51.2112 & 62.7916 & 59.097 & 84.4572 & 80.5976 & 98.5751 & 93.4866 \\
\hline 16 & 54.9867 & 51.0158 & 62.9776 & 59.4689 & 88.2908 & 84.2119 & 123.0524 & 113.2417 \\
\hline 17 & 55.8159 & 51.9608 & 69.8849 & 66.6032 & 74.6543 & 71.4148 & 115.1912 & 107.2289 \\
\hline 18 & 44.763 & 42.5394 & 59.6408 & 56.7874 & 79.1366 & 73.4723 & 95.554 & 93.2643 \\
\hline 19 & 46.8114 & 44.1682 & 64.9024 & 62.5331 & 82.9272 & 79.2773 & 92.8023 & 91.7577 \\
\hline 20 & 56.0153 & 52.1927 & 60.3016 & 57.4868 & 76.9268 & 72.0065 & 101.0627 & 96.3706 \\
\hline 21 & 42.4924 & 41.0546 & 59.2534 & 56.7876 & 75.6321 & 71.348 & 104.3597 & 100.3195 \\
\hline 22 & 49.2749 & 47.5809 & 62.9275 & 60.8669 & 88.6414 & 83.0073 & 115.6182 & 108.8491 \\
\hline 23 & 48.7811 & 44.6751 & 63.2836 & 59.6261 & 73.9847 & 68.9939 & 100.3244 & 92.6211 \\
\hline 24 & 47.9865 & 45.3615 & 50.6056 & 50.9479 & 84.0641 & 79.7731 & 90.9135 & 88.2268 \\
\hline 25 & 47.0408 & 45.9366 & 64.6834 & 60.2677 & 79.5128 & 75.3619 & 107.3699 & 98.6447 \\
\hline 26 & 45.6268 & 42.9372 & 56.2626 & 51.1656 & 83.405 & 76.4452 & 113.8768 & 105.8677 \\
\hline 27 & 46.0656 & 43.0235 & 65.6426 & 62.6421 & 78.9759 & 76.6566 & 106.3532 & 100.3352 \\
\hline 28 & 53.6398 & 48.7271 & 69.6333 & 66.0722 & 69.9935 & 68.3626 & 109.5045 & 102.416 \\
\hline 29 & 43.5002 & 41.0715 & 63.4577 & 58.8232 & 86.1265 & 77.8024 & 96.4417 & 90.7002 \\
\hline 30 & 48.2232 & 46.0762 & 66.6506 & 63.481 & 81.1695 & 74.9272 & 100.3428 & 95.5506 \\
\hline
\end{tabular}


Table B-2. IRI Results (2)

\begin{tabular}{|c|c|c|c|c|c|c|c|c|}
\hline \multirow{3}{*}{ Run } & \multicolumn{8}{|c|}{ PI Group } \\
\hline & \multicolumn{2}{|c|}{0.03} & \multicolumn{2}{|c|}{0.035} & \multicolumn{2}{|c|}{0.04} & \multicolumn{2}{|c|}{0.045} \\
\hline & Golden & Test & Golden & Test & Golden & Test & Golden & Test \\
\hline 1 & 127.7907 & 120.2919 & 131.4958 & 126.7585 & 151.3029 & 141.0293 & 182.4964 & 179.3504 \\
\hline 2 & 113.5794 & 106.4032 & 152.0493 & 140.4013 & 155.7912 & 147.4462 & 172.0998 & 158.6212 \\
\hline 3 & 112.0192 & 107.2101 & 135.552 & 129.211 & 143.6999 & 138.0686 & 181.4071 & 171.8561 \\
\hline 4 & 136.2586 & 130.8745 & 146.3151 & 139.5384 & 162.9467 & 156.4569 & 169.9078 & 159.0466 \\
\hline 5 & 111.2584 & 106.4574 & 124.3318 & 117.9325 & 158.2129 & 146.4172 & 171.7131 & 165.3913 \\
\hline 6 & 136.0925 & 123.9742 & 143.4466 & 138.7671 & 176.3945 & 161.7039 & 177.0327 & 167.9975 \\
\hline 7 & 127.5409 & 123.5786 & 151.2397 & 145.0656 & 159.5233 & 149.0175 & 182.0519 & 171.368 \\
\hline 8 & 113.8087 & 110.8582 & 151.6666 & 140.8363 & 161.5283 & 159.694 & 195.6251 & 184.6154 \\
\hline 9 & 146.8546 & 135.9452 & 160.9743 & 149.4679 & 178.6934 & 160.9348 & 148.5948 & 145.9056 \\
\hline 10 & 126.0831 & 118.4924 & 130.5728 & 123.5663 & 147.2937 & 143.1071 & 189.7131 & 187.9029 \\
\hline 11 & 124.3801 & 117.5666 & 138.897 & 132.647 & 153.0616 & 144.6996 & 207.0581 & 190.7648 \\
\hline 12 & 147.2423 & 135.6969 & 130.3774 & 120.9234 & 147.2239 & 142.0195 & 184.1927 & 176.6141 \\
\hline 13 & 138.8902 & 130.9026 & 149.8275 & 142.5216 & 190.0465 & 181.4686 & 195.2884 & 181.8759 \\
\hline 14 & 127.7541 & 119.4038 & 151.871 & 141.4991 & 163.0438 & 155.0849 & 175.6001 & 167.4977 \\
\hline 15 & 131.9012 & 127.0164 & 144.3153 & 135.1716 & 167.1095 & 157.4168 & 195.5035 & 185.0194 \\
\hline 16 & 113.6985 & 107.2308 & 136.7777 & 132.3596 & 156.1645 & 153.1783 & 186.0567 & 180.1029 \\
\hline 17 & 122.123 & 116.2742 & 135.535 & 132.9901 & 161.7484 & 151.9116 & 202.7718 & 186.9273 \\
\hline 18 & 124.513 & 116.1423 & 130.2312 & 124.4875 & 153.4848 & 144.1218 & 177.1441 & 168.238 \\
\hline 19 & 128.2065 & 121.9018 & 139.4134 & 137.8466 & 143.7183 & 136.4351 & 185.1903 & 175.2467 \\
\hline 20 & 120.8068 & 116.3094 & 121.4529 & 115.2767 & 148.2791 & 144.4481 & 185.0988 & 176.4314 \\
\hline 21 & 130.2581 & 119.4414 & 123.0036 & 117.8222 & 154.0262 & 142.9384 & 164.7695 & 161.9045 \\
\hline 22 & 142.5427 & 133.3564 & 142.7828 & 132.0729 & 181.1265 & 170.5655 & 164.2026 & 160.5587 \\
\hline 23 & 122.3415 & 116.5438 & 153.5478 & 139.1536 & 136.8585 & 133.2623 & 201.3536 & 191.6874 \\
\hline 24 & 132.1701 & 126.2971 & 152.4788 & 143.4602 & 181.7535 & 169.8493 & 181.0943 & 172.3361 \\
\hline 25 & 130.2051 & 124.4891 & 143.804 & 138.7163 & 153.1081 & 143.7417 & 165.6707 & 155.0359 \\
\hline 26 & 139.8914 & 130.1643 & 129.3668 & 124.4809 & 162.8351 & 153.9547 & 184.5765 & 174.9271 \\
\hline 27 & 132.0043 & 126.3296 & 125.0118 & 119.3779 & 196.3838 & 187.7773 & 185.0045 & 179.925 \\
\hline 28 & 118.1599 & 116.475 & 137.2411 & 125.7933 & 150.7487 & 144.8468 & 193.6581 & 187.7683 \\
\hline 29 & 137.0453 & 130.2321 & 144.6314 & 138.2807 & 179.915 & 172.4843 & 214.6447 & 196.6589 \\
\hline 30 & 108.9067 & 106.0735 & 131.1163 & 128.0816 & 146.7485 & 145.769 & 162.4097 & 158.3484 \\
\hline
\end{tabular}


Table B-3. IRI Results (3)

\begin{tabular}{|c|c|c|c|c|c|c|c|c|}
\hline \multirow{3}{*}{ Run } & \multicolumn{8}{|c|}{ PI Group } \\
\hline & \multicolumn{2}{|c|}{0.05} & \multicolumn{2}{|c|}{0.06} & \multicolumn{2}{|c|}{0.07} & \multicolumn{2}{|c|}{0.08} \\
\hline & Golden & Test & Golden & Test & Golden & Test & Golden & Test \\
\hline 1 & 173.7144 & 170.7334 & 197.3534 & 193.3057 & 239.3521 & 226.5893 & 307.585 & 292.8938 \\
\hline 2 & 202.1496 & 189.9866 & 206.6591 & 196.7784 & 226.6947 & 211.943 & 317.028 & 300.7837 \\
\hline 3 & 181.362 & 173.0456 & 228.7294 & 210.1292 & 235.1505 & 218.1707 & 295.6509 & 284.2284 \\
\hline 4 & 176.2035 & 165.0521 & 197.2923 & 186.3321 & 195.7081 & 189.6023 & 283.9909 & 269.0702 \\
\hline 5 & 188.4989 & 179.5874 & 226.2378 & 211.9499 & 232.7719 & 218.831 & 282.1939 & 261.7107 \\
\hline 6 & 212.5566 & 202.098 & 177.6787 & 176.352 & 260.2811 & 237.5939 & 243.5595 & 232.1166 \\
\hline 7 & 183.5759 & 180.2667 & 225.8582 & 214.2142 & 235.1804 & 225.3933 & 310.9964 & 299.0195 \\
\hline 8 & 170.6814 & 167.3218 & 255.5945 & 235.0112 & 229.7939 & 212.0341 & 283.7157 & 279.2181 \\
\hline 9 & 179.5397 & 165.984 & 183.0774 & 179.4787 & 222.8294 & 211.0789 & 273.5095 & 260.1318 \\
\hline 10 & 176.9034 & 166.8341 & 268.5099 & 251.2443 & 198.6675 & 189.9476 & 295.6128 & 278.0813 \\
\hline 11 & 220.0984 & 200.2927 & 225.2832 & 206.444 & 237.0221 & 220.7774 & 307.8784 & 283.3547 \\
\hline 12 & 178.7701 & 171.8035 & 198.7792 & 185.2447 & 222.5292 & 216.6289 & 284.927 & 266.8257 \\
\hline 13 & 176.0533 & 170.4235 & 203.1952 & 194.9363 & 237.1551 & 227.8909 & 308.359 & 290.064 \\
\hline 14 & 185.5788 & 172.1592 & 218.7879 & 206.941 & 214.4893 & 211.5399 & 329.4513 & 309.1579 \\
\hline 15 & 177.7107 & 168.5426 & 212.8336 & 207.0716 & 250.9946 & 244.3127 & 306.0585 & 284.149 \\
\hline 16 & 179.5696 & 170.9229 & 202.7029 & 188.2324 & 236.1808 & 225.0221 & 315.8541 & 300.5457 \\
\hline 17 & 193.5295 & 187.3035 & 178.4139 & 173.1919 & 250.6678 & 235.4623 & 278.0897 & 270.7042 \\
\hline 18 & 196.6481 & 187.9857 & 3112 & 078 & 234.4344 & 225.0695 & 294.9457 & 269.7338 \\
\hline 19 & 28 & 91 & 776 & 0305 & 209.7242 & 203.0986 & 273.7478 & 258.686 \\
\hline 20 & 170.9464 & 170.4843 & 228.5223 & 215.0808 & 246.928 & 224.133 & 315.0491 & 290.8273 \\
\hline 21 & 214.2081 & 202.2125 & 190.0365 & 182.6291 & 210.3563 & 202.5605 & 291.2339 & 298.5626 \\
\hline 22 & 129.7342 & 127.0352 & 207.1827 & 201.6604 & 241.3346 & 217.1768 & 281.6781 & 274.3551 \\
\hline 23 & 189.1934 & 170.5065 & 236.0133 & 215.1125 & 210.343 & 202.2304 & 282.1035 & 269.1446 \\
\hline 24 & 172.3123 & 169.1381 & 211.8395 & 200.6684 & 240.5025 & 227.1821 & 324.5828 & 304.1128 \\
\hline 25 & 229.128 & 212.9265 & 228.3943 & 209.1967 & 220.556 & 210.5142 & 280.9825 & 258.5223 \\
\hline 26 & 210.0155 & 193.4989 & 207.2486 & 197.8923 & 221.839 & 213.5645 & 318.8675 & 298.9489 \\
\hline 27 & 193.8132 & 184.9204 & 202.6798 & 199.0446 & 250.6833 & 233.195 & 235.577 & 233.3948 \\
\hline 28 & 181.8934 & 170.415 & 222.6305 & 206.9653 & 246.8365 & 234.5417 & 297.1749 & 280.9633 \\
\hline 29 & 184.9134 & 173.9713 & 217.6124 & 205.9186 & 193.7473 & 190.0628 & 293.3607 & 280.6583 \\
\hline 30 & 229.3362 & 209.3969 & 205.65 & 186.9748 & 251.9871 & 245.8232 & 280.1158 & 278.7674 \\
\hline
\end{tabular}

